\title{
Situation analysis of behavior change communication activities in Bihar: A step towards developing a comprehensive BCC strategy
}

\author{
M.E. Khan \\ Population Council \\ Isha Bhatnagar \\ Population Council \\ Avishek Hazra \\ Population Council \\ Mukesh Kumar
}

Follow this and additional works at: https://knowledgecommons.popcouncil.org/departments_sbsr-rh

Part of the Demography, Population, and Ecology Commons, Family, Life Course, and Society Commons, Health Policy Commons, International Public Health Commons, and the Public Health Education and Promotion Commons How does access to this work benefit you? Let us know!

\section{Recommended Citation}

Khan, M.E., Isha Bhatnagar, Avishek Hazra, and Mukesh Kumar. 2012. "Situation analysis of behavior change communication activities in Bihar: A step towards developing a comprehensive BCC strategy." New Delhi: Population Council. 


\section{SITUATION ANALYSIS OF BEHAVIOR CHANGE COMMUNICATION ACTIVITIES IN BIHAR}

\section{A STEP TOWARDS DEVELOPING A COMPREHENSIVE BCC STRATEGY}

M.E. KHAN

ISHA BHATNAGAR

AVISHEK HAZRA

MUKESH KUMAR

(2) Population Council 


\section{SITUATION ANALYSIS OF BEHAVIOR CHANGE COMMUNICATION ACTIVITIES IN BIHAR}

\section{A STEP TOWARDS DEVELOPING A COMPREHENSIVE BCC STRATEGY}

M.E. KHAN

ISHA BHATNAGAR AVISHEK HAZRA MUKESH KUMAR 


\section{(1) Population Council}

The Population Council confronts critical health and development issues-from stopping the spread of HIV to improving reproductive health and ensuring that young people lead full and productive lives. Through biomedical, social science, and public health research in 50 countries, we work with our partners to deliver solutions that lead to more effective policies, programs, and technologies that improve lives around the world. Established in 1952 and headquartered in New York, the Council is a non-governmental, non-profit organization, governed by an international board of trustees.

\section{Population Council}

Zone 5A, Ground Floor

India Habitat Center

Lodi Road, New Delhi 110003

www.popcouncil.org

(C) 2012 The Population Council, Inc.

Suggested Citation: Khan M.E., I. Bhatnagar, A. Hazra and M. Kumar. 2012. Situation Analysis of Behavior Change Communication Activities in Bihar: A Step Towards Developing a Comprehensive BCC Strategy. New Delhi: Population Council. 


\section{TABLE OF CONTENTS}

List of Abbreviations $\quad$ vi

Acknowledgements $\quad$ ix

Executive Summary $\quad$ xi

Chapter 1: Introduction 1

$\begin{array}{ll}\text { Chapter 2: } & \text { Status of selected behaviors in Bihar }\end{array}$

Chapter 3: Reach of media in rural Bihar and functioning of the State Mass Media Unit 17

Chapter 4: Mapping of development partners' activities in BCC 31

Chapter 5: Exploring partnership with other government departments in implementing 45 a BCC strategy

Chapter 6: Conceptualizing a Behavior Change Communication strategy in health sector: Need of a paradigm shift 


\section{LIST OF TABLES}

Table 2.1: $\quad$ National and State level goals in $\mathrm{MCH}$ and progress made so far 7

Table 2.2: $\quad$ Current status of the selected behaviors/indicators, India and Bihar 13

Table 3.1: Health infrastructure and health personnel, Bihar 22

Table 3.2: $\quad$ Current status of availability of human resources at the Mass Media Units 23 in the three districts of Bihar

Table 4.1: Development partners working in Bihar, by themes addressed, coverage and BCC activity

Table 5.1: Operational definition of indicators for determining strength of department

Table 5.2: Community and family health behaviors and interests which overlap among different government departments

Table 5.3: Estimate of coverage (districts, blocks, families and individuals) of program

Table 5.4: Key target audience of the program

Table 5.5: Strength of organizational structure

Table 5.6: Roles, opportunity of contact with community and profile of grassroots workers by program

Table 5.7: $\quad$ Training related information by grassroots worker of each program

Table 5.8: Possible platforms/change agents for BCC and available BCC budget under the program/scheme

Table 5.9: $\quad$ Scores of departments on the basis of their strengths and role in heath sector

Table 6.1: $\quad$ BCC matrix for change agents and mechanisms for reinforcing messages 


\section{LIST OF FIGURES}

Figure 1.1: Framework for situational analysis and potential partners' roles in implementing the BCC strategy

Figure 3.1: Structure of program management functioning in the State of Bihar

Figure 3.2: Structure of the State Health Society, Bihar

Figure 6.1: Framework for implementing a BCC strategy in health

Figure 6.2: Human resource requirement at the state BCC unit and key responsibilities

Figure 6.3: Constitution of district media planning \& implementation committee

\section{LIST OF BOXES}

Box 3.1: $\quad$ Key audience and themes for focused counseling during VHSND

Box 5.1: Various government departments assessed for their potential to partner with SHSB

Box 5.2: $\quad$ Services offered by ICDS

Box 5.3: $\quad$ Payment of installments of IGMSY

Box 5.4: $\quad$ Roles of JEEViKA Sahelis

Box 5.5: $\quad$ Potential of all SHGs of JEEViKA, WDC and Mahila Samakhya together

\section{LIST OF APPENDICES}

Appendix A: List of officials met at the district, block and community level by department

Appendix B: Informants from development partners working in Bihar, by themes addressed, coverage and BCC activities

Appendix C: Districts covered by various programs 


\section{ABBREVIATIONS}

\begin{tabular}{|c|c|}
\hline ACMO & Assistant Chief Medical Officer \\
\hline AC & Area Coordinator \\
\hline ANC & Antenatal Checkup \\
\hline ANM & Auxiliary Nurse Midwife \\
\hline APHC & Additional Primary Health Center \\
\hline APL & Above Poverty Line \\
\hline APMAS & Andhra Pradesh Mahila Abhivruddhi Society \\
\hline ARC & ASHA Resource Centre \\
\hline ARI & Acute Respiratory Infection \\
\hline ARSH & Adolescent Reproductive and Sexual Health \\
\hline ASHA & Accredited Social Health Activist \\
\hline AWC & Anganwadi Center \\
\hline AWW & Anganwadi Worker \\
\hline $\mathrm{BCC}$ & Behavior Change Communication \\
\hline $\mathrm{BCM}$ & Block Community Mobilizer \\
\hline BEE & Block Extension Educator \\
\hline BMGF & Bill and Melinda Gates Foundation \\
\hline BPL & Below Poverty Line \\
\hline BPM & Block Project Manager \\
\hline $\mathrm{BRC}$ & Block Resource Coordinator \\
\hline BRLPS & Bihar Rural Livelihoods Promotion Society \\
\hline BWO & Block Welfare Officer \\
\hline $\mathrm{CC}$ & Community Coordinator \\
\hline CCDU & Communication and Capacity Development Unit \\
\hline CDPO & Child Development Project Officer \\
\hline CIFF & Children's Investment Fund Foundation \\
\hline CLTS & Community Led Total Sanitation \\
\hline $\mathrm{CM}$ & Community Mobilizer \\
\hline COMBI & Communication for Behavioral Impact \\
\hline CRP & Community Resource Person \\
\hline CRP & Cluster Resource Person \\
\hline CS & Civil Surgeon \\
\hline$D M \& E$ & District Monitoring and Evaluation Officer \\
\hline DAM & District Accounts Manager \\
\hline DCM & District Community Mobilizer \\
\hline DDA & District Data Assistant \\
\hline DFID & Department for International Development \\
\hline DHS & District Health Society \\
\hline DLHS & District Level Household Survey \\
\hline DP & Development Partners \\
\hline DPM & District Program Manager \\
\hline DPMU & District Program Management Unit \\
\hline DPO & District Project Officer \\
\hline DWO & District Welfare Officer \\
\hline DWSC & District Water and Sanitation Committee \\
\hline
\end{tabular}




\begin{tabular}{|c|c|}
\hline ECCE & Early Childhood Care and Education \\
\hline ED & Executive Director \\
\hline ESP & Effective Social Persuasion Platform \\
\hline GEP & Girls Education Program \\
\hline GoB & Government of Bihar \\
\hline Gol & Government of India \\
\hline GoN & Government of the Kingdom of Norway \\
\hline $\mathrm{HE}$ & Health Educator \\
\hline HRF & Health Risk Fund \\
\hline HSC & Health Sub Center \\
\hline HSP & Hygiene and Sanitation Promotion \\
\hline ICDS & Integrated Child Development Services \\
\hline ICT & Information Communication Technology \\
\hline IDDP & lodine Deficiency Disorder Program \\
\hline IEC & Information, Education and Communication \\
\hline IGMSY & Indira Gandhi Matritva Sahyog Yojana \\
\hline IIHMR & International Institute of Health Management Research \\
\hline IIPS & International Institute for Population Sciences \\
\hline IMR & Infant Mortality Rate \\
\hline IPC & Interpersonal Communication \\
\hline IPE & Infrastructure Professionals Enterprise \\
\hline IRS & Indian Readership Survey \\
\hline IYCF & Infant and Young Child Feeding \\
\hline JBSY & Janani evam Bal Suraksha Yojana \\
\hline JSY & Janani Suraksha Yojana \\
\hline KGBV & Kasturba Gandhi Balika Vidyalayas \\
\hline KMC & Kangaroo Mother Care \\
\hline LiST & Lives Saved Tool \\
\hline$M \& E$ & Monitoring and Evaluation \\
\hline MCP & Micro Credit Plan \\
\hline MCTS & Mother Child Tracking System \\
\hline MDG & Millennium Development Goal \\
\hline MI & Micronutrient Initiative \\
\hline MIB & Ministry of Information and Broadcasting \\
\hline MMR & Maternal Mortality Ratio \\
\hline MNSY & Mukhyamantri Nari Shakti Yojana \\
\hline MoHFW & Ministry of Health and Family Welfare \\
\hline MOIC & Medical Officer in Charge \\
\hline MRUC & Media Research Users Council \\
\hline NFHS & National Family Health Survey \\
\hline NGO & Non-Governmental Organization \\
\hline NHE & Nutrition and Health Education \\
\hline NHSRC & National Health System Resource Centre \\
\hline NIPI & Norway India Partnership Initiative \\
\hline NRCIM & National Research Council and Institute of Medicine \\
\hline NRDWP & National Rural Drinking Water Program \\
\hline NRHM & National Rural Health Mission \\
\hline NRLM & National Rural Livelihoods Mission \\
\hline
\end{tabular}




\begin{tabular}{|c|c|}
\hline ODF & Open Defecation Free \\
\hline ORS & Oral Rehydration Salt \\
\hline ORT & Oral Rehydration Therapy \\
\hline PHED & Public Health Engineering Department \\
\hline PRD & Panchayati Raj Department \\
\hline PTI & Press Trust of India \\
\hline $\mathrm{RHP}$ & Rural Health Practitioner \\
\hline RI & Routine Immunization \\
\hline RKS & Rogi Kalyan Samiti \\
\hline SBA & Skilled Birth Attendant \\
\hline SBCC & Social and Behavior Change Communication \\
\hline SC & Scheduled Caste \\
\hline SGSY & Swarnjayanti Gram Swarojgar Yojana \\
\hline SHG & Self Help Group \\
\hline SHS & State Health Society \\
\hline SHSB & State Health Society, Bihar \\
\hline SLI & Standard of Living Index \\
\hline SPO & State Program Officer \\
\hline ST & Scheduled Tribe \\
\hline STSC & Skin-To-Skin Care \\
\hline SWASTH & Sector Wide Approach to Strengthen Health \\
\hline SWD & Social Welfare Department \\
\hline TA & Technical Assistance \\
\hline TAG & Technical Advisory Group \\
\hline TAM & Television Audience Measurement \\
\hline TFR & Total Fertility Rate \\
\hline THR & Take Home Ration \\
\hline TOR & Terms of Reference \\
\hline TSC & Total Sanitation Campaign \\
\hline TVC & Television Commercial \\
\hline UNFPA & United Nations Population Fund \\
\hline UNICEF & United Nations Children's Fund \\
\hline VHSC & Village Health and Sanitation Committee \\
\hline VHSNC & Village Health Sanitation and Nutrition Committee \\
\hline VHSND & Village Health Sanitation and Nutrition Day \\
\hline VM & Vikas Mitra \\
\hline VO & Village Organization \\
\hline VRP & Village Resource Person \\
\hline WDC & Women Development Corporation \\
\hline WHO & World Health Organization \\
\hline
\end{tabular}




\section{ACKNOWLEDGMENTS}

We wish to thank a number of senior officials of the Government of Bihar, colleagues from UNICEF Patna and Development Partners who gave their time, provided information and input to this report. We are particularly thankful to Mr. Yameen Muzamdar, Chief of Field, Mr. Rajiva Sinha, Program Manager and Ms. Arupa Shukla, C4D Specialist for their contributions in conceptualizing the overall framework.

We are grateful to Mr. Sanjay Kumar, Secretary, Health and Executive Director, State Health Society Bihar for valuable inputs and guidance in shaping the BCC framework; and Dr. A.K. Shahi, Program Officer (FP), State Health Society Bihar for providing insights on the present functioning and resources of the BCC Cell.

We also thank Mr. Ravindra Pawar, Principal Secretary, Public Health Engineering Department; Mr. Manoj Srivastav, Principal Secretary, Panchayati Raj Department; Mr. Sandeep Paundrik, Secretary, Department of Social Welfare; Ms. Vandana Kini, Managing Director, Women Development Corporation; Mr. Raghavendra Jha, Project Director, Mahadalit Vikas Mission; Mr. Arvind Chaudhary, CEO, JEEV iKA and senior officials of various departments for sharing their perspectives on BCC and how their departments could contribute in implementing the proposed strategy.

We would like to thank our Population Council colleagues, Ms. Anvita Dixit and Mr. Rakesh Kumar, for editing, formatting and giving shape to this report. 


\section{EXECUTIVE SUMMARY}

\section{Background}

Maternal and child health indicators of Bihar have remained poor even though there are a large number of evidence-based and cost-effective interventions that have shown to reduce maternal, neonatal, infant and child mortality and improve reproductive health and nutritional outcomes. Inappropriate social norms, lack of knowledge, and inappropriate attitudes and practices of key population groups are important contributors to maternal, neonatal and child mortality and morbidity. However, evidence suggests that social norms and practices can be changed if appropriate messages are delivered through a combination of communication channels including mass, mid- and other media, coupled with improved interactions between frontline healthcare workers and target populations at family and community level.

\section{Objectives}

The objectives of the present situation analysis were to assess:

- Current status of selected health indicators,

- Reach of media and status of State Media Units,

- Develop a framework to implement BCC strategy for the health sector, and

- Identify potential partners for rolling out the BCC strategy.

\section{Methodology}

Data for the study was collected by: (a) analysis of national surveys like NFHS, DLHS and a recent formative study on 'Shaping Demand and Practices to Improve Family Health Outcomes' carried out by the Population Council; (b) review of various policy papers and program documents; (c) in-depth interviews of about 100 key officials including 7 Principal Secretaries and other Senior State Officials, Chiefs of Party or Senior Program Managers of development partners, and district and block level officials; and (d) field visits of four districts to observe the functioning of heath department as well as other social sector programs like ICDS, PHED and JEEViKA.

Apart from State Health Society, Bihar (SHSB), seven social sector departments or programs which could have significant stake in the implementation of BCC strategy include ICDS program of Social Welfare Department, the Public Health Engineering Department (PHED), the Mahadalit Vikas Mission, the Women Development Corporation (WDC), the Mabila Samakbya, JEEViKA -Bihar Rural Livelihoods Promotion Society, and the Panchayati Raj Department. The six parameters while analyzing these social sector departments for their strength and possible role in implementing BCC strategy included: (a) common interests in health with SHSB, (b) program coverage (number of districts, blocks, and total population), (c) key target audience (e.g. women of reproductive age, Mahadalits), (d) organizational strength for reaching communities with messages, (e) their community workers' profiles and capability, (f) program platforms that could be used for BCC, including available budget for BCC/IEC activities. 


\section{Key findings}

\section{Status of health indicators}

While certain healthy practices such as four ANC visits, institutional delivery, and complete immunization are improving steadily, postnatal care (PNC) for mother and newborn, up to seven days after delivery, remains neglected. High impact, simple behaviors such as early breastfeeding initiation, clean cord care, skin-to-skin care, timely seeking health care after danger signs, and contraceptive use remain low for various reasons, primarily lack of knowledge and poor counseling. Appropriate complementary feeding, adequate and balanced diet, Vitamin A consumption, and use of iodized salt are far from satisfactory levels. Access to improved water and sanitation facilities is much better in the state; however, this should not imply that all people are drinking safe water, using clean toilets, and washing hands after defecation. Improving hygienic practices and removing open defecation are major challenges leading to high disease burden that the program still faces.

\section{Reach of media}

The study shows that majority of the rural population in Bihar is out of reach from any mass medianewspaper, radio or television. An analysis of NFHS-3 data (2005-06) reveals that 65 percent of women, aged 15 to 34, in Bihar were not exposed to any mass media. A recent Population Council (PC) study (2011) shows no improvement in rural women's mass media exposure. Interpersonal communication with ASHAs is better: 57 percent of women have met an ASHA at least once during their last pregnancy, to discuss health-related issues; in rural Bihar, however, the PC study shows both content and quality of counseling was poor. Further, ASHAs generally do not approach poor and Below Poverty Line (BPL) families, scheduled castes, and minorities living in cluster/hamlets, the families who need information and services the most. Mid-media such as wall paintings, posters, and leaflets for clients or counseling aids for effective counseling are hardly available at PHCs or with providers.

\section{Status of the state mass media units}

Discussions and interviews with state, district, and block officials revealed that the health sector's Media Unit and its sub-system in districts and blocks are too weak to implement an effective BCC strategy for all target audiences. None of Bihar's 38 districts have Mass Media Officers or deputies. Within blocks, the post of Block Extension Educator (BEE), who earlier was responsible for BCC, has been vacant for eight to 10 years. Many district and block community mobilize positions, responsible for monitoring and guiding ASHA work, are also vacant. To make the Media Unit a viable instrument for health behavior change, it needs to be revamped, with a minimum of key staff. Furthermore, as implementation of different health sector components is a shared responsibility, SHSB needs to involve other departments for implementing the BCC strategy with a broader health sector mandate.

\section{Development partners' activities in BCC}

Discussions with Development Partners (DP) and international agencies show, while many focus on maternal, child and reproductive health (RH), few work on FP, and still less on hygiene and sanitation; only one or two agencies address them all. Flood-prone districts have poor health and development indicators and, far from Patna, are generally not chosen for intervention or BCC activities. BCC continues to be a vertical program, campaigns are short, and few partners have integrated BCC in their programs. No rigorous evaluations have assessed BCC campaigns' impacts, and most DPs work in isolation with little or no sharing with other DPs or international NGOs. Mass media is often the main BCC vehicle, 
with little interpersonal communication (IPC) or efforts aligning and reinforcing messages. Each DP develops its own package of messages and BCC tools with little standardization of themes.

\section{Potential partners in implementing the health sector BCC strategy}

A detailed analysis of six different departments, including their strengths and weaknesses, coverage and organizational strength at the grassroots level, shows that ICDS has the most overlapping health sector responsibilities with SHSB and address the same audiences including pregnant women, adolescent girls, and children under six years of age. Similarly, PHED manages a key health component by ensuring access to safe drinking water and sanitation, without which the health burden on the family cannot be significantly reduced. Inducing healthy practices related to making water safe, keeping surroundings clean, and rejecting open defecation are major BCC challenges for PHED programs and constitute an integral part of the health sector BCC strategy. Self-help groups (SHGs) formed under different programs such as JEEViKA, WDC, and Mahila Samakbya are all striving for women's economic empowerment, and Mahadalit Vikas Mission for Mabadalit families' social and economic empowerment. These programs' managers appreciate that economic development of a family with a heavy disease burden is not possible and, hence, adoption of healthy behavior is critical for achieving their program objectives. SHGs provide captive audiences of about 1.07 million families and Mabadalit Vikas Mission to about 2.2 million families, who belong to the poorest and most disadvantaged groups without access to information and services, even from ASHAs. The Panchayat is responsible for planning and local governance of all development programs in villages, conceived to fulfill the key role of providing supportive supervision, bringing the programs under community monitoring, and facilitating convergence of various programs at the VHSND forum.

\section{Way forward}

Three important aspects must be understood when conceptualizing the framework for developing a BCC strategy for the health sector. First, SHSB has to take the lead role in bringing about desired health practices. For that, urgent actions are required for revamping the media unit and related human resources at all levels.

Second, SHSB is not the only department responsible for BCC activities related to the health sector. Other programs and departments such as the ICDS program of the Social Welfare Department and PHED also have program objectives of promoting healthy practices. While ICDS promotes healthy practices related to $\mathrm{MCH}$ and nutrition, PHED manages hygiene, sanitation, and safe drinking water at home and in the community.

Third, several departments and programs may not have a health component in their departmental goals directly but their program success is dependent on improving healthy practices ensuring improvement in family health. Families with heavy disease burden cannot achieve economic development, and thereby most families, without adopting hygienic practices, cannot reduce social barriers. Thus, adoption of healthy practices is strongly associated with the objectives and goals of all these departments. 
Figure 1: Framework for implementing BCC strategy in health

\section{Planning, implementation and monitoring of BCC strategy (SHSB BCC Cell, CCDU of PHED, VHSNC of PRI)}
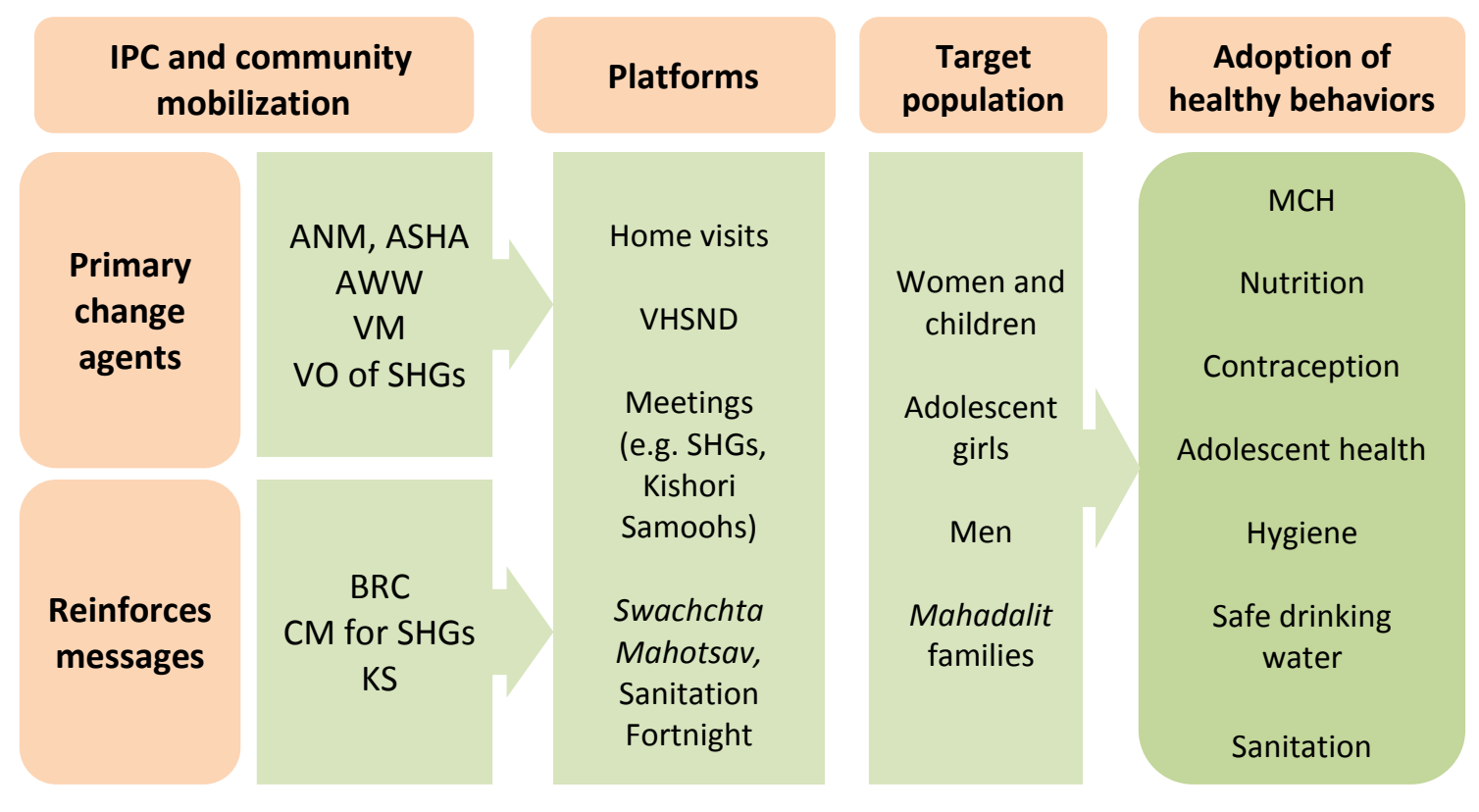

Health sector BCC is, therefore, a broader concept, and BCC strategy implementation should be a collective responsibility of all departments whose programmatic achievement of goals is contingent on adoption of healthy practices and sustaining them for long enough to make them community norms. Figure 1 presents the conceptual framework for implementing a BCC strategy in the health sector. The Figure shows, different change agents and forums provided by different programs that could play a role in the BCC strategy either as prime change agents or reinforcing messages through IPC and community mobilization. While different departments will execute their collective responsibility in implementing a BCC strategy for health sector, however, the key stakeholder is SHSB. SHSB should take immediate steps to strengthen existing IEC and the Mass Media Unit, and initiate dialogue with other departments to establish a mechanism to collaborate, complement, and jointly monitor each other's efforts. To take a lead role in this collaborative initiative for behavior change, SHSB needs to revamp its Media Unit. Our suggestion for the proposed State Media Unit is elaborated in Figure 2. 
Figure 2: Human resource requirement at state $\mathrm{BCC}$ Unit and

Executive Director (SHSB) key responsibilities

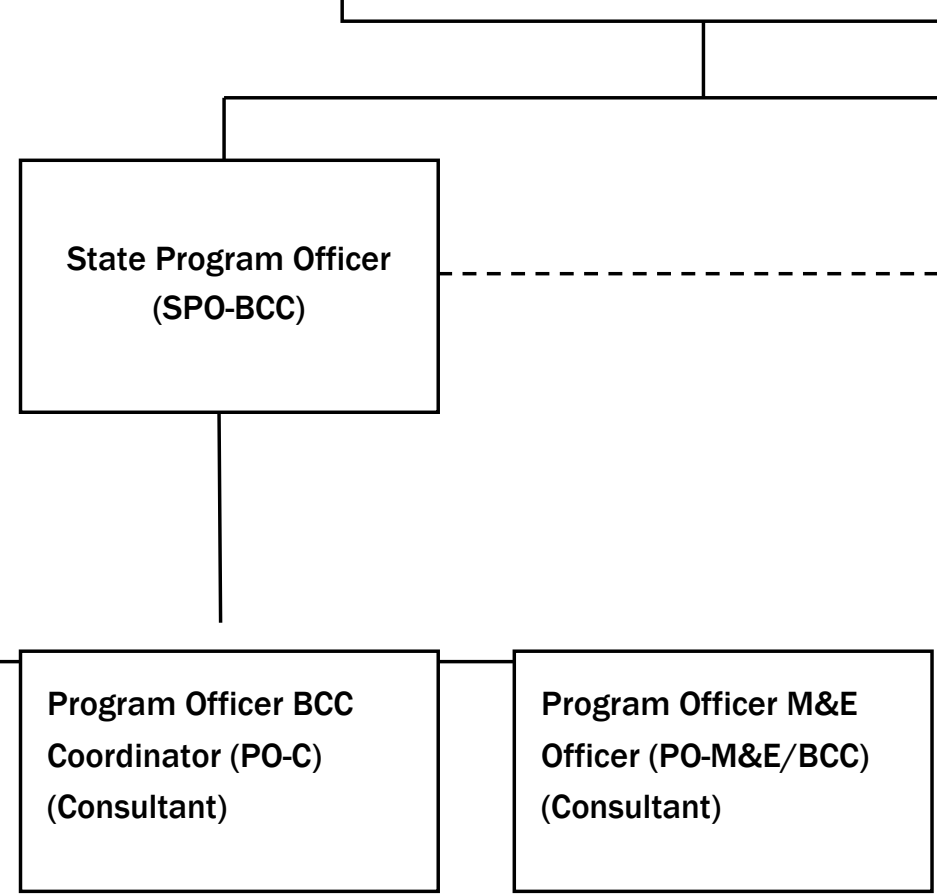

- Developing messages by consultative processes and field testing

- Designing, printing/production

- Developing counseling tools

- Coordinating with districts for material development and supply

- Strategizing efficient use of diverse forms of media channels to reach entire community
- M\&E of all activities of the BCC program

- Developing required checklists for monitoring and feedback from DCMs and BCMs.

- Analyzing and providing feedback to districts and blocks on their BCC activities/ performance

- Undertaking special BCC studies to understand barriers and evaluation of the BCC program
- Coordinating BCC activities of development partners

- Standardizing all BCC messages of development partners (DP) (requires development of guideline)

- Ensuring approval of SHSB for communication activities of DP in a time bound manner

- Coordinating with media houses

- Coordinating with other departments to partner in implementing the communication strategy
ASHA Resource Center

(ARC)

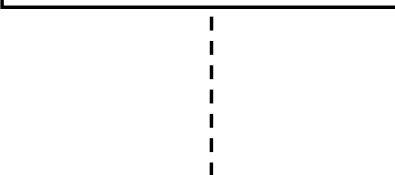

- Capacity building of ASHAs and ensuring competency-based training, Overseeing ASHA Diwas is utilized for sustained reorientation of ASHAs by $\mathrm{BCM}$

- Closely monitoring IPC activities of ASHAs

- Ensuring all vacant positions of DCMs and BCMs are filled

- Reorienting of DCMs and BCMs so that they perform their work and strengthen monitoring of ASHAs' activities including community mobilization

- Overseeing activities of DCMs and BCMs

- Providing allowances for field travel and mobile phone charges to BCMs so they could do field visits and monitor ASHAs 
Figure 3: Constitution of District Media Planning \& Implementation Committee

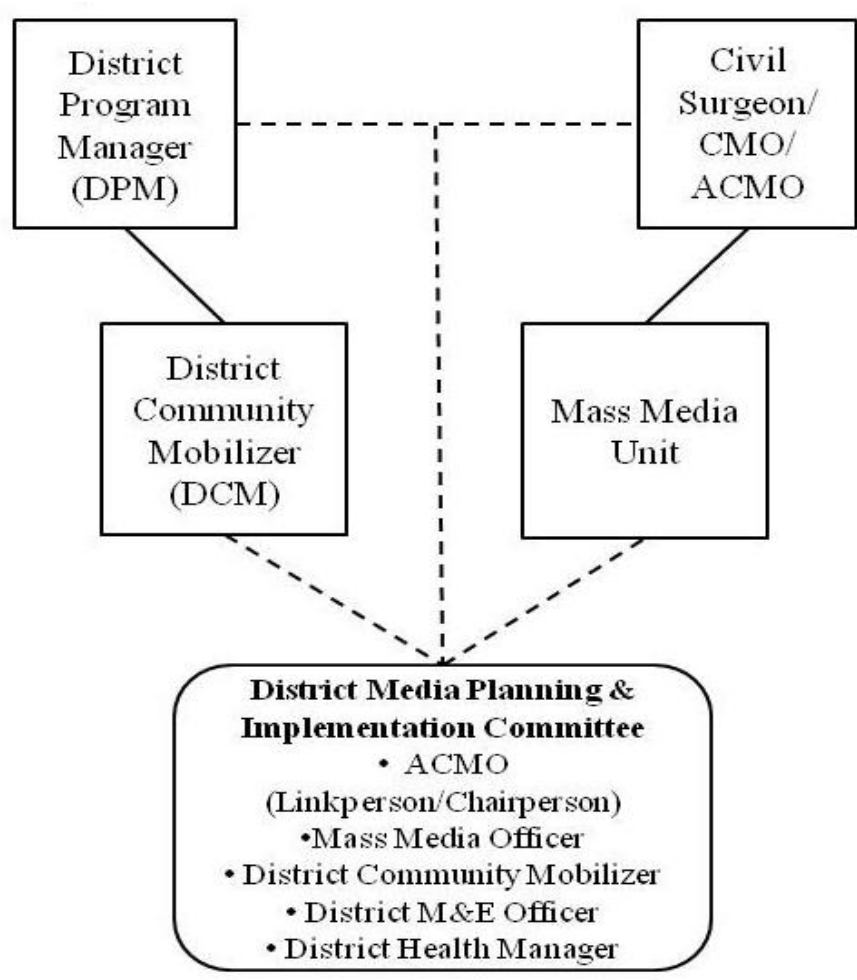

impact are discussed in Chapter 6.
Within districts, all mass media units are defunct. To strengthen and implement the BCC strategy, it is important that district mass media units should also be revamped and a clear linkage between the DHS and Mass Media Unit can be established so they can work jointly to achieve departmental goals (Figure 3). To oversee district BCC activities and give guidance, we have suggested a District Media Implementation Committee should be constituted (Figure 3). The implementation plan and roles and responsibilities of different staff are detailed in the report.

An effective BCC strategy should be measured in terms of actual behavior change. Impact of BCC activities can be measured by immediate outputs and intermediate and final outcomes depending on implementation duration. Detailed examples of indicators that could be used for measuring BCC 


\section{CHAPTER 1}

\section{INTRODUCTION}

\section{Introduction}

According to India's 2011 census, Bihar is the country's third most populous state, with a population of 103.8 million, and contributes to nine percent of India's total population (RGI 2011a). Bihar has one of India's highest maternal mortality ratios (261 per 100,000 live births) and infant mortality rates (48 per 1,000 live births) (RGI 2011b; RGI 2011c). Bihar also has the highest total fertility rate (TFR), of 3.9 children per woman, in India (RGI 2011c). Bihar is also marked by stark gender inequities and social inequities related to access to health, education, and other associated services. Economically, Mahadalits, Scheduled Castes (SCs), and Scheduled Tribes (STs) constitute the most marginalized communities in the state, and these groups, along with minority communities, are mostly socially excluded, often residing in distant hamlets (tolas) and village outskirts. Moreover, 60 percent of households in Bihar fall in the lowest wealth index category (IIPS and Macro International 2008).

\section{Problem}

India's achievement of the Millennium Development Goals (MDGs), especially MDGs 4 and 5, largely depends on the progress made by states such as Bihar and Uttar Pradesh (UP) in improving reproductive health $(\mathrm{RH})$, nutrition and hygienic practices among adolescent girls and women, delaying age at marriage to at least 18 years, and increasing adoption of healthy maternal and child health behaviors. These behaviors include at least four antenatal checkups (ANC), institutional delivery, postpartum care for mother and the newborn, early and exclusive breastfeeding, timely introduction of appropriate complementary food, postpartum contraception, complete immunization, toilet use, and hand washing practices. Studies across the globe show that exposure to well-coordinated and aligned Behavior Change Communication (BCC) messages from different channels of communication such as mass media, mid media and interpersonal communication (IPC), play a key role in increasing knowledge, changing attitudes, and encouraging adoption of healthy behaviors (Darmstadt and Tarigopula 2010, Khan et al. 2012, Prasar Bharti 2009, Singhal et al. 2006, UNICEF 2005). These healthy behaviors must become community norms, adopted and consistently practiced by the community.

The communication department of the health sector and its sub-system in districts and blocks are too weak to implement effective BCC. None of the 38 districts in Bihar and District Mass Media Officers are in position. Moreover, at the block levels, the post of Block Extension Educator (BEE), earlier responsible for BCC work, has been vacant for up to 10 years. Hence, a comprehensive BCC strategy needs to be designed and implemented through existing departments and institutions addressing different health issues. An analysis of NFHS-3 data (2005-06) reveals that 65 percent of women in Bihar were not exposed to any mass media-newspaper, radio or television (TV). A recent Population Council (PC) study shows that 69 percent of women and 47 percent of men in rural Bihar were not exposed to any mass media (Khan and et al. 2012). Hence, mass media alone cannot be used to reach women as well as the poorest and least educated, who are the crucial audiences for a BCC strategy. Further, frontline health workers such as Accredited Social Health Activists (ASHAs) and Auxiliary Nurse Midwives (ANMs) do not contact more than 50 percent of rural women. Therefore, a BCC strategy on health should be 
developed using all communication channels to reach all segments of potential audiences particularly the most disadvantaged segments of the population in Bihar.

\section{Objectives}

The objectives of the study, as proposed in the protocol, included a rapid situation analysis of:

- The existing mechanism for developing a BCC plan and its functioning at the State, district and block levels and;

- BCC activities of relevant development partners and their potential to complement SHSB's initiative to develop an integrated BCC strategy and to synergize the impact.

\section{Methodology}

At the beginning of the project, in December 2011, meetings were held with the Executive Director (ED) of Bihar's State Health Society (SHSB) and the State Program Officer for Family Planning, SHSB, who also manages all of SHSB's media activities. During the meetings, the ED reported that SHSB does not have a clear BCC policy and expressed his hopes this exercise will provide a policy paper that could be used for designing a comprehensive BCC strategy. Subsequently, PC staff met with UNICEF officials several times and reached a consensus that, until media units at all levels are fully developed, the health department alone cannot implement a comprehensive BCC strategy for all segments of the population, particularly the poorest and most disadvantaged groups who need it. The broader framework, presented by the Program Manager, UNICEF at a meeting on March 12, 2012 is given in Figure 1.1.

Based on these discussions, it was decided to broaden the project objectives beyond the health department to explore a wider range of departments with program goals that have a direct bearing on health sector. This included the Integrated Child Development Services (ICDS) and the Public Health Engineering Department (PHED), and some other potential departments or programs that may not have any direct responsibility in the health sector but for their program success are contingent to ensuring a healthy family. For example the Mahadalit Vikas Mission, the Women Development Corporation (WDC), the Mabila Samakhya, JEEViKA, Bihar Rural Livelihoods Promotion Society, and the Panchayati Raj Department. 
Figure 1.1: Framework for situational analysis and potential partners' roles in implementing the BCC strategy

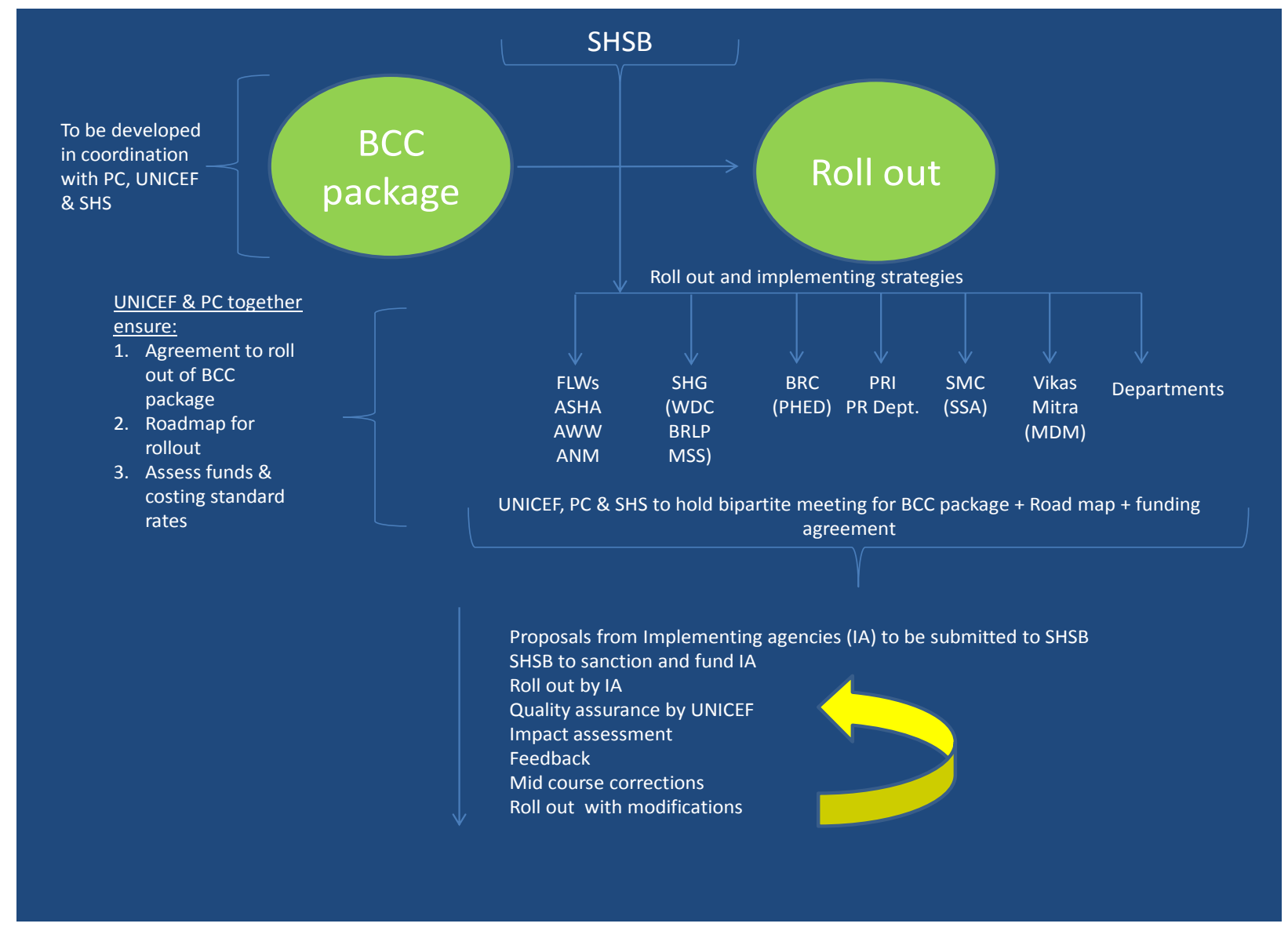

After finalizing the design of the study the required data and information were collected by:

- Analysis of national surveys like NFHS, DLHS and a recent study, Shaping Demand and Practices to Improve Family Health Outcomes, by the Population Council;

- Review of various policy papers and program documents;

- In-depth interviews of approximately 100 key officials including seven Principal Secretaries and other Senior State Officials, Chiefs of Party or Senior Program Managers of development partners, and district and block level officials and;

- Field visits of four districts to observe functioning of the heath sector as well as other social sector programs like ICDS, PHED and JEEV IKA.

UNICEF had been a facilitator, both in conceptualizing the overall strategy and arranging meetings with Principal Secretaries and senior officials of concerned departments, for understanding their perspective on BCC and how their departments could contribute in implementing the proposed BCC strategy. While analyzing strength and exploring feasibility and possible roles of the selected departments and programs in implementing BCC strategy, key elements considered include:

- Common interests with SHSB;

- Program coverage (number of districts, blocks, and total population);

- Key target audiences (e.g. women of reproductive age, Mahadalits); 
- Organizational strength for reaching communities with messages;

- Presence of grassroots workers;

- Program platforms that could be used for BCC;

- Available budget for BCC/IEC activities.

\section{Structure of the report}

This situation analysis is divided into six Chapters. The present chapter introduces this study's methodology and also gives an overview of the key findings.

Chapter Two deals with the current status of selected family health indicators which have direct bearing on maternal, neonatal and child health and nutrition. As the results show, although some progress has been made in increasing certain healthy practices such as four ANC visits, institutional delivery, full immunization, and treatment of Acute Respiratory Infections (ARI), high impact, simple behaviors such as PNC, early initiation of breastfeeding, clean cord care, skin-to-skin care, rushing to a health facility after a danger sign, and contraceptive use remains low because of various reasons, primarily lack of knowledge and poor counseling. Other important components of child care like appropriate complementary feeding, adequate and balanced diet, consumption of Vitamin A and use of iodized salt are far from satisfactory. These have remained a grey area and especially after the introduction of JBSY, attention has been given to the mother and the newborn rather than to child care. Access to improved water and sanitation facilities is much better in the State, however, does not imply that all people are drinking safe water, using clean toilets and washing hands after defecation.

The third chapter presents the reach of the media and status of BCC activities in the State of Bihar. The majority of the rural population in Bihar is out of reach of any mass media. Interpersonal communication with the ASHA is better and 57 percent of women, who had delivered their baby in a health facility, had met an ASHA and discussed with her any health-related issues. However, the Population Council study shows that contact with ASHA is limited to relatively affluent high caste families who are also better educated and have access to mass media. ASHAs generally do not approach SCs/STs and minorities who are living in clusters and BPL families. These are the families who need information and service the most. Analysis shows that mid media like wall paintings, posters and availability of leaflets for distribution to clients or counseling aids to make the counseling effective are rarely available at the PHCs or with providers.

Analysis of the Mass Media Units at the State shows that there is no State Program Officer (SPO) for BCC and in his/her absence, this work is being looked after by the State Program Officer (FP). At the district level, the Mass Media Units are non-functional. The Mass Media Officers, Deputy Mass Media Officers and artists have either retired or been transferred elsewhere. The Unit is presently attached with the Health Department and is practically non-existent except for the presence of peons and drivers. Visits at the block level did not offer a different picture. All the Block Extension Educators (BEEs), the key media persons at the block level, have retired and the posts are vacant. They also function from PHCs or district rather than additional PHCs. Half of the Health Educator posts are vacant thus major burden of motivational effort lies with frontline workers like ANMs, ASHAs and AWWs. District Community Mobilizers (DCMs) and Block Community Mobilizers (BCMs) who have been appointed to give direction and strengthen capacity of ASHAs in community mobilization have a limited impact. The study thus shows that to develop and implement a BCC strategy, the SHSB has to take a major step in establishing a Media Unit at the State level, revamping the district Mass Media Units, restructuring the roles and responsibilities of DCMs District Program Mangers and Block Health Managers (BHM) involved in planning the communication strategy. Major shift has to take place in the mindset of the officers 
responsible for motivational and educational campaigns and they should understand that BCC is not IEC and that BCC has to be an integral and equally important part of service delivery of the health program.

The fourth Chapter deals with different development partners and international agencies which are carrying out communication activities in the State. The findings show that key behaviors related to maternal, child and reproductive health and water and sanitation are being addressed by many development partners in the State, but only a few organizations are addressing a wide range of themes. The number of districts being covered by different development partners varies considerably; while districts around Patna have had intense development activity, districts farthest from Patna which are flood affected and have poor health and development indicators are the most neglected districts. Few organizations have well integrated BCC with health in their program activities. BCC campaigns are mostly of short duration and few evaluation studies with scientific rigor have been conducted to assess the impact of the BCC campaigns and only in negligible cases was impact measured in terms of behavior change. In many cases, it is not clear how much the campaign or messages developed are evidence-based. All organizations taken together are carrying out a wide range of communication activities using mass media, mid media and IPC, though, little effort has been made for alignment and reinforcement of messages from mass media and simultaneously by IPC.

The fifth Chapter gives an analysis of six different departments which have some overlapping interest in the health sector and could play a role in implementing the communication strategy. An analysis of their strengths and weaknesses, coverage and organizational strength at grassroots level shows that ICDS has the highest overlapping interest, coverage and presence of workers at the village level and it appears to be the first natural ally in implementing the BCC strategy. The second closest and most potential department appears to be JEEViKA, which can contribute in reaching to 40 percent of the poorest and disadvantaged group who do not have access to information and services even from ASHAs. The platform provided by JEEViKA in the form of SHGs is strong, attractive and could contribute significantly in reaching with messages and selected services like condoms, pills, sanitary napkins and Oral Dehydration Salt (ORS) to those who are in general isolated from the mainstream society.

The final Chapter provides a framework for implementing a BCC strategy for the health sector and shows how change agents and platforms provided by various departments can play a role with the monitor BCC activities. It identifies various activities each department could play for delivering BCC messages and reinforcing them and what input would be required by the department in order to do so, the chapter also suggests to establish a Media Unit at the State, its roles and responsibilities, how it could interact with other parallel institutions at the State level such as the ASHA Resource Centre (ARC) and people at the district, block and community level. We hope that these suggestions would lead to certain discussions and finally help shape and revamp the BCC activities in Bihar. 


\section{References}

Darmstadt G. L. and U. K. Tarigopula. 2010. "Behavior change communication as an intervention to improve family health outcomes.” The Journal of Family Welfare, 56 (Special Issue): 1-7.

International Institute for Population Sciences (IIPS) and Macro International. 2007. National Family Health Survey (NFHS-3), 2005-06: India: Volume I. Mumbai: IIPS.

Khan M. E., F. Donnay, U. K. Tarigopula and D. Ganju (eds). 2012. Shaping Demand and Practices to Improve Family Health Outcomes Designing a Behavior Change Communication Strategy in India, Volume 1: Uttar Pradesh. New Delhi: SAGE Publications.

Prasar Bharti. 2009. Kalyani Impact Evaluation by Gfk Mode (2008-09). www.ddindia.gov.in/devcom/Program+Column+2/Research_Evaluation.htm. (accessed on 10 February 2012).

Registrar General of India (RGI) and Census Commissioner, India. 2011a. Provisional Population Totals Paper 1 of 2011 India Series. Delhi: RGI.

Registrar General of India (RGI). December 2011b. SRS Bulletin, Sample Registration System. Delhi: RGI.

Registrar General of India (RGI). June 2011c. Special Bulletin on Maternal Mortality in India 2007-09, Sample Registration System. Delhi: RGI.

Singhal, A., M.J. Papa, D. Sharma, S. Pant, T. Worrell, N. Muthuswamy and K. Witte. 2006. "Entertainment education and social change the communicative dynamics of social capital." Journal of Creative Communications, 1 (1): 1-18.

United Nations Children's Fund (UNICEF). 2005. Strategic Communication for Behavior and Social Change in South Asia, Working Paper. Nepal: UNICEF. 


\section{CHAPTER 2}

\section{STATUS OF SELECTED BEHAVIORS IN BIHAR}

\section{Introduction}

The achievement of Millennium Development Goals (MDGs), especially MDG 4 and 5, in India largely depends on the progress made by the large northern states like Bihar and Uttar Pradesh in increasing adoption of healthy maternal, newborn care practices and other family health behaviors such as hygiene practices, delaying marriage to at least 18 years, early and exclusive breastfeeding, timely introduction of appropriate complementary food, adoption of postpartum contraceptive methods, complete immunization, and hand washing before eating and after defecation.

Impact of poor or limited adoption of these family health behaviors is reflected in the state's demographic condition and is evident from national and state level goals and their achievements in maternal and child health so far (Table 2.1). Among children under five years of age, the majority of deaths are either neonatal or due to infectious disease after the neonatal period. Even among neonatal deaths, prematurity, low birth weight, infections, and birth-related complications are the major reasons, most of which are preventable.

Table 2. 1: National and State level goals in $\mathrm{MCH}$ and progress made so far

\begin{tabular}{|c|c|c|c|c|}
\hline Indicators & $\begin{array}{c}\text { XI FYP } \\
(2007-12)\end{array}$ & India & $\begin{array}{c}\text { Goal of Bihar } \\
(2011-12)\end{array}$ & Bihar \\
\hline IMR & 28 & $\begin{array}{c}47 \\
(\mathrm{SRS}, 2011)\end{array}$ & 45 & $\begin{array}{c}48 \\
(S R S, 2011)\end{array}$ \\
\hline MMR & 100 & $\begin{array}{c}212 \\
\text { (SRS, 2007-09) }\end{array}$ & 200 & $\begin{array}{c}261 \\
\text { (SRS, 2007-09) }\end{array}$ \\
\hline TFR & 2.1 & $\begin{array}{c}2.6 \\
(S R S, 2008)\end{array}$ & 3.7 & $\begin{array}{c}3.9 \\
\text { (SRS, 2008) }\end{array}$ \\
\hline
\end{tabular}

Source: Data obtained from XI five-year plan, and Sample Registration System estimates of corresponding years.

Extracting information from available published and unpublished reports, websites, and analysis of secondary datasets, this chapter presents the status of selected health, nutrition, hygiene, and sanitation practices in Bihar. These behaviors have direct bearing on maternal and child health and on community development.

\section{Status of behaviors}

\section{Registration of births and birth certificates}

In India, per the Registration of Births and Deaths Act of 1969, registering every birth or stillbirth with the state/UT government is mandatory within 21 days of its occurrence. In India, birth registration is slowly increasing, yet according to the Registrar General of India (RGI), in 2007 about 25 percent of births (about 6.6 million) were not registered (TOI 2012). 
In Bihar, birth registration is only 26 percent, the lowest in the country. The RGI officials says, "Bihar and Uttar Pradesh are the two worst performing states, since they have the highest population and low (birth) registration levels. If these two states are taken off, the national average of birth registration will increase to about 88 percent" (TOI 2012a). Concerned over poor registration of births in Bihar, the Principal Secretary of the State planning and development department says, "people should get their children registered at the time of birth" of 31 lakh births in the state in a year, 15 lakhs are girls and of these, barely 1.5 lakhs are registered. Around 50 percent primary health care centres do not report birth registration. The situation is similar in urban areas-only 48 percent of urban bodies report birth registration. District variation in birth registration in the state is evident from the fact districts have extremely low birth registration of five percent, with other districts report birth registration at 45 percent (The Telegraph 2010).

\section{Reduction in early marriages}

Data from District Level Household Surveys (DLHS-2 and DLHS-3) show, in rural Bihar during 200708, 48 percent of girls were married before age 18, slightly better than the figure reported in 2002-04 (59\%). In rural India, 27 percent of girls married below age 18 during that period. The percentage of currently married women aged 20 to 24 who were married before age 18 was estimated around 68 percent (IIPS 2010). Early marriage is primarily associated with early childbearing. Most studies show that the risk of dying because of maternal causes is higher among women below age 20 than among women in their 20s and 30s (NRCIM 2005).

\section{Maternal and child survival}

\section{Uptake of at least 4 antenatal checkups}

Proper care during pregnancy is crucial for the health of the mother as well as the development of the unborn baby. It also improves other healthy behaviours. For instance, mothers who received proper antenatal care are about three times more likely to deliver in a medical institution than mothers who did not receive such care (Sugathan et al. 2001, Varma et al. 2012).

JSY's introduction has contributed significantly to increasing pregnant women in India's receiving at least three ANC checkups. A study in rural Bihar shows, in 2011, 48 percent of women received three or more antenatal checkups compared to 27 percent in 2007-08 (Hazra et al. 2012). However, the study further shows that that just six percent of women received full ANC including examination of abdomen, blood pressure measurement, blood and urine tests, two doses of TT injections and 100 IFA tablets. Findings indicate that ANC is considered equivalent to two doses of TT injections (Hazra et al. 2012). The Coverage Evaluation Survey (CES 2009) also reported similar findings-full ANC was received by five percent of women. The corresponding figure for India was 53 percent (UNICEF 2010).

Recently, following the World Health Organization's (WHO) recommendation, GoI has recommended four ANC for every pregnant woman (Lincetto et al. n.d.). Presently, in rural Bihar the percentage of women receiving four ANCs is quite low, around 15 percent (UNICEF 2010, Hazra et al. 2012).

\section{Deliveries attended by a skilled person}

Delivery assisted by a skilled person is an important indicator for monitoring Millennium Development Goal 5 progress. According to DLHS-3 data, in 2007-08 only about 31 percent of deliveries in Bihar were attended by a skilled person (IIPS 2010). Recent studies, however, show some improvement (54\%) (UNICEF 2010, Hazra et al. 2012), significantly lower than the national average of 76 percent. Home deliveries were mostly conducted by unskilled persons (Hazra et al. 2012). 


\section{Postnatal care of women}

Analyses of NFHS and DLHS and findings from the Population Council formative study reveal that in rural Bihar, the percentage of young women aged 15 to 34 who received PNC within seven days of delivery increased from 16 percent in 2005-06 (NFHS-3) to 26 percent in 2007-08 (DLHS-3), and remained the same in 2011 (Varma and Khan 2012). CES-2009 found that postnatal visits within 10 days were at 30 percent in Bihar, while the corresponding figure in India was 60 percent (UNICEF 2010).

\section{Newborn care including cord care, delayed bathing and thermal care}

WHO recommends essential newborn care practices which include: (a) clean cord care, i.e. cutting the umbilical cord with a sterile and sharp instrument, tying it, and keeping the cord stump clean and dry (not applying anything on the cord stump); and (b) thermal care through keeping the newborn warm to prevent neonatal hypothermia (WHO 1994).

The practice of cutting the umbilical cord with a new blade is now universal in India (IIPS and Macro International 2007). Population Council's study showed that irrespective of the place of delivery, very few women $(10 \%)$ did not apply anything on the cord stump as follow up cord care. About three-fourths of women reported that they applied gentian violet on the cord stump of the baby while another few applied ghee/oil, talcum powder, ash or ointment obtained from providers (Varma and Khan 2012). It was found that there is a lack of awareness among women and their family members as well as frontline health care workers regarding healthy cord care practices (Varma and Khan 2012).

Analysis for thermal care shows that 38 percent of women in rural Bihar delayed bathing their newborn for more than 24 hours after birth. Institutional delivery helps delaying the first bath of the newborn. Half $(50 \%)$ of those who delivered at the institution and 24 percent of those who delivered at home delayed the first bath by at least 24 hours after birth. Traditional beliefs or misconceptions such as an un-bathed newborn is impure or the vernix on a newborn is dirty are found to be a significant barrier to delayed bathing (Varma and Khan 2012).

The study further shows that only nine percent of the total women interviewed and 11 percent of mothers-in-laws had heard of Skin-to-Skin Care (STSC) or Kangaroo Mother Care (KMC) as a method to keep the newborn warm. Merely six percent of women practiced STSC/KMC in rural Bihar in 2011. However, among those few women who knew about STSC/KMC, 69 percent practiced STSC for their last child (Varma and Khan 2012).

\section{Early initiation of breastfeeding and exclusive breastfeeding for at least six months}

Early breastfeeding is an important family health intervention, if implemented widely, it can reduce neonatal mortality rate by 20 percent (Mullany et al. 2008). Population Council's study reveals that a little more than a third $(36 \%)$ of women in rural Bihar initiated breastfeeding within one hour of birth of their child (Aruldas et al. 2012a). The CES-2009 report shows that only 17 percent newborns were breastfed within one hour after birth as compared to the national average of 34 percent (UNICEF 2010).

A trend analysis of existing datasets shows a slow increase in early breastfeeding. Analysis shows that newborns breastfed within an hour increased from about 1 percent in 1992-93 (NFHS-2) to 16 percent in 2009 (Concurrent Evaluation of NRHM) and 36 percent in 2011 (Hazra and Khan 2012). According to the CES-2009 report, 37 percent of children aged six to nine months were exclusively breastfed in India. In rural Bihar, only 34 percent of children aged six months were exclusively breastfed in 2011. About 47 percent of the children were given water well before completing six months of age since women thought their child may be thirsty (Aruldas et al. 2012b). 


\section{Full immunization of children}

The Government of Bihar has made concerted efforts during the last four years by integrating Department of Health and Family Welfare, Integrated Child Development Scheme (ICDS) of Department of Women and Child Development and UNICF to improve immunization coverage. In 2007-08 (DLHS-3) the full immunization rate in rural Bihar was 41 percent. Subsequently since October 2007, routine immunization (RI) services were introduced in the outreach mode in Bihar through a mission named Muskan ek Abhiyan ('The Smile Campaign'). This has led to significant increase in full immunization-49 percent in 2009 (UNICEF 2010) and around 65 percent in 2011 (Ahmad and Khan 2012).

\section{Postpartum contraception among young women}

Analysis of available secondary data shows very low use of any contraceptive method among young women aged 15 to 34 who had given birth in one year preceding the survey dates. A comparison of results of NFHS, DLHS, and the Council's formative study shows, in the last 16 years, only a five percent increase reported (Hazra and Khan 2012). This, perhaps, indicates a lack of program emphasis on promoting contraception among young couples and increasing birth intervals for healthy pregnancy outcome.

The Council's study shows, among the currently non-pregnant women aged 15 to 34 who had given birth in three years preceding the survey, only 31 percent were using a contraceptive method, which is far below the national average of 43 percent. In the last 18 years, there has been a rise of 20 percent $(11 \%$ in $1992-93$ to 31\% in 2010-11), which is around one percent point per year (Bhatnagar et al. 2012).

\section{Use of ORS in diarrhea management and care for acute respiratory infection}

Diarrhea and ARI, primarily pneumonia are the leading causes of childhood morbidity and mortality. Early diagnosis and treatment can prevent a large proportion of diarrhoea and ARI related deaths. The CES-2009 report reveals that in Bihar, around 18 percent of the children had suffered from diarrhoea during two weeks preceding the survey. Treatment-seeking behavior shows that 74 percent children who suffered from diarrhoea during two weeks preceding the survey, received advice/treatment in Bihar. In Bihar, merely 22 percent of the mothers, whose children suffered from diarrhoea during the two weeks preceding the survey, gave ORS to their children; the corresponding percentage was almost double (43\%) in India (UNICEF 2010).

\section{Nutrition of children}

\section{Appropriate complementary feeding}

Complementary feeding for infants is recommended to be initiated when the infant completes six months of age. Key reasons for widespread malnutrition among infants and children under two is early introduction of animal milk and water to children less than six months old exposing them to risk of diarrhoea, delayed introduction of complementary food, and inappropriate quantity and quality of complementary feeding.

The findings from the Council's study show that, in rural Bihar, around 64 percent of children aged six months were fed complementary foods, indicating no significant change since 2005-06 (NFHS-3), when it was 67 percent (Aruldas et al. 2012). A comparison of the results of different rounds of NFHS shows that the introduction of semi-solid food has been increasing over time from 17 percent in NFHS-1 (1992-93) 
to 67 percent in NFHS-3 (2005-06), which could be credited to because of program emphasis and promotional efforts of the ICDS program (Aruldas et al. 2012, Hazra and Khan 2012).

\section{Malnutrition in children}

The most recent data in India on the nutrition status of children is available from the National Family Health Survey (NFHS-3) from 2005-06. The survey included three indicators-height-for-age (stunting), weight-for-height (wasting), and weight-for-age (underweight) to describe the nutritional status of children. According to NFHS-3, 56 percent children in Bihar were stunted, 27 percent were wasted, and 56 percent were underweight against the national averages for these three indicators which are 48 percent, 20 percent and 43 percent, respectively (IIPS 2007). According to the Hunger and Malnutrition survey inter-district variation in Bihar is visible as 43 to 65 percent of children were stunted, seven to 14 percent of children were wasted, and 35 to 40 percent were underweight across the districts (HUNGaMA 2011).

\section{Consumption of vitamin A}

The Government of India recommends that children should be given vitamin A supplement every six months, starting at nine months, until they reach three years of age (IIPS 2007). In NFHS-3 (2005-06), information was collected on consumption of vitamin A-rich foods ${ }^{1}$ and administration of Vitamin A supplements. The results show, in Bihar, around half of children (51\%) aged six to 35 months living with their mother consumed foods rich in Vitamin A in the 24 hours preceding the survey date. The corresponding national figure was 47 percent. One-third (33\%) of children 12 to 35 months were given vitamin A supplements in the last six months, slightly better than the national average (25\%) (IIPS 2007). According to the CES-2009 report, 49 percent children of age 12 to 23 months received at least one dose of vitamin A, and 45 percent received it within the past six months (UNICEF 2010).

\section{Use of iodized salt}

Among micronutrients, iodine is important: Lack of iodine in the diet may lead to Iodine Deficiency Disorder (IDD), which can cause miscarriages, stillbirths, brain disorders, retarded psychomotor development, speech and hearing impairments, and depleted levels of energy in children. Iodine deficiency can be avoided using salt fortified with iodine. In 2005-06, half of the households in India used iodized salt (IIPS 2007); since then it has increased to 71 percent in 2009 (UNICEF 2010). In Bihar, the percentage is much lower: Only 54 percent of households used iodized salt (UNICEF 2010).

\section{Hygiene and sanitation}

\section{Access to improved water sources and adequate sanitation facilities}

Access to safe water and adequate sanitation facilities are prerequisites to good health. The WHO defines access to safe drinking water as the proportion of people using improved drinking water sources ${ }^{2}$ (WHO 2012). Target 10 of MDG 7 aims to halve by 2012 the proportion of people without sustainable access to safe drinking water and basic sanitation.

\footnotetext{
${ }^{1}$ Such as meat, organ meat, fish, poultry, eggs, pumpkin, carrots, sweet potatoes, dark green leafy vegetables, ripe mango, papaya, cantaloupe and jackfruit.

${ }^{2}$ Household connection, public standpipe, borehole, protected dug well, protected spring and rainwater.
} 
According to the Census 2001, about 86 percent of households in Bihar had access to safe drinking water $^{3}$ which has increased to 93 percent in 2011. In this respect the average of Bihar is slightly better than the national average which was around 88 percent in 2008. Furthermore, according to a UNICEF estimate, only a quarter of the total population in India has drinking water on their premises. While there are traditional problems with frequent break down of old assets, lack of repairs and maintenance, and irregular power supply, the problem of contamination of water sources is becoming critical. As many as 22 of the 38 districts in Bihar have either arsenic or fluorine in excess, while the two districts of Bhagalpur and Munger have excess of both fluoride and arsenic (SWASTH-WATSAN 2012).

According to 2011 Census only 23 percent of households in Bihar and 47 percent of households in India had a toilet facility within their premises (RG\&CCI 2012). Efforts are being made to increase use of toilet facilities, for that, in 2010, as part of the Government's Total Sanitation Campaign (TSC), the Public Health Engineering Department (PHED) in collaboration with UNICEF organized a State-wide campaign, Bihar Gram Gaurav Yatra, to enhance community participation and weave in a sense of ownership of the program. The campaign had covered 23 districts and 273 blocks and their villages, across the State and inspired and sensitized large groups of school children to take pride in good health and to adopt good hygiene practices. In Bihar, a specific day is celebrated as Swachhata Diwas, which stands for overall cleanliness, including the issues of personal hygiene, washing hands, safe disposal of dirty water, and safe drinking water.

\section{Hand washing with soap}

Hand washing with soap is one of the most effective and cost-effective means of preventing infections that kill millions of children in the developing world each year. Using the Lives Saved Tool (LiST), it is estimated that diarrhoea risks reduced up to 48 percent by washing hands with soap (Cairncross et al. 2010). According to the Public Health Association, only 53 percent of India's population wash hands with soap after defecation, 38 percent wash hands with soap before eating and only 30 percent wash hands with soap before preparing food. As an impact of Water, Sanitation and Hygiene (WASH) interventions, hand washing with soap reduced diarrhoeal morbidity by 44 percent (UNICEF n.d.).

\section{Conclusion}

Some behaviors, such as at least three ANCs, institutional delivery, and complete immunization have significantly improved. Other important practices such as early initiation of breastfeeding, cord care and delaying first bath by 24 hours have also shown some increase, likely due to the increase in institutional delivery. However, practices like thermal care of newborn, postnatal care, delay in marriage to at least 18 years and adoption of postpartum contraception have remained poor and the pace of increase is very slow. Other sets of behaviours such as timely introduction of complementary feeding, exclusive breastfeeding, consumption of Vitamin A and iodized salt are increasing but the pace needs to be accelerated. Similarly, while access to safe drinking water is high, the practice of using the toilet and washing hands with soap is quite low. The variation of adoption of different healthy practices shows difficulties in changing cultural beliefs and practices as well as lack of access to information and services due to social barriers and constraints on health care delivery services.

This points to the fact that each specific behavior needs to be addressed appropriately and designing the communication strategy after identifying the barriers should be carefully dealt with comprehensively and in an integrated manner. Some of the challenges in addressing these issues will be discussed in the next chapter.

\footnotetext{
${ }^{3}$ Tap, hand pump or tube well.
} 
Table 2.2: Current status of the selected behaviors/indicators, India and Bihar

\begin{tabular}{|c|c|c|c|c|}
\hline No. & Indicators/Behaviors & India & Bihar & Source \\
\hline 1. & $\begin{array}{l}\text { Complete birth } \\
\text { registration/ obtaining } \\
\text { birth certificates }\end{array}$ & 75 percent in 2007 & - 26 percent in 2007 & RGI \\
\hline 2. & $\begin{array}{l}\text { Number of early } \\
\text { marriages (children } \\
\text { getting married before } \\
\text { they are } 18 \text { years) }\end{array}$ & 27 percent in 2007-08 & - 48 percent in 2007-08 & DLHS-3 (2007-08) \\
\hline 3. & $\begin{array}{l}\text { Women receiving at } \\
\text { least } 4 \mathrm{ANC} / \text { complete } \\
\text { ANC }\end{array}$ & $\begin{array}{l}\text { - At least } 4 \text { ANC: } 53 \\
\text { percent in } 2009 \\
\text { - Complete ANC: } 27 \\
\text { percent in } 2009\end{array}$ & $\begin{array}{l}\text { - At least } 4 \text { ANC: } 15 \\
\text { percent in } 2009 \text { and } \\
14 \text { percent in } 2011 \\
\text { - Complete ANC: } 5 \\
\text { percent in } 2009 \\
\end{array}$ & $\begin{array}{l}\text { CES } 2009 \text { and } \\
\text { Population Council } \\
\text { formative study } \\
2011\end{array}$ \\
\hline 4. & $\begin{array}{l}\text { Deliveries attended by } \\
\text { a skilled person }\end{array}$ & 76 percent in 2009 & - 53 percent in 2009 & $\begin{array}{l}\text { CES } 2009 \text { and } \\
\text { Population Council } \\
\text { formative study } \\
2011\end{array}$ \\
\hline 5. & $\begin{array}{l}\text { Women receiving } \\
\text { postnatal care }\end{array}$ & $\begin{array}{l}60 \text { percent (within } 10 \\
\text { days of delivery) in } \\
2009\end{array}$ & $\begin{array}{l}30 \text { percent (within } 10 \\
\text { days of delivery) in } \\
2009 \\
26 \text { percent (within } 7 \\
\text { days of delivery) in } \\
2011\end{array}$ & $\begin{array}{l}\text { CES } 2009 \text { and } \\
\text { Population Council } \\
\text { formative study } \\
2011\end{array}$ \\
\hline 6. & $\begin{array}{l}\text { Newborn care } \\
\text { practices such as cord } \\
\text { care, delay in bathing } \\
\text { and thermal care }\end{array}$ & $\begin{array}{l}\text { NA in corresponding } \\
\text { year }\end{array}$ & $\begin{array}{l}\text { - } 10 \text { percent clean cord } \\
\text { care in } 2011 \\
\text { - } 38 \text { percent delayed } \\
\text { bathing in } 2011 \\
\text { - } 6 \text { percent STSC in } \\
2011\end{array}$ & $\begin{array}{l}\text { Population Council } \\
\text { formative study } \\
2011\end{array}$ \\
\hline 7. & $\begin{array}{l}\text { Early initiation of } \\
\text { breastfeeding and } \\
\text { exclusive } \\
\text { breastfeeding for six } \\
\text { months }\end{array}$ & $\begin{array}{l}\text { EB: } 34 \text { percent in } \\
2009 \\
\text { ExBF: } 37 \text { percent in } \\
2009 \text { among } \\
\text { children age 6-9 } \\
\text { months }\end{array}$ & $\begin{array}{l}\text { EB: } 17 \text { percent in } \\
2009 \text { and } 36 \text { percent } \\
\text { in } 2011 \\
\text { ExBF: } 34 \text { percent in } \\
\text { 2011 among children } \\
\text { age } 6 \text { months }\end{array}$ & $\begin{array}{l}\text { CES } 2009 \text { and } \\
\text { Population Council } \\
\text { formative study } \\
2011\end{array}$ \\
\hline 8. & $\begin{array}{l}\text { Children fully } \\
\text { immunized }\end{array}$ & 61 percent in 2009 & $\begin{array}{l}\text { - } 49 \text { percent in } 2009 \\
\text { - } 76 \text { percent in } 2011\end{array}$ & $\begin{array}{l}\text { CES } 2009 \text { and } \\
\text { Population Council } \\
\text { formative study } \\
2011\end{array}$ \\
\hline 9. & $\begin{array}{l}\text { Children with diarrhea } \\
\text { using ORS and } \\
\text { receiving competent } \\
\text { care during acute } \\
\text { respiratory infection }\end{array}$ & $\begin{array}{l}\text { - Use of ORS: } 43 \\
\text { percent in } 2009 \\
\text { Treatment for ARI: } \\
83 \text { percent in } 2009\end{array}$ & $\begin{array}{l}\text { - Use of ORS: } 22 \text { percent } \\
\text { in } 2009 \\
\text { - Treatment for ARI: } 83 \\
\text { percent in } 2009\end{array}$ & CES 2009 \\
\hline 10. & $\begin{array}{l}\text { Children initiated with } \\
\text { appropriate } \\
\text { complementary food at } \\
6 \text { months }\end{array}$ & $\begin{array}{l}\text { NA in corresponding } \\
\text { year }\end{array}$ & - 64 percent in 2011 & $\begin{array}{l}\text { Population Council } \\
\text { formative study } \\
2011\end{array}$ \\
\hline 11. & Malnourishment & $\begin{array}{l}\text { - Stunted: } 48 \text { percent } \\
\text { in 2005-06 } \\
\text { - Wasted: } 20 \text { percent } \\
\text { in 2005-06 } \\
\text { - Underweight: } 43 \\
\text { percent in 2005-06 }\end{array}$ & $\begin{array}{l}\text { - Stunted: } 56 \text { percent in } \\
\text { 2005-06 } \\
\text { - Wasted: } 27 \text { percent in } \\
\text { 2005-06 } \\
\text { - Underweight: } 56 \\
\text { percent in 2005-06 }\end{array}$ & NFHS-3 (2005-06) \\
\hline 12. & $\begin{array}{l}\text { Children consuming } \\
\text { sufficient amount of } \\
\text { vitamin A }\end{array}$ & 64 percent in 2009 & 49 percent in 2009 & CES 2009 \\
\hline
\end{tabular}




\begin{tabular}{|c|l|l|l|l|}
\hline 13. & $\begin{array}{l}\text { Women adopting } \\
\text { postpartum } \\
\text { contraception /LAM, } \\
\text { especially young } \\
\text { women }\end{array}$ & $\begin{array}{l}\text { NA in corresponding } \\
\text { year }\end{array}$ & 31 percent in 2011 & $\begin{array}{l}\text { Population Council } \\
\text { formative study } \\
2011\end{array}$ \\
\hline 14. & $\begin{array}{l}\text { Households using } \\
\text { iodized salt }\end{array}$ & 71 percent in 2009 & 54 percent in 2009 & CES 2009 \\
\hline 15. & $\begin{array}{l}\text { Households having } \\
\text { access to improved } \\
\text { water sources }\end{array}$ & 74 percent in 2011 & 93 percent in 2011 & Census 2011 \\
\hline 16. & $\begin{array}{l}\text { Households having } \\
\text { access to adequate } \\
\text { sanitation facilities }\end{array}$ & 47 percent in 2011 & 23 percent in 2011 & Census 2011 \\
\hline 17. & $\begin{array}{l}\text { Hand washing with } \\
\text { soap }\end{array}$ & NA & NA & -- \\
\hline
\end{tabular}




\section{References}

Ahmad, J. and M. E. Khan. 2012. "Increasing compliance to complete immunization of children in rural Bihar," in Khan, M. E., F. Donnay, U. K. Tarigopula and K. Aruldas (eds), Shaping Demand and Practices to Improve Family Health Outcomes in Bihar, Final Survey Report. New Delhi: Population Council (forthcoming).

Aruldas, K., M. E. Khan and A. Hazra. 2012a. "Increasing early and exclusive breastfeeding in rural Bihar," in Khan, M. E., F. Donnay, U. K. Tarigopula and K. Aruldas (eds), Shaping Demand and Practices to Improve Family Health Outcomes in Bihar, Final Survey Report. New Delhi: Population Council (forthcoming).

Aruldas, K., M.E. Khan and A. Hazra. 2012b. "Increasing appropriate complementary feeding in rural Bihar" in Khan, M. E., F. Donnay, U. K. Tarigopula and K. Aruldas (eds), Shaping Demand and Practices to Improve Family Health Outcomes in Bihar, Final Survey Report. New Delhi: Population Council (forthcoming).

Bhatnagar, I., M.E. Khan and A. Hazra. 2012. "Increasing postpartum contraception in rural Bihar", in Khan, M. E., F. Donnay, U. K. Tarigopula and K. Aruldas (eds), Shaping Demand and Practices to Improve Family Health Outcomes in Bihar, Final Survey Report. New Delhi: Population Council (forthcoming).

Cairncross, S., C. Hunt, S. Boisson, K. Bostoen, V. Curtis, I. C. Fung and W. P. Schmidt. 2010. "Water, sanitation and hygiene for the prevention of diarrhoea," International Journal of Epidemiology, 39 (Suppl. 1): i193-i205.

Hazra, A. and M. E. Khan. 2012. "Trend and status of the eight target behaviors from the secondary data analysis," in Khan, M. E., F. Donnay, U.K. Tarigopula and D. Ganju (eds), Shaping Demand and Practices to Improve Family Health Outcomes: Designing a Behavior Change Communication Strategy in India, Volume 2: Bihar. New Delhi: SAGE Publications.

Hazra, A., M. E. Khan and D. S. Varma. 2012. "Increasing institutional deliveries and access to emergency obstetric care services in rural Bihar," in Khan, M. E., F. Donnay, U. K. Tarigopula and K. Aruldas (eds), Shaping Demand and Practices to Improve Family Health Outcomes in Bihar, Final Surveyt Report. New Delhi: Population Council.

HUNGaMA. 2011. The HUNGaMA Survey Report 2011. Hyderabad: Nandi Foundations

International Institute for Population Sciences (IIPS) and Macro International. 2007. National Family Health Survey (NFHS-3), 2005-06: India: Volume I. Mumbai: IIPS.

International Institute for Population Sciences (IIPS). 2010. District Level Household and Facility Survey (DLHS-3), 2007-08: India. Mumbai: IIPS.

International Institute for Population Sciences (IIPS). 2010. Concurrent Evaluation National Rural Health Mission (NRHM), 2009. Mumbai IIPS

Lawn, J. E., S. Cousens and J. Zupan. 2005. “4 million neonatal deaths: When? Where? Why?” The Lancet, 365 (9462): 891-900.

Lincetto, O., S. Mothebesoane-Anoh, P. Gomez, S. Munjanja. n.d. Opportunities for Africa's Newborns, Chapter 2, Antenatal Care. www.who.int/pmnch/media/publications/aonsectionIII_2.pdf. (accessed on 14 May 2012). 
Mullany, L. C., J. Katz, Y.M. Li, S.K. Khatry, S.C. LeClerge, G.L. Darmstadt and J.L. Tielsch. 2008. Breast-feeding patterns, time to initiation, and mortality risk among newborns in southern Nepal. Journal of Nutrition, 138, 599-603.

National Research Council and Institute of Medicine (NRCIM). 2005. Growing Up Global: Youth and Marriage: Trends and Challenges.

www.advocatesforyouth.org/storage/advfy/documents/marriage.pdf. (accessed on 14 May 2012).

Sugathan, K. S., V. Mishra, and R. D. Retherford. 2001. "Promoting institutional deliveries in rural India: The role of antenatal-care services." National Family Health Survey Subject Reports, Number 20. Mumbai: IIPS.

SWASTH-WATSAN. 2012. Strengthening Safe Water Provisions in Bihar. http://swasthwatsanbihar.blogspot.in/ (accessed on 12 May 2012)

The Telegraph. 2010. Registration Must for Births. www.telegraphindia.com/1101021/jsp/bihar/story_13082002.jsp. (accessed on 30 April 2012).

Times of India. 2012a. 25\% of Indian Births Not Registered. http://articles.timesofindia.indiatimes.com/2012-03-02/india/31116505_1_registration-indianStates-death. (accessed on 30 April 2012).

United Nations Children's Fund (UNICEF). 2010. Coverage Evaluation Survey 2009: All India Report. New Delhi: UNICEF.

UNICEF. n.d. Water, Environment and Sanitation. www.unicef.org/india/wes.html.

Varma D.S., M.E. Khan and A. Hazra. 2012. "Increasing institutional delivery and access to emergency obstetric care services” in Khan, M.E., G. L. Darmstadt, U.K. Tarigopula and D. Ganju (eds), Shaping Demand and Practices to Improve Family Health Outcomes: Designing a Behavior Change Communication Strategy in India, Volume 1: Uttar Pradesh. New Delhi: SAGE Publications.

Varma D.S. and M.E. Khan. 2012. "Increasing Postnatal Care of Mothers and Newborns Including Cord Care and Thermal Care in Rural Bihar," in Khan, M. E., F. Donnay, U. K. Tarigopula and K. Aruldas (eds). Shaping Demand and Practices to Improve Family Health Outcomes in Bihar, Final Survey Report. New Delhi: Population Council (forthcoming).

World Health Organization (WHO). 2012. Health Through Safe Drinking Water and Basic Sanitation. www.who.int/water_sanitation_health/mdg1/en/index.html. (accessed on 12 May 2012) 


\section{CHAPTER 3}

\section{REACH OF MEDIA IN RURAL BIHAR AND FUNCTIONING OF THE STATE MASS MEDIA UNIT}

\section{Introduction}

The State Health Society, Bihar (SHSB) was established to guide its functionaries towards receiving, managing, and accounting for funds from the Ministry of Health and Family Welfare, Government of India (SHS 2008). The society also aims to strengthen the technical and management capacity of the Directorate of Medical and Health Services, Patna as well as the district Societies by various means including recruitment of individual or institutional experts from the open market and mobilizing financial and non-financial resources for complementing and/or supplementing NRHM activities in the state.

\section{Objectives}

To assess the current status and capacity of the health sector to take a lead role in developing and implementing a BCC strategy, Population Council's research team met from December 2011 to April 2012 and had extensive yet informal discussions with several officials at the state, district and block levels on the functioning of the state Mass Media Unit and the mechanism they use to disseminate information and help adopt healthy practices. Their views were sought on how it could be improved to bring about synergy and alignment in provision of informals through different modes of communication including IPC. In addition to the Executive Director (ED) of the State Health Society, Bihar (SHSB) and the State Program Officer (SPO, FP), 15 health officials at the district level and 12 at the block PHC level from three selected districts were also interviewed. The districts were suggested by the SPO (FP) to represent different regions of Bihar. The officials met are listed in Appendix A of this report.

\section{Key findings}

\section{Health system: Structure and gaps in terms of coverage of all segment of population}

The overall picture of program management functioning in the State is given in Figure 3.1 and detailed structure of the SHSB at the State, district and block level is given in Figure 3.2 at the end of this Chapter. The State PIP (2011-12) mentioned that with growing opportunities in Bihar soon it may become a challenge to retain the existing trained human resource. In the past two years, 12 districts had new District Program Managers (DPM), 18 had new District Accounts Managers (DAM) and three districts saw new District Monitoring and Evaluation Officers (D M\&E). At present, four of the 38 districts are without a DPM, three districts are without a DAM and two districts do not have an M\&E Officer (SHSB 2011). Many of the district and block level community mobilizers who were appointed recently, joined but left, soon after filling these vacant posts again requires a long administrative procedure. 
Figure 3.1: Structure of program management functioning in the State of Bihar

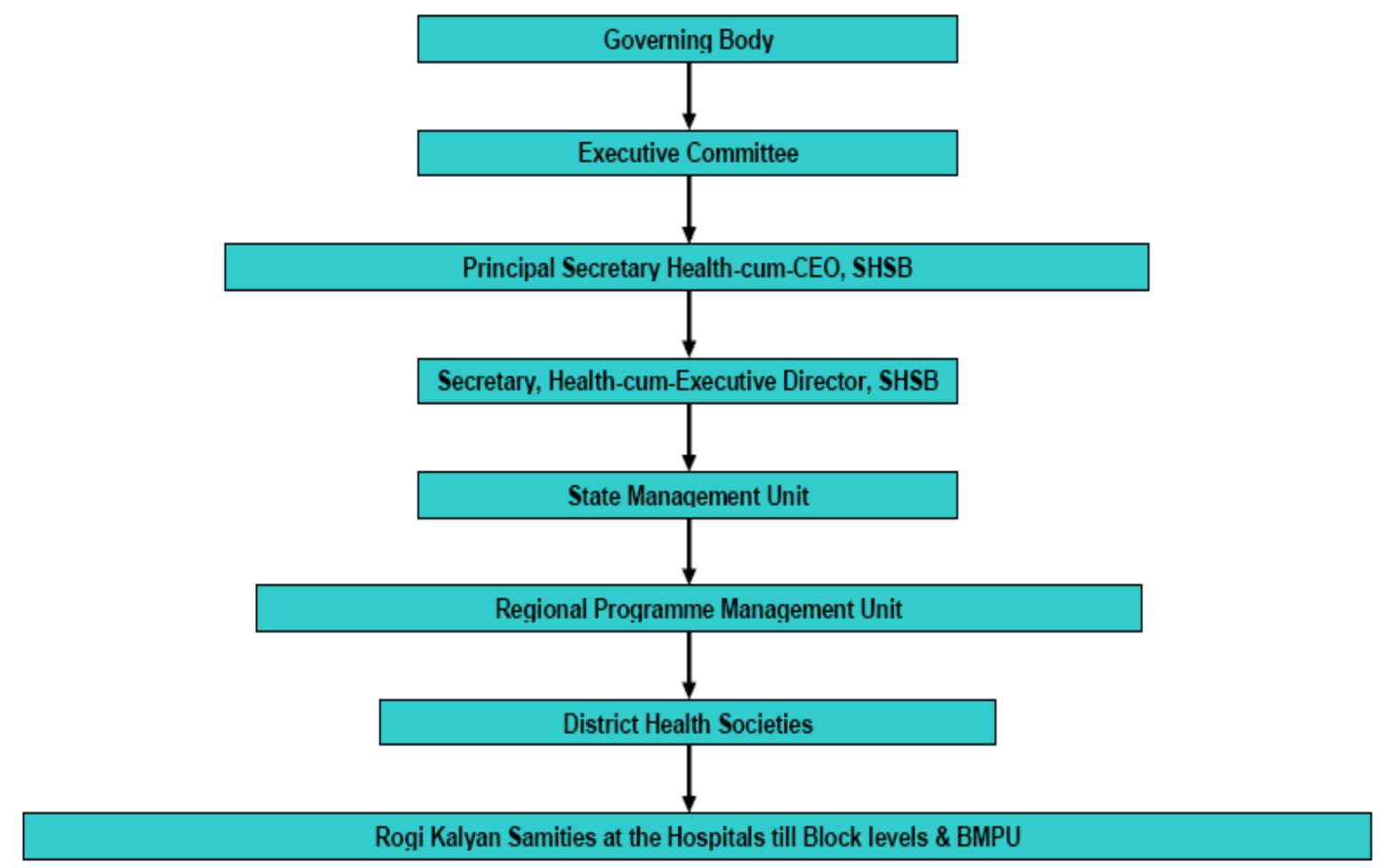

Source: PIP (2011-12)

As per the PIP 2011-12, the existing Health System of Bihar under NRHM consists of its contractual staff of 1,319 Staff Nurse, 7,258 regular ANMs, 78,943 ASHAs and nearly 1,616 contractual doctors reaching out to the people living in more than 45,000 revenue villages (SHSB 2011). However, the reality is people who are poor, non-literate, belong to Scheduled Castes (SC)/Scheduled Tribes (ST), minorities and living in distant hamlets are still not reached by an ASHA or ANM. A recent study shows that 50 percent of minorities and 40 percent of SC/ST women during their last pregnancy were not contacted by the ASHA of their area (Hazra et al. 2012). According to an official conversation, about 25 percent of the ASHAs are almost defunct as they have not motivated a single case for institutional delivery or sterilization. An important step recently taken by SHSB to remedy this situation was the establishment of an ASHA Resource Center, an autonomous body for training and streamlining functioning of ASHAs in the state.

\section{Status of various media and BCC effort}

In planning any communication strategy and selecting the most effective media combination, it is important to understand the reach of different types of media, media exposure pattern of different target groups, and the challenges in reaching target audience belonging to the most disadvantaged groups. The following paragraphs provide a brief overview of various media reach. Diverse sources of datasets and studies have been used for the analysis. These include data from National Family Health Survey-3 (NFHS-3) conducted during 2005-06, Indian Readership Survey Round 2 (MRUC 2010), and primary survey data of Population Council conducted in 2011.

The analysis shows, in rural Bihar, reach of mass media is quite limited, particularly among non-literate and poor women, who constitute the majority of target audience. According to NFHS-3 data, 65 percent women were not exposed to any mass media: newspaper, radio, or television (TV). A recent large-scale survey covering nine districts of rural Bihar and its different regions provides a corresponding figure 
as high as 85 percent (Khan et al. 2012a). Further analysis of NFHS data on exposure by types of mass media shows that in 12 years, exposure to newspapers remained stationary, exposure to TV increased by five percentage points, and exposure to radio increased by 15 percent. Overall, exposure to any mass media has increased very slowly, and there is no reason to believe that it will change significantly over the next five years (Bhatnagar et al. 2012).

The analysis of NFHS-3 data indicates that as many as 53 percent of men and women in Bihar had not heard or seen a single family planning message on the radio, TV, newspapers or magazines or wall paintings and hoardings in the month preceding the interview. Further, just 19 percent of women had contact with an ANM, lady health visitor, Anganwadi worker (AWW), or a community health worker in the three months preceding the interview. Furthermore, not all of these women were satisfied with the information provided if any such contact had occurred. Reach of mass media is significantly less among the poor and marginalized segment of population. Population Council's study further indicated that a woman's socio-economic characteristics, especially caste, standard of living index (SLI) and education have a significant bearing on her exposure to mass media at the individual and family level (Bhatnagar et al. 2012). Further analysis of IRS Round 2 data (MRUC 2010) reconfirms most of the above observations and indicates that reach of mass media is higher among men than women. Analysis of IRS 2010 data shows that almost 60 percent of women aged 15 to 34 have no access to any mass media and access of TV and radio is only in the range of 20 to 25 percent (MRUC 2010). Therefore, health information given through mass media may reach to the urban audience, but it would not reach to majority of the rural audiences, particularly to women. It is a question for further research whether these messages seen by husbands, belonging to relatively higher economic strata, would be shared among their wives.

\section{IEC material at public health facilities}

In a recent study in Bihar (Khan et al. 2012a) information was collected from 90 public health facilities on the availability of educational materials or leaflets for distribution to clients and counseling tools for healthcare providers. Two-thirds of the PHCs surveyed did not have any Information, Education and Communication (IEC) materials either for clients or for providers. Wall paintings at the PHC informing about JSY, tuberculosis (TB), family size and posters about polio day were observed. However, in none of the PHCs surveyed, information/chart on services available at the facility was displayed. The most neglected themes, on which no IEC materials, not even wall paintings were observed included newborn care, skin-to-skin care, delivery preparedness, danger signs during pregnancy and nutrition, postpartum contraception and specific family planning methods like male sterilization or condom. An analysis of a similar nature in Uttar Pradesh showed almost the same pattern.

\section{Interpersonal communication}

The study shows, in rural Bihar, only 57 percent of women delivering a baby within three years preceding the survey had met an ASHA and discussed health-related issues. Further, very few topics were covered by the ASHA during these discussions. The most frequent discussion points were Janani Evam Bal Suraksha Yojana (JBSY), institutional delivery, and child immunization. Other issues like personal hygiene, FP, and nutrition were covered by less than 15 percent of ASHAs (Bhatnagar et al. 2012). Generally, most ASHAs advised women to take a TT injection and call her (ASHA) when labor starts, so the ASHA could take the woman to a PHC. ASHAs seldom gave advice on topics such as ANC, delivery preparedness, danger signs during pregnancy, and importance of postpartum check-ups. This is well reflected in this quote from an informal conversation in the study:

"The ASHA only came to register my pregnancy and told me to go for institutional delivery... she did not tell me how many antenatal check-ups are to be done." (Woman, SC, illiterate) 
"I was not advised to have an antenatal check-up; the ASHA told me only to go for TT vaccination."

(Woman, OBC, educated up to Class 9)

This shows, while ASHAs are able to reach more clients than mass media channels, the content of counseling is poor and needs to be improved. The frequency of contact with ASHA during pregnancy or after delivery was very low if women were living in a remote hamlet of the village, belonged to a small and less developed village and or belonged to SC or Other Backward Class (OBC) community. The Population Council's study also provides some insight of why the ASHA does not visit to all houses. Some of the typical quotes were:
"The ASHA of our village did not help me during my pregnancy or give any advice. She does not visit all the houses and only makes home visits to upper caste households. She never came to my house. I never went to meet her." (Woman, OBC, illiterate)
"The ASHA does not come to this hamlet to check on pregnant women. Even for pulse polio her husband comes. We don't go and talk to the ASHA because she does not come to meet us or talk." (Woman, SC, illiterate, residing in a moderately developed village)
"I only visit to those families who listen to me and will deliver at health facility. Talking to other women who are mainly poor, SC/ST or minority is a waste of time". (ASHA, higher caste)

\section{Training of ASHAs and competency in carrying out BCC}

Several studies show that ASHAs in Bihar have received very limited training, and almost 80 percent have received 10 or less days of training (Bajpai and Dholakia 2011, Ahmad et al. 2012, NHSRC 2011).

As part of the NRHM's overall mandate, and to ensure that training, monitoring and supervisory functions related to ASHAs and other community processes are effectively coordinated, and to expedite these processes, ASHA Resource Centre (ARC), an autonomous body has been established by SHSBunder the Society Registration Act. At the state level, the ARC operates under strategic direction and leadership of Executive Director, SHSB. The ARC comprises of team of a project manager and deputy project manager and some support staff at State level, District Community Mobilizers at the district level and Block Community Mobilizers at the block level. Further, to support activities of ASHAs, every twenty-first ASHA who is identified as most active and knowledgeable is designated as an ASHA facilitator. Training of ASHAs has been out outsourced to 19 NGOs selected on competitive basis. The master trainers of these 19 NGOs have been trained by Janani. The principle is to give competency based training and hence during training each ASHA has to appear for 3 different examinations. Currently, ASHAs are receiving training in batches. ASHAs are expected to mobilize the community by participating along with ANM in the Village Health Sanitation and Nutrition Committee (VHSNC).

However, in Bihar the standing committee on health and sanitation of Gram Panchayat also acts as a VHSNC, and the ASHA is not necessarily included in the committee. A recent evaluation of NHSRC found that district officials in Bihar had limited understanding of the VHSNC. It was observed that the management of the VHSNC account, which is supposed to be jointly by Mukbiya and ANM, was not effective and in many places available funds were not used (NHSRC 2011). Furthermore, the study by Bajpai and Dholakia (2011) underlined lack of AHSA refresher training, unavailability of communication and counseling aids to make counseling easy to understand for clients, and less or insufficient incentives for all of their activities as barriers in optimizing benefits of JSY and availability of ASHA within community. The Council's study (2011) reveals that only 15 to 20 percent of ASHAs had received any pamphlets, leaflets or flipchart which they could use to explain and illustrate key messages to their clients. 


\section{Reach and use of mobile phones}

The reach of mobile phones in India even in rural areas is increasing steadily. A recent study on use of mobile phone reveals that out of the 10,080 households listed in rural Bihar, 42 percent owned at least one mobile phone. Reach of mobile phones at the individual level, however, is still very low, particularly among women. Furthermore the study showed that only 10 percent of women owned a mobile phone (Khan et al. 2012b). According to the IRS Round 2 data, only about 15 percent of individuals own a mobile phone in Bihar (MRUC 2010).

More than 90 percent of health care providers and health workers in Bihar either own or have access to a mobile phone; apart from making personal calls, they use the phone to contact their clients or contact their supervisors for guidance. In some cases, their supervisors call them regarding official work. These interactions are not planned; however, if planned and monitored properly, such interactions could help in significantly improving health care service delivery (Khan et al. 2012b). The study concluded that presently while reaching to women through mobile phone for providing information is not possible, the potential for using mobile phone in supportive supervision of health care workers, strengthening their skills or providing them mobile phone as counseling aid is high and needs experimentation.

\section{Status of mass media unit and IEC/BCC activities at state, district and block level}

\section{State level}

The ED of SHSB and Secretary, Health feels that "there should be one policy on IEC, which the SHSB does not bave right now." The key concerns of the ED, about the proposed BCC strategy in the State are that it should address the following issues:

- Creating demand for services-people need to ask for services as their right, which requires community mobilization;

- Developing key messages that should be easy and effective to understand and adopt;

- Using multiple modes of communication platforms to maximize the reach of these messages, particularly to the illiterate, poor, mahadalit and minorities who constitute the majority of the hard to reach segment of the population;

- Understanding how effectively modern information technology, such as mobile phones can be used in implementation of the BCC strategy and how to use them in the best possible manner;

- Assessing how to align and synchronize efforts of different development partners so that messages reinforce each other and not confuse the audience.

The discussion with the ED further brought some issues to light. He said,

"Muskan Ek Abhiyan has been successful and we could learn from it. About 160,000 PRI functionaries operate in the State out of which 55 percent are women; how to leverage them for a BCC strategy?"

It was felt that Self Help Groups (SHGs) need to be used to mobilize the community, and ways to improve coordination between ASHAs, AWWs, and ANMs should be outlined. Postpartum contraception is critical to reduce fertility and ensure healthy mother and baby. It is important to target the parents of adolescents and youths who get their children married at an early age and develop, test and adopt innovative strategies to encourage spousal communication among young couples living in rural as well as urban areas. The problem of human resources in the health sector is grueling. Table 3.1 clearly shows the shortage of communication related manpower in the state. 
Table 3.1: Health infrastructure and health personnel, Bihar

\begin{tabular}{lcc}
\hline \multicolumn{1}{c}{ Particulars } & Sanctioned & In Position \\
\hline Medical Colleges & NA & $*$ \\
District Hospital & 37 & 97.3 \\
Sub-divisional Hospital & 53 & 75.5 \\
Community Health centre & $\mathrm{NA}$ & $* *$ \\
APHC & 1,544 & 86.1 \\
HSC & 16,623 & 58.3 \\
ASHA & 87,135 & 94.7 \\
Health Educator\# & 539 & 56.2 \\
District Community Mobilizer (DCM) & 38 & 71.1 \\
Block Community Mobilizer (BCM) & 546 & 72.0 \\
\hline
\end{tabular}

Source: NRHM PIP, Bihar, 2011-12

Note: * 6 are in position, percentage could not be calculated since sanctioned posts are not available

** 70 are in position, percentage could not be calculated since sanctioned posts are not available

\# Approximate figure from informal source

At the SHSB, the State Program Officer (SPO, IEC) post is vacant. Although, the SPO (FP) is looking after the work of IEC division, he felt that,

"There must be one BCC expert in place to monitor and oversee the IEC/BCC activities at the State level.

Applications were received for a consultant, who will look after the BCC activities. But nothing has happened till date."

Like the ED, the SPO, (FP) who presently coordinates the IEC activities of ASHA also expressed his concern about alignment and synchronized efforts of different development partners. According to him, many development partners are carrying out their BCC activities independently for communicating similar messages but using different words or phrases and concepts which could be confusing to the audience. He strongly felt the need for bringing all these institutions and development partners to one platform to think strategically, collectively and provide messages that reinforce to each other.

"There is a need to have consensus on content, language of messages and development partners should plan in such a way that they reinforce each other's efforts rather than to create confusion among the intended audiences."

In absence of required minimum human resources, SHSB is trying to reach the masses using newspapers, TV and radio. The department is aware that majority of the women in rural Bihar neither read newspapers nor can they be reached by other mass media. Yet one of the senior State officials felt that, "messages are reaching to urban poor living in slums as their access to TV and radio is high." To some extent this is also true for sub-urban areas and larger villages; community leaders and healthcare providers have more exposure to mass media than the less educated and those belonging to distant villages. These community leaders and healthcare providers in turn could help to disseminate messages through diffusion by being the early accepters and adopters of healthy practices. The State Program Officer added,

"We are poor in IPC. Generally community health workers do not have communication skills. Right now we are doing a project on IPC with DFID in two districts in Bihar (Jamui and Banka) to assess the needs of communication skills of CHWs."

\section{District level}

Each district of Bihar is supposed to have a functional Mass Media Unit. In order to understand the status of District Mass Media units and type of IEC/BCC activities that are being carried out, the Population Council team visited three districts-Muzaffarpur, Gopalganj and Bhagalpur. At the district level, we met 15 people including Civil Surgeons (CS), Assistant Chief Medical Officers (ACMO), District Program Managers (DPM) and District Community Mobilizers (DCM) and discussed current BCC 
activities and their role in perusing these activities. Our observation and discussion with the district health functionaries revealed that a mass media unit was not functional in any of the districts. There is no Mass Media Officer to help guide in planning and implementing BCC programs and manage distribution of IEC material. BCC activities are almost non-existent. The key reason is lack of trained human resources to carry out these activities. All important positions of the District Mass Media Unit are vacant (Table 3.2).

Table 3.2: Current status of availability of human resources in the mass media units in the 3 districts of Bihar

\begin{tabular}{lccc}
\hline Position & Muzaffarpur & Gopalganj & Bhagalpur \\
\hline Mass Media Officer & Vacant & Vacant & Vacant \\
Deputy Mass Media Officer (male) & Vacant & Vacant & Vacant \\
Deputy Mass Media Officer (female) & Vacant & Vacant & Vacant \\
Clerk & In position & In position & In position \\
Operator (Chal Chitra Chalak) & Vacant & Vacant & In position \\
Artist/Painter & Vacant & Vacant & In position \\
Peon & In position & In position & In position \\
Helper (Khalasi) & In position & Vacant & In position \\
\hline
\end{tabular}

Source: Findings from interviews with district officials, 2012

The clerk or peon generally collect IEC materials which come from State Health Society or other departments like UNICEF and distribution is done as per the plan provided by the respective departments or as instructed by in-charge of Mass Media Unit. The problem of lack of trained human resources for carrying out BCC activities was mentioned in all the three districts which were covered under the study. As said by a senior district level official,

"The status of human resource (manpower) is sent along with the monthly report to the State Office every month; but no action has been taken so far. Once I also discussed with State Minister of Health about filling these vacant positions. Still nothing has been done. What can we do?"

An ACMO, who is in-charge of the mass media unit, said,

"No educational campaign has been organized during the last 6 months. Only regular activities like polio programs and bi annual catch-up round of Vitamin 'A' was organized in February, 2012. Posters and banners, which come from the State office we just sent them to PHCs. Hum postman ka kaam karte hai, poster aaya or bum usko PHC mein direct kar dete hain (we work. like postmen; responsible for distribution of banners and posters to PHCs)."

In each district, the ARC is supposed to have a team of one District Community Mobilizer (DCM) and one District Data Assistant (DDA), with the DCM closely coordinating with the District Program Management Unit (DPMU) in the District Health Society (DHS) and reporting to the State Program Manager, ARC, through the DPMU. Out of the 38 sanctioned DCM posts in Bihar, 27 are in position.

Discussion with DCMs revealed, in general, they are aware of their role and responsibilities, try to be useful at district level work, and organize BCM training. However, they also revealed that they are not effective in monitoring and ensuring BCMs execute their work effectively. We were informed that, generally, BCMs do not visit the field to help guide ASHAs or attend ASHA meetings organized by ASHA facilitators. In places where DCM posts are vacant, they look after the work of the DCM, but they lack interest in doing this extra work. This lack of interest is well expressed in the Statement of one of a DDAs interview,

"I do not know what the exact roles of DCMs are and I do not want to know also. I just forward instructions that I receive from State office to the BCMs." 


\section{Block level}

The research team visited six block PHCs, two in each of the three districts, and met block level functionaries to explore status of IEC/BCC activities in their work area. The situation is the same: Hardly any BCC activities are carried out. The post of Block Extension Educator (BEE), who earlier was responsible for BCC work, has been vacant for eight to 10 years, although it is still a sanctioned position.

The other important position at the block level is the Block Community Mobilizer (BCMs) who is supposed to coordinate and guide ASHAs in their work, build their skills to mobilize community for adopting healthy practices and monitor their functioning. Presently, however out of the 534 blocks, only in 393 PHCs BCMs are in position. For instance, in Bhagalpur district it was found that out of 16 BCMs hired eight to 10 months ago, nine had resigned after joining, mainly because of place of posting, as Bhagalpur district was far from their home districts. Places where BCM posts are vacant, BHMs are expected to manage some of the key activities of BCM. However, discussions with MOICs and some of the BHMs revealed that, they neither monitor/supervise ASHA's work nor send reports timely to DCM. The MOICs feel that BHMs are overburdened and cannot do extra work of BCM.

"Block Community Mobilizer had joined last year, but he left after some time have several times I requested for filling this post again but I have not get any direction from the district or State. This is a major drawback of monitoring ASHA's activities. BHM Cannot manage all work" (MOIC, of one of the study blocks)

During the meeting with $\mathrm{BCMs}$, when the question was asked on why they do not visit their field area to help facilitate ASHA's work or meetings organized by ASHA facilitators ${ }^{4}$, one of the BCMs commented,

"We do not get any allowances for field visits or to attend ASHA facilitator meetings. Why should I spend money from my own pocket?"

Investigating their ASHA supervision and, if they do not visit the field, why they do not use their mobile phone for this purpose, revealed that, as BCMs are not remunerated for recharging their mobile phones, they do not want to use them for official work. Visits to other blocks, however, reveal no fixed pattern. For example, at one block PHC in Bhagalpur district the BCM receive Rs. 300/ per month for recharging his mobile phone from the Rogi Kalyan Samiti (RKS) seeds money without any appreciable difference in his performance. Discussion with BCMs also revealed that they did not have required skills to provide supportive supervision or knew the types of questions that they could ask to assess ASHAs performance or skills to guide ASHAs on how to do community mobilization. These findings point to the need of providing some standard check list which could help BCM carrying out their activities effectively.

At each Additional Primary Health Centre (APHC), there is supposed to be a Health Educator (HE) responsible for BCC activities. In the whole state, however, only about 43 percent of APHCs have an HE. At some APHCs, although HEs were in position, in reality either they worked from the block PHC or from the district hospital; their salaries were, however, drawn from the APHC account. When we asked why HEs are not working from their assigned APHC, the MOIC simply replied,

"At least we are using him for some useful work at the Block PHC (not necessarily related with BCC). If he remains posted at APHC, be will not do any work."

Interviews with HEs revealed they are involved in the regular activities like Routine Immunization (RI), polio rounds, measles program, and sometimes Chetna Yatra and Vitamin 'A' Catch-up. However, their presence or absence as far as BCC is concerned is inconsequential. A HE from a study block said,

"I stay in the premises of the APHC but when MOIC of the PHC assigns some work, I do that, otherwise no specific work per se."

${ }^{4}$ There is an ASHA facilitator for every 20 ASHAs to help build and develop the necessary skill required for an ASHA in a sustainable way (SHSB 2011-12). 
The MOICs informed that they have never been asked on the number of posters, leaflets, banners and wall charts required to do any educational campaign. During a campaign or special days the State sends BCC/IEC material to districts and district officials in turn dispatch these materials to the Block PHCs who arrange to paste them at different places in the work area by either a temporary hired person or the ASHA or ANM. Generally, these materials come just a few days before a particular event like Polio day or TB programs, and giving the PHC staff to paste all of them within one or two days. It is then left to the temporary hired person or ASHA/ANM. No planning is done to place the poster at a strategic location. MOIC of one of the PHC block of one of the district visited said,

'We don't know how much IEC material should come...there is no planning process... if the program is on the eighteenth, we get the posters on sixteenth or the seventeenth, so you can imagine how much publicity could be done. If planning is done properly, our requirement is assessed and then we can identify the key places to paste the poster, the campaign will be much more successful."

\section{Village Health Sanitation and Nutrition Day}

Village Health Sanitation and Nutrition Day (VHSND) is an important forum at the community level for awareness generation, health and sanitation education and counseling on $\mathrm{MCH}$ and $\mathrm{RH}$ and bringing a convergence of efforts by SHSB, PHED, ICDS, and Panchayat. It is generally organized on Friday at the AWC and Wednesday at Health Sub Centre in which maternal and child health $(\mathrm{MCH})$ and family health related services are offered.

During this day, beside $\mathrm{MCH}$ and immunization services thematic and focused counseling is offered to pregnant women, lactating women, adolescent girls, young couples and the community by the ANM, ASHA, AWW and PHED staff on the following topics, (Box 3.1).

SHSB has a budget of Rs. 224,100,000 (\$4.5 million) for VHSND, Rs 99.6 million for logistics (Rs 100/ VHSND), Rs 996 million for community moblization and IEC/BCC work one day before VHSND (Rs 100/VHSND), and Rs. 24.9 million for VHSD monitoring. Field observations revealed that VHSNDs are organized irregularly and are not attended by staff of other stakeholders like PHED and PRD.

Box 3.1: Key audience and themes for focused counseling during VHSND

\begin{tabular}{|c|c|}
\hline Audience & Key themes for focused counseling \\
\hline Pregnant women & $\begin{array}{ll}\text { - } & \text { Importance of ANC, TT, IFA/prevention of anemia } \\
\text { - } & \text { Importance of nutrition, rest, danger signs during pregnancy } \\
\text { - } & \text { Need for identifying facility and arranging transport for institutional delivery } \\
\text { - Importance of birth spacing of at least } 2 \text { years and breastfeeding }\end{array}$ \\
\hline Lactating women & $\begin{array}{l}\text { - } \text { Cleanliness after delivery } \\
\text { - Importance of breastfeeding, nutritious food and initiation of } \\
\text { complementary food after } 6 \text { months } \\
\text { - } \text { Newborn care and immunization } \\
\text { - Importance of ORS for prevention of diarrhea } \\
\text { Importance of not delaying rushing to health provider of newborn has illness } \\
\text { such as acute respiratory infection (ARI) }\end{array}$ \\
\hline Adolescent girls & $\begin{array}{ll}\text { - } & \text { Importance of menstrual hygiene, anemia and IFA and nutrition } \\
\text { - } & \text { Right age for marriage } \\
\text { - } & \text { Information on STIs, RTIs and HIV/AIDS } \\
\text { - } & \text { Information on PC/PNDT Act/hygiene } \\
\end{array}$ \\
\hline Couples & $\begin{array}{ll}\text { - } & \text { Registration of newly married couples } \\
\text { - } & \text { Importance of safe sex and information on family planning methods } \\
\text { - } & \text { Importance of birth spacing } \\
\text { - } & \text { Child health }\end{array}$ \\
\hline
\end{tabular}

Source: Policy document, 15 March 2011, Ministry of Health and Family Welfare and Ministry of Social Welfare, Patna 


\section{Budget for IEC/BCC}

In the last PIP budget (2011-12), about Rs. 110 million ( $\$ 2.2$ million) was allocated for communication activities. It was mostly spent on printing modules and books for training, printing advertisements in newspapers, TV and radio spots, printing pamphlets and posters. Some funds were also spent on Sonpur Mela and Swasthya Chetna Yatra of the Chief Minister. In the current PIP (2012-13), Rs.165 million (\$3.3 million) has been allocated for IEC/BCC activities (SHSB 2012-13).

The budget heads on BCC/IEC activities as mentioned in the State PIP (2011-12) include:

- Press/Media and newspaper ads on various health related days, information, recruitment notice and tender notice advertisement;

- Hoardings, Wall Painting, Bill boards, Cinema slides, Local Cable and others;

- Wall writing, Miking and others;

- Workshop, Fair (Mela) Stall organization, Tableau exhibit and other media;

- Health Camps and other health related activities;

- Posters, Flex banners, Pannels, Banners, Strikers, Leaflets, Brochures, Badhai Cards, Booklet, IPC flip card, Letter with message, $T$ shirts, Desk Calendar, Pocket calendar, wall calendar, health calendar, dairy, quarterly magazines and others;

- Banner, Letter with message, Rally Flag, T shirts, Flex banner and others.

The observation and findings from districts clearly show there is no post or person responsible for IEC/ BCC at DPMU. DHS does not conduct any educational campaign except for swasthya mela. The state neither asks nor do the districts report on any IEC/BCC activities at district or block levels. There is no separate activity specific budget allocation. The district budget is provided based on the area or need for specific activity. DHS is instructed by the state office to use the budget for IEC/BCC, for activities such as Chetna Yatra. During our visit to Bhagalpur, we were informed about a two-day Mahakumbh Mela, which was organized last year at the cost of Rs. 2.8 million. Out of this Rs 0.9 million was spent on making advertisements in newspapers, banners and posters, and remaining 1.9 million were used for giving fees to specialists, making their arrangements, meeting their transportation and vehicle costs, among others.

\section{Conclusion}

Available data about the health system, discussions with diverse informants at different levels, and our field level observations indicate that until SHSB revamps its media unit at all levels, for the present, SHSB alone is not in a position to reach all of its target audiences or implement an integrated comprehensive communication strategy. This is particularly true for families who belong to scheduled castes, minorities and families below the poverty line, living in small and remote villages, or in distant hamlets. The BCC activity is mostly dependent on mass media and a major portion of the budget goes into giving advertisements in newspapers and radio or TV spots. Given the fact that reach of mass media is very poor in rural areas and worse for women, the impact a newspaper advertisement or messages from radio/TV would having is questionable.

Effective implementation of IPC, which needs to be the leading strategy (and mass media to support and reinforce the messages) faces several hurdles. Community-based health workers (ASHAs) are not covering all houses due to caste, class differences, and other social barriers. Most ASHAs lack communication skills and do not have user-friendly counseling aids they can use when meeting women 
and families. Recent initiatives by BBC World Service Trust to use mobile phones preloaded with information appears to be an innovative approach for developing and strengthening both counseling skills of ASHAs and providing them with counseling tools. However, the social distance and ASHA reservation to serve the most disadvantaged groups seems to continue. To reach all intended audiences and create demand for services, other change agents and social platforms provided by other departments need to be explore and utilized.

While adding a Mass Media Unit with a minimum number of trained human resources at the state level, and activating the Media Unit at district level, are essential steps, the health system also needs to address barriers to strengthening existing BCC activities, with better supportive supervision of community mobilizers, monitoring their performance using measureable indicators, providing checklists to all $\mathrm{BCMs}$ to help their monitoring work, and providing minimum travel and mobile phone recharging costs. These aspects are discussed, along with alternative forums that can be used to complement SHSB's efforts in implementating a BCC strategy. 
Figure 3.2: Structure of State Health Society, Bihar
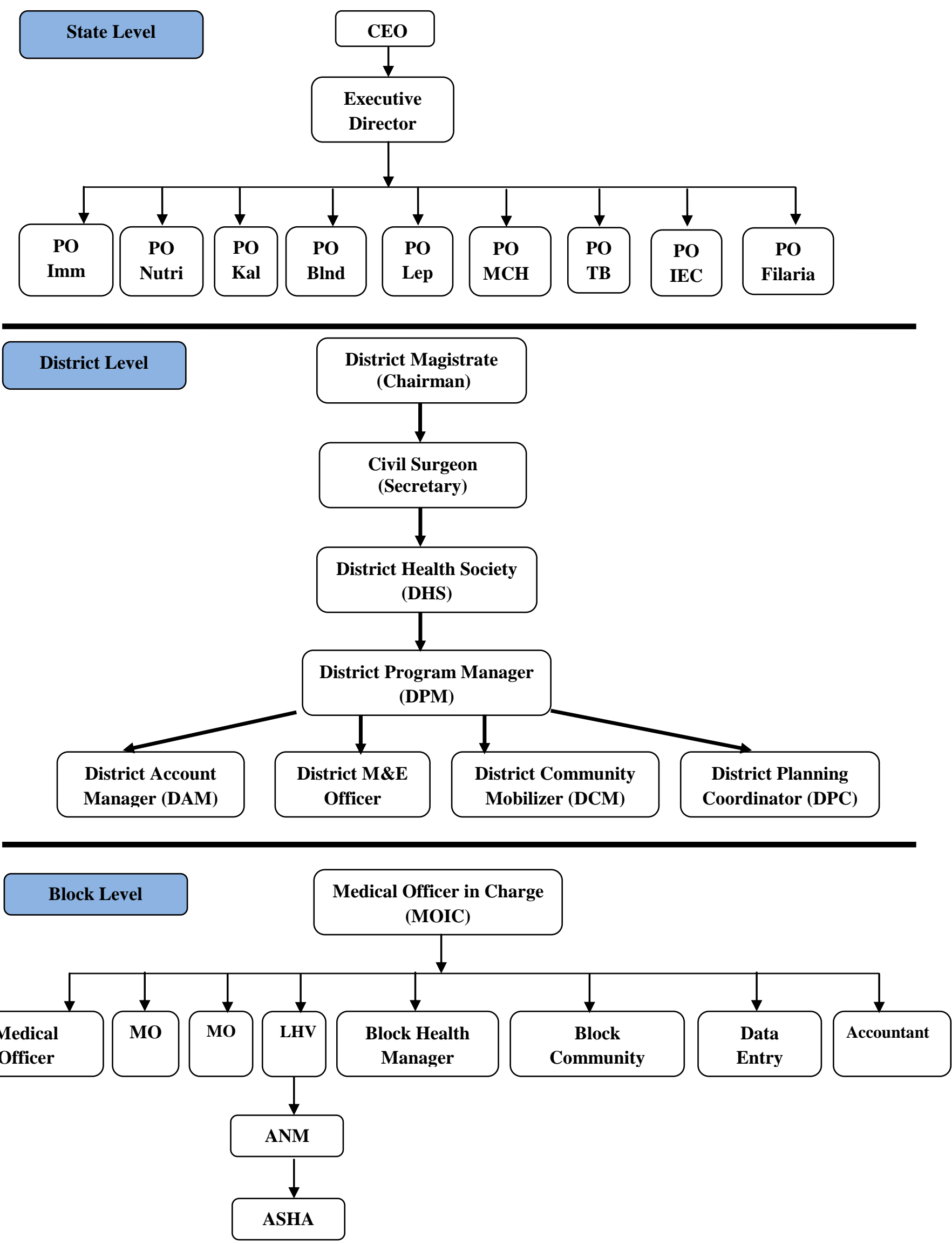


\section{References}

Ahmad, J., I. Bhatnagar and M.E. Khan. 2012. Increasing Access to Family Planning and Reproductive Health Services Through Community Health Workers: A Case Study of a Dual Cadre Model in India. Washington, DC: Population Council.

Bajpai, N. and R. H. Dholakia. 2011. "Improving the performance of accredited social health activists in India," Working Paper No. 1, Working Papers Series. Columbia Global Centers, South Asia, Columbia University.

Bhatnagar, I., M. E. Khan and A. Hazra. 2012. "Reaching audiences in rural Bihar: A situation analysis of alternative modes of communication and challenges," in Khan M. E., F. Donnay, U. K.

Tarigopula and D. Ganju (eds), Shaping Demand and Practices to Improve Family Health Outcomes: Designing a Behavior Change Communication Strategy in India, Volume 2: Bihar. New Delhi: SAGE Publications.

Hazra, A., M. E. Khan and D. S. Varma. 2012. "Increasing institutional deliveries and access to emergency obstetric care services in rural Bihar," in Khan M. E., F. Donnay, U. K. Tarigopula and K. Aruldas (eds), Shaping Demand and Practices to Improve Family Health Outcomes in Bihar, Final Survey Report. New Delhi: Population Council (forthcoming).

International Institute for Population Sciences and Macro International. 2007. National Family Health Survey (NFHS-3) 2005-2006, Fact Sheet, Uttar Pradesh. Mumbai: IIPS.

Khan, M. E., F. Donnay, U. K. Tarigopula and K. Aruldas (eds). 2012a. Shaping Demand and Practices to Improve Family Health Outcomes in Bihar, Final Survey Report. New Delhi: Population Council (forthcoming).

Khan, M. E., A. Hazra and J. Ahmad. 2012b. "Reach and use pattern of mobile phones in rural Bihar: Current scenario and future prospects," in Khan M. E., F. Donnay, U. K. Tarigopula and D. Ganju (eds), Shaping Demand and Practices to Improve Family Health Outcomes: Designing a Behavior Change Communication Strategy in India, Volume 2: Bihar. New Delhi: SAGE Publications.

Media Research Users Council (MRUC). 2010. Indian Readership Survey (IRS), 2010 Round 2. New Delhi: MRUC.

National Health Systems Resource Centre (NHSRC). 2011. ASHAs: Which Way Forward Evaluation of ASHAs Programme. New Delhi: NHSRC.

State Health Society Bihar (SHSB). 2011. Project Implementation Plan 2011-12. http://statehealthsocietybihar.org/pip2011-12/statepip-2011-12/BHR\%20SPIP\%201112\%20_Final-April\%202011_12.pdf. (accessed on 12 June 2012).

State Health Society Bihar (SHSB). 2012. Project Implementation Plan 2012-13. http://statehealthsocietybihar.org/pip2012-13/statepip-2012-13/Final_BHR_SPIP_2012-13.pdf. (accessed on 23 June 2012). 


\section{CHAPTER 4}

\section{MAPPING DEVELOPMENT PARTNERS' ACTIVITIES IN BCC}

\section{Background}

In the last few years, various UN agencies, international NGOs, and DPs have been working extensively in Bihar. One of the key reasons for increasing focus on Bihar has been the supportive political and administrative environment by the government (Aruldas and Goel 2012). Currently, every district has the presence of an international donor agency such as the Department for International Development (DfID), European Commission, The Bill and Melinda Gates Foundation (BMGF), United Nations Population Fund (UNFPA), United Nations Children's Fund (UNICEF), and Norway India Partnership Initiative (NIPI). Many of these development partners are using various traditional (mass media and mid-media) and innovative (mobile phones, community driven approaches) communication platforms to reach to their specific audiences. The present chapter discusses the roles and activities of selected development partners in Bihar as part of exploring possible partners who could complement the efforts of SHSB for implementing the BCC strategy.

\section{Objectives}

For this study, the study team did a mapping exercise to identify key development partners and international NGOs working on health in Bihar and using behavior change communication to achieve their projects objectives. The specific issues that were address during this mapping exercise included:

- Key themes and coverage of health related activities by these partners;

- Communication activities that partners are using to promote healthy behavior and to document any innovative communication approach or technology used by them;

- Assessment of strengths of these partners and their potential for partnering in implementation of planned BCC strategy by SHSB.

\section{Methodology}

For the present study, we purposely identified 10 development partners and international agencies which have an interest and were carrying out communication activities to promote healthy behavior including contraceptive use. In-depth interviews were conducted with 12 chiefs of party or senior program managers of these organizations/State representatives or communication specialists (Appendix B). Selection of the informant was done purposely by judging who would know best about the organization's activities in the health and communication sectors in Bihar.

A short interview guideline was developed and used for carrying out the in depth interviews. The interview guideline captured information on the key focus areas, coverage, current BCC activities, mechanism of implementing and monitoring the BCC activities, communication platforms being used, specific communication related budget and experiences and challenges. 
Each interview was conducted by two professionals from the Population Council, one of whom is a senior professional with more than 30 years of experience working in the health sector. All interviews were recorded, transcribed the same day and main points were noted during the interview as well. This chapter is based on an analysis of these interviews.

\section{Key findings}

Table 4.1 provides an overview of the 10 agencies covered in this study. Following the table observations are given from the discussion on the BCC activities carried out by the development partners.

Table 4.1: Development partners working in Bihar, by themes addressed, coverage and BCC activity

\begin{tabular}{|c|c|c|c|}
\hline Organization & Key themes addressed & Coverage & BCC activity \\
\hline \multirow[t]{10}{*}{ UNICEF } & $\begin{array}{l}\text { Adolescent and maternal } \\
\text { health }\end{array}$ & Vaishali district & \multirow{10}{*}{$\begin{array}{l}\text { Trained SHG members on health } \\
\text { and social issues. } \\
\text { Developed IPC skills of CHWs } \\
\text { Works with NGOs to carry out } \\
\text { mid media activities such as } \\
\text { nukkad nataks, iodine raths and } \\
\text { so on }\end{array}$} \\
\hline & $\begin{array}{l}\text { Newborn and childhood } \\
\text { illness }\end{array}$ & Vaishali district & \\
\hline & Breastfeeding & All districts & \\
\hline & Nutrition (Dular program) & $\begin{array}{l}\text { Piloted in Vaishali, } \\
\text { Nalanda, Gaya and } \\
\text { Muzaffarpur districts; } \\
\text { now scaled up to all } \\
\text { districts by GoB }\end{array}$ & \\
\hline & $\begin{array}{l}\text { Nutrition (Nutrition } \\
\text { Rehabilitation Centers) }\end{array}$ & $\begin{array}{l}\text { Muzaffarpur and East } \\
\text { Champaran districts }\end{array}$ & \\
\hline & Routine immunization & All districts & \\
\hline & Diarrhea management & Vaishali district & \\
\hline & Sanitation campaign & All districts & \\
\hline & Education & All districts & \\
\hline & $\begin{array}{l}\text { Micronutrients: lodine } \\
\text { Deficiency Disorder Program } \\
\text { (IDD) }\end{array}$ & All districts & \\
\hline \multirow[t]{5}{*}{ UNFPA } & $\begin{array}{l}\text { Family planning including } \\
\text { postpartum contraception }\end{array}$ & All districts & \multirow{5}{*}{$\begin{array}{l}\text { Printed reports with } \\
\text { communication budget } \\
\text { Partnered with Jagran Pehel for } \\
\text { communication campaign to } \\
\text { empower young women in } 6 \\
\text { districts }\end{array}$} \\
\hline & $\begin{array}{l}\text { Technical assistance (TA) to } \\
\text { State Government to draft } \\
\text { State population and } \\
\text { development policy }\end{array}$ & All districts & \\
\hline & $\begin{array}{l}\text { Technical assistance to } \\
\text { strengthen HMIS }\end{array}$ & All districts & \\
\hline & Youth fertility & Gaya district & \\
\hline & TA in preparing PIP & All districts & \\
\hline NIPI & $\begin{array}{l}\text { Mother, newborn and child } \\
\text { care }\end{array}$ & $\begin{array}{l}\text { All districts with } \\
\text { intensive focus in } \\
\text { Nalanda, Jehanabad }\end{array}$ & $\begin{array}{l}\text { Mamtas appointed at district } \\
\text { hospitals and PHCs in all } \\
\text { districts for delivery care and to }\end{array}$ \\
\hline
\end{tabular}




\begin{tabular}{|c|c|c|c|}
\hline & & $\begin{array}{l}\text { and Sheikhpura } \\
\text { districts }\end{array}$ & $\begin{array}{l}\text { counsel on breastfeeding and } \\
\text { immunization }\end{array}$ \\
\hline DFID/B-TAST & $\begin{array}{l}\text { Essential health, nutrition, } \\
\text { water and sanitation services }\end{array}$ & All districts & $\begin{array}{l}\text { Carrying out a scoping study to } \\
\text { understand the IPC skill related } \\
\text { needs of CHWs } \\
\text { Carrying out Gram Varta } \\
\text { program for promoting dialogue } \\
\text { in community on health, } \\
\text { sanitation and gender through } \\
\text { SHGs } \\
\text { Strengthening capacity of State } \\
\text { and district monitoring cells of } \\
\text { ICDS } \\
\text { Plans to have at least one } \\
\text { community radio in each district }\end{array}$ \\
\hline \multirow[t]{3}{*}{ CARE } & $\begin{array}{l}\text { System strengthening of } \\
\mathrm{MCH} \text { services, family } \\
\text { planning services and } \\
\text { nutrition }\end{array}$ & $\begin{array}{l}8 \text { districts: Purba } \\
\text { Champaran, Saharsa, } \\
\text { Gopalganj, Samistipur, } \\
\text { Begusarai, Khagaria, } \\
\text { Patna, Paschim } \\
\text { Champaran }\end{array}$ & \multirow{3}{*}{$\begin{array}{l}\text { Facilitating training of CHWs in } \\
\text { communication skills and } \\
\text { providing job aids in partnership } \\
\text { with communication specialists } \\
\text { Community mobilization } \\
\text { activities for promoting family } \\
\text { health behaviors }\end{array}$} \\
\hline & Education & All districts & \\
\hline & $\begin{array}{l}\text { Essential health, nutrition, } \\
\text { water and sanitation services } \\
\text { as lead member of B-TAST }\end{array}$ & All districts & \\
\hline \multirow[t]{2}{*}{$\begin{array}{l}\text { Pathfinder } \\
\text { International }\end{array}$} & $\begin{array}{l}\text { Adolescent sexual and } \\
\text { reproductive health }\end{array}$ & $\begin{array}{l}\text { Nalanda, Nawada, } \\
\text { Patna, Gaya and } \\
\text { Sheikhpura districts }\end{array}$ & \multirow{2}{*}{$\begin{array}{l}\text { Carried out eight year PRACHAR } \\
\text { project to promote change in } \\
\text { reproductive health behavior } \\
\text { through community level } \\
\text { communication interventions } \\
\text { and multiple audiences } \\
\text { including young couples, } \\
\text { adolescents, elders and } \\
\text { influential members of } \\
\text { community }\end{array}$} \\
\hline & $\begin{array}{l}\text { Prevention of maternal } \\
\text { deaths due to postpartum } \\
\text { hemorrhage }\end{array}$ & $\begin{array}{l}\text { Patna and Hajipur } \\
\text { districts }\end{array}$ & \\
\hline $\begin{array}{l}\text { Population } \\
\text { Services } \\
\text { International }\end{array}$ & Reproductive health & $\begin{array}{l}\text { Bhagalpur, Banka, } \\
\text { Khagaria, Patna, } \\
\text { Begusarai, } \\
\text { Samastipur, Munger, } \\
\text { Lakhisarai, Purba } \\
\text { Champaran and } \\
\text { Paschim Champaran } \\
\text { districts }\end{array}$ & $\begin{array}{l}\text { Carried out Birth Spacing } \\
\text { Program including social } \\
\text { marketing of modern } \\
\text { contraceptive methods and BCC } \\
\text { through TVCs, static media and } \\
\text { mid media }\end{array}$ \\
\hline Janani-DKT & $\begin{array}{l}\text { Family planning and abortion } \\
\text { services including social } \\
\text { marketing and franchise } \\
\text { clinics }\end{array}$ & All districts & $\begin{array}{l}\text { Offers family planning services } \\
\text { and counseling at Janani stalls } \\
\text { during Jan Swasthya Chetna } \\
\text { Yatra }\end{array}$ \\
\hline
\end{tabular}




\begin{tabular}{|l|l|l|l|}
\hline & $\begin{array}{l}\text { Training doctors in } \\
\text { sterilization }\end{array}$ & All districts & $\begin{array}{l}\text { Development and use of IEC } \\
\text { materials and counseling aids } \\
\text { for doctors and RHPs of Janani } \\
\text { clinics } \\
\text { IOT of NGOs which are } \\
\text { Innovative strategies such as } \\
\text { ASHAs } \\
\text { relaying audio messages at } \\
\text { railway stations } \\
\text { Development of radio } \\
\text { documentaries }\end{array}$ \\
\hline BBC-WST & $\begin{array}{l}\text { All districts } \\
\text { spacing }\end{array}$ & $\begin{array}{l}\text { Eight BMGF priority } \\
\text { districts }\end{array}$ & $\begin{array}{l}\text { TVC 'Ek Teen Do' being aired } \\
\text { across the State } \\
\text { IPC toolkit being piloted }\end{array}$ \\
\hline $\begin{array}{l}\text { Inicronutrient } \\
\text { Initive }\end{array}$ & $\begin{array}{l}\text { Promoting use of zinc and } \\
\text { ORS for efficient diarrhea } \\
\text { management }\end{array}$ & $\begin{array}{l}\text { 15 demonstration } \\
\text { districts }\end{array}$ & $\begin{array}{l}\text { Trained CHWs on IPC } \\
\text { Developed and given counseling } \\
\text { aids on importance and use of } \\
\text { zinc and ORS for diarrhea } \\
\text { management to CHWs } \\
\text { Provided BCMs with checklists } \\
\text { for monitoring }\end{array}$ \\
\hline
\end{tabular}

\section{UNICEF}

UNICEF supports the BCC cell of the SHSB and the Communication and Capacity Development Unit (CCDU) of the PHED in developing their communication capacity. For the BCC cell of SHSB, it is supporting the State Program Officer with two consultants: Consultant Graphic Designer (NRHM) and a State SBCC Coordinator. The Consultant Graphic Designer is required to support the SPO in developing communication materials (posters, leaflets, wall paintings, hoardings, tin plates, bus panels, etc.), pre-testing them, finalizing them and developing specifications for the reproduction of these materials. The state SBCC Coordinator is required to help develop a State specific communication strategy for NRHM, facilitate training of DPMs of DHSs for this strategy, support training of ANMs and ASHAs for building their IPC skills, preparing district wise communication plans and guidelines for their implementation, planning and monitoring communication activities at the district and sharing the status of implementation of communication activities with the ED/SHSB.

For the CCDU, which is the BCC cell of PHED, UNICEF is supporting a State Communication Coordinator (SCC, Graphics) and a State Coordinator BCC \& Capacity Development. The SCC (Graphics) is required to support the CCDU in developing communication material, pretesting and finalizing it, and developing specifications for reproducing the material. The coordinator is also required to visit at least three districts each month, to monitor implementation of communication plans and provide guidance to the DWSCs for effective implementation of the district communication plans. The State Coordinator for BCC and Capacity Development is required to support the CCDU in developing the annual training for implementing the TSC and National Rural Drinking Water Program (NRDWP), organizing modules and material for training DWSCs and its partners including NGOs and PRIs and facilitating state-level consultations for finalization of the communication strategy for TSC. The Coordinator is also required to visit the districts every month, to monitor implementation of communication plans in districts and provide guidance to the DWSCs to develop appropriate IEC 
materials and tools for effective implementation of the district communication plans and to carry out field assessments of hygiene and sanitation related practices in the community.

UNICEF has been carrying out intensive communication activities in its integrated Vaishali district. In 2011-12, different Social and Behavior Change Communication (SBCC) activities were carried out using mid media like folk shows and magic shows and training SHG members on health for community mobilization and building IPC skills of CHWs (UNICEF 2012).

UNICEF partnered with the Women Development Corporation (WDC) for training 4,000 women of SHGs from 350 villages of 12 blocks on health and social issues including IYCF, immunization, diarrhea management, early danger signs, safe motherhood and hand washing. These behaviors have been mainstreamed into the regular curricula of SHGs (UNICEF 2012). It has piloted a capacity building program for community health workers (CHWs) on interpersonal communication (IPC) based on the 'Facts for Life framework' in Vaishali and Gaya districts.

In 2007-08, UNICEF carried out a year-long campaign in Bihar through social mobilization, called Muskaan ek Abbiyaan in all blocks of the state, to achieve 100 percent immunization of infants and pregnant women (UNICEF 2009). Through its Social Mobilization Network (SMNet), UNICEF involved 10 Regional Coordinators, 38 Social Mobilization Coordinators and 263 and Block Mobilization Coordinators for the program. The Social Mobilization Coordinators and Block Mobilization Coordinators were responsible to identify and track target beneficiaries till they reach their target of complete immunization, coordinate between the health department and ICDS for effective service delivery, sensitize mothers for immunization during regular Mabila Mandal meetings, increase the number of immunization sessions and ensure that they are held at all health centers. Besides these activities, they were also responsible to review micro-plans of ANMs, monitor immunization sessions and ensure provision of regular data to the Government. The program also introduced performance based incentives or penalties for mobilizers at all levels of service providers (UNICEF 2009).

UNICEF and ICDS jointly organized a breastfeeding campaign wherein facility-based ANMs were trained in breastfeeding techniques and IPC. UNICEF also facilitated the Jan Swastbya Chetna Yatra which was carried out by the Government of Bihar $(\mathrm{GoB})$ on health in all districts and other mid media activities such as iodine ratbs to celebrate the global month of Iodine (21 October to 20 November).

As part of the Total Sanitation Campaign (TSC) of the Public Health Engineering Department (PHED), UNICEF organized a statewide campaign, Bihar Gram Gaurav Yatra, for enhancing community participation in the water and sanitation program. Recently, it developed a training module for Block Coordinators of PHED for the TSC program. UNICEF has also seconded two staff each to SHSB and PHED to strengthen BCC coordination and planning.

\section{UNFPA}

In Bihar, UNFPA plays a key role in supporting the government's FP program activities particularly postpartum contraception. UNFPA provided TA to Bihar's government for drafting a population and development policy, helped strengthen the HMIS in the state, and has evaluated MCH and RH programs such as JSY. Currently, it is focusing on youth fertility through ASHAs and developing an Adolescent Reproductive and Sexual Health (ARSH) school program as an extracurricular activity in Gaya district.

UNFPA is conducting very little BCC activities in Bihar, with only $\$ 5,000$ per annum that could be used for minor communication activity upon SHSB's request. There is no state-specific communication officer. Communication activities cannot be carried out by the State office in Bihar without direct intervention and support of the UNFPA headquarters in New Delhi. The most recent flexi-fund was spent on printing reports such as the State Population Report and activities under the World Population Day. 
UNFPA was one of the partners with Jagran Pehel and WDC to strategize and implement the communication campaign Sapnon Ko Chali Chhoone to empower young women of 20 colleges in six districts ${ }^{5}$ of Bihar which covered more than 50,000 girls. The program had a strong communication component including increasing dialogue between students and opinion makers in the media and selection of 'champions of change', i.e. girls recognized as local champions by the media. The intervention lasted nine months and was implemented by a project management team, recruited for this purpose. The total fund spent was about 59 lakhs $(\$ 118,000)$, primarily on manpower and coordination. Print space and media support was contributed by Jagran Private Limited (India Social 2010).

Discussions with the State Representative showed that UNFPA is piloting community radio in Maharashtra, experiences and learning from which could help understand how to implement community radio in Bihar as well.

\section{Norway India Partnership Initiative}

The Norway-India Partnership Initiative (NIPI) was setup to achieve MDG 4 is an outcome of a bilateral cooperation between the Government of India (GoI) and the Government of the Kingdom of Norway (GoN) in 2005. NIPI aims to provide catalytic, strategic support to NRHM that would make a vital and sustainable difference in scaling up of good quality child health care service delivery in India (NIPI 2008). Ensuring equity of services to all section of population is the leading principal of the program. NIPI focuses on five States, specifically Uttar Pradesh, Bihar, Madhya Pradesh, Rajasthan, and Orissa.

JSY has engendered a sudden influx of beneficiaries at public health facilities, bringing about a serious challenge in providing quality health services such as delivery care and counseling. For this, NIPI introduced a woman volunteer, Mamta, to assist during delivery and support counseling at a facility with high delivery volumes. A Mamta is generally present at the time of delivery and assists the ANM in delivery and then counsels mothers on newborn care, early initiation of breastfeeding, advantages of exclusive breastfeeding and immunization. Mamtas also motivate women to stay at the facility for a longer duration after delivery. Often these Mamtas are traditional dais (midwives) of the village and are compensated by performance based incentives. NIPI extended support to NRHM in Bihar for training Mamtas and appointing them at all district hospitals and primary health centers in the whole state.

\section{DfID/B-TAST}

The project Technical Assistance Support Team for Bihar (B-TAST) was awarded by DfID to a consortium led by Care International UK, with Options Consulting UK and IPE Global (Infrastructure Professionals Enterprise) in June 2010 for providing technical and managerial assistance to GoB specifically to support implementation of the Sector Wide Approach to Strengthen Health (SWASTH) program. B-TAST will serve for six years—from 2010 to 2016. The total allocated fund for the project is $£ 145$ million out of which $£^{25}$ million is for GoB and $£ 25$ million for B-TAST for its services and TA. SWASTH covers all districts of Bihar has 56 professionals in the state and 60 field officers. To achieve its program objectives, B-TAST has allocated a District Program Officer (DPO) along with a team of resource persons consisting of a Regional Manager, a Health Coordinator and a Water and Sanitation Coordinator in six districts-Muzaffarpur, Bhagalpur, Purnea, Buxar, Saran and Gaya. Each team covers a cluster of six districts. Besides it has a resource pool and a support cell allocated in the departments of PHED, SHSB and Social Welfare. Each of these cells consists of a professional hired by B-TAST and administrative officers placed by the Government.

\footnotetext{
${ }^{5}$ Bhojpur, Bhagalpur, Gaya, Jehanabad, Muzaffarpur and Patna
} 
In terms of BCC activities, B-TAST is working to strengthen the Village Health Nutrition and Sanitation Committee (VHNSC) by training and orienting CHWs to carry out their tasks effectively, carrying out a scoping study to understand IPC skills of CHWs and steps needed to be taken to build their capacity to mobilize the community and make their IPC effective. The team plans to have at least one community radio (CR) in each district and plan to launch it initially in Jamui and Banka districts. The application for license is awaiting approval of the Ministry of Information and Broadcasting (MIB).

B-TAST is piloting a Self-Help Group (SHG) based intervention called Gram Varta to facilitate SHGs to discuss basic health issues including nutrition, water and sanitation and health practices that could improve family health and the community at large. Besides health, SHGs are also encouraged to discuss gender issues and violence against women. Fortnightly meetings with SHGs and other community members are organized to empower women to improve their own health and that of their families. Gram Varta is presently covering 90 SHGs of Maner Block in Patna District established by WDC (Care, IPE Global and Options Ltd. 2012). B-TAST has now taken initiative to increase its coverage to least 4,500 SHGs in 12 districts $^{6}$ by September 2013.

B-TAST is also trying to promote Community Led Total Sanitation (CLTS), through a community mobilization approach. The focus of the initiative is to create Open Free Defecation (OFD) communities, improve usage of constructed toilets and improve hygiene and sanitation practices. To achieve this objective it has given TA to PHED to develop a road map for the CLTS and initiated its implementation in April 2012 in one block each in Gaya, Nalanda, Purnea and West Champaran. B-TAST plans to make another three blocks ODF through community mobilization using SHG platforms; one each supported by SHG federations of JEEViKA in Madhubani, Mabila Samakbya in Kishanganj and Women Development Corporation in Jehanabad.

\section{Carelndia}

CareIndia has two large projects in Bihar. It is the lead consortium member of the BMGF supported Ananya Alliance which aims to reduce maternal, newborn, and child mortality by 40 percent during the project period 2011-15. Under the initiative, the main roles of CareIndia are to increase availability of high impact and cost-effective family health interventions, improve quality of key family health services, increase utilization of available facilities and services and increase adoption of healthy behaviors. CareIndia is also expected to facilitate identification and adoption of successful approaches at the State level. It is using a mother child tracking system (MCTS) to identity and track pregnant women to ensure they receive health services.

For the Ananya Alliance, Care Bihar is also facilitating training of CHWs in communication skills which is being implemented by Pathfinder International and providing job aids to CHWs which are being developed by BBC-WST. Another partner of the Ananya Alliance is Project Concern International (PCI) which aims to accelerate the adoption of healthy practices and empower the community to collectively demand its right to have access to good quality health services. The Alliance is working in eight BMGF priority districts of Bihar.

\section{Pathfinder International}

Pathfinder International implemented the PRACHAR (Promoting Change in Reproductive Behavior) project from 2001-2009 in five districts in Bihar, in two phases. The project aims to increase awareness and understanding of reproductive health issues including birth spacing and healthy timing and spacing of

${ }^{6}$ Purnea, Patna, Jehanabad and Gaya, Madhepura, Supaul, Araria, Sheohar, Madhubani, Kishanganj, Jamui and Banka. 
pregnancies to create a supportive environment for behavior change. Several BCC interventions were adopted to reach to different segments of the population-- unmarried adolescents, young couples, elders in the family (parents and parents-in-law) and influential community members. Such interventions included IPC (counseling at individual and community levels by trained health care providers), media and infotainment activities (street theatre, wall paintings) and group meetings to inform and involve elders and influential members of the community (Pathfinder International 2011).

Key lessons from PRACHAR for a BCC strategy include: (a) culturally appropriate community based BCC programs which influence decision making have an impact on behaviors (such as dialogue and joint decision making between spouses to space births), (b) longer duration comprehensive interventions have greater impact on behavior such as contraceptive use, (c) home visit based counseling is the most effect model to adoption of behavior, (d) engaging men has greater impact on behaviors such as contraceptive use, (e) creating a supportive environment by involving influential community members helps behavior change and community based interventions can increase behavior change among disadvantaged groups.

Phase III of the project is in progress in Gaya district. The objective of this phase is to apply and test a service delivery model in partnership with the Government and civil society for adoption of health behaviors which impact youth fertility and ultimately maternal and child health. The GoB is using ASHAs as change agents to reach to young women with BCC while NGOs have employed male workers to reach to young men. Pathfinder International is also a partner of BBC-WST as a part of the Ananya Alliance.

\section{Population Services International}

Population Services International's mission is to empower people to lead healthy lives by creating informed demand and providing quality supplies of affordable products, including condoms, OCPs, injectable contraceptives, IUDs, ECPs, vitamin supplements and drugs to prevent post-partum hemorrhage. PSI India's comprehensive family planning messaging and maternal health programs span in 17 States. In Bihar, PSI has been focusing on TB control, tobacco control, increasing use of injectable contraceptives and birth spacing.

Their Birth Spacing Program, funded by the Packard Foundation, was carried out in four phases in Jharkhand and Bihar, of which the first three were carried out in Jharkhand and last two phases were carried out in Bihar. In Bihar, the program was first implemented in five districts in the third phase (20082010) and then expanded to another five districts 7 in the fourth phase (2010-12). Extensive educational campaigning using advocacy, mass media, static media and mid media campaigns were carried out to promote use of modern contraceptive methods (condoms, OCPs, ECPs and injectables).

PSI is a core member of the working group developing NRHM's communication strategy. It played a key role in advocating the Government to use the tagline "Teen saal ka antar achcha, swasth maa aur majboot bacha" as a birth spacing message. PSI produced three television commercials (TVCs) aired by SHSB using the IEC budget provided in the PIP and funded by NRHM. The first TVC focused on increasing knowledge of birth spacing and was aired for two months on four TV channels: Doordarshan, ETC Bihar and Jharkhand, Sahara Samay, and Mahuaa. It was also played in 80 cinemas in all 38 districts and at Patna railway station, for three months. The second TVC was aired in October 2011 and focused on spousal communication. It was aired for a week on five TV channels and at Patna railway station for more than a month. The third TVC focused on family support and social norms supporting birth spacing with a message to have the first child at 21 years and the next child after three years. The TVC has been handed to the SHSB and will be aired shortly in 2012 (PSI 2012).

\footnotetext{
${ }^{7}$ Bhagalpur, Banka, Khagaria, Patna, Begusarai, Samastipur, Munger, Lakhisarai, Purba Champaran and Paschim Champaran.
} 
PSI on behalf of SHSB monitored and provided supportive supervision to the public health facilities to ensure their proper functioning on the eve of Family Welfare Week/Month, each in 2010 and 2011, and participated in the Lok Swashtya Abbiyaan and the Sonpur Mela. In these events, IEC materials were distributed and displayed and skits were performed highlighting the importance of birth spacing. PSI organized 920 rural nukkad nataks (street theatres) and 900 urban road shows in 45 towns. Impact evaluation of its program on promotion of spacing methods presented in a dissemination meeting held at Patna on 27 April 2012 showed positive results. However, since these were only preliminary findings, they raised many methodological issues for which PSI has to do further analysis before drawing a precise conclusion about the impact. The small increase in contraceptive use particularly spacing methods also raised the need of a cost analysis to decide whether the model could be scaled up in the remaining districts.

\section{Janani}

Janani, affiliated to DKT- International, provides family planning and comprehensive abortion care services. Janani aims to make available the entire range of clinical and non-clinical family planning methods so that people could have choice. Equity, affordability and reaching to the most disadvantaged groups of people with services are other central themes of Janani organizational goals and vision

Janani offers its products and services through three delivery channels. First, Janani has its own brand of clinics, called Surya clinics at the district level in 28 districts in Bihar. Surya Clinics offer an entire range of non-clinical services such as contraceptives (condoms, OCPs, injectable contraceptives, ECPs), and clinical services including IUD insertion, tubal ligation, NSV, Surgical Abortion with MVA and medical abortion. Contraceptive social marketing product (condoms and OCP) as well Janani own branded of contraceptives methods are offered at its all outlets Janani also offers substantial subsidy on its own procured branded products.

Second, Janani uses its franchised clinics named as Titti Centers (butterfly) with private sector doctors to increase access to services (Janani n.d.). Titli Centers are a franchisee network of rural health providers which sell non-clinical contraceptives and provide counseling regarding family planning and reproductive health to the village community. There centers also provide other services such as testing for pregnancy, detecting sugar and protein in the urine and refer clients to Surya Clinics for clinical services. Before the rural health providers are franchised they receive training by experts from Janani. To enhance the accessibility of the services to all women, wives of rural health practitioners have also been trained along with the male counterpart.

Third, Janani offers outreach family planning services at government facilities particularly tubal ligation. Janani actively promotes injectable contraceptives through chemists both in urban as well as rural areas, up to block level. Besides these three service delivery mechanisms, Janani has recently set up family planning counseling centers at 15 PHCs in nine districts which the State will scale up to 161 PHCs. The budget has been added in the PIP. For social marketing Janani has tied up with 25,000 chemists in Bihar in below census level towns. Among these, 50 percent are located in rural areas.

Janani promotes its brand, Surya, through various communication campaigns. All its advertisements carry the message of multiple choices of contraceptive methods, and Janani does not promote any specific method. Janani replayed 373,000 seconds of family planning messages at Patna railway station throughout the year. Over 8,000 scrolls also ran through the year displaying the message on family planning (Janani 2012). In January 2012, five episodes of Janani's radio program PAL were broadcast across 13 radio channels across Bihar and Jharkhand. In the year 2011, Janani has participated in over 285 local fairs in the State, carried out 637 street theatre performances with family planning messages, which reached to over 250,000 people. Janani also partnered with Jagran Pehel for the Sapnon Ko Chali Chooney Campaign. 
Janani has been selected as a State Training Site along with three other agencies for the Training of Master Trainers (ToTs) in ASHA Training Modules 5, 6 and 7 which deal with Empowerment, Leadership, Maternal and Newborn Care and Family Planning. Janani will be training master trainers of 19 NGOs who have been selected for training ASHAs in the State.

\section{BBC-World Service Trust}

BBC-WST has been using media to improve health and rights of people in India since 2001. Its mass media campaigns on HIV/AIDS and TB such as 'Condom is Just Another Word' and Bulgam Bhai have a wide audience at the national level, i.e. all those who have access to mass media in rural and urban India, including Bihar (BBC Media Action n.d.).

Currently, BBC-WST is implementing media components of the five-year BMGF supported Ananya Alliance in Bihar. BCC-WST is taking initiative to address barriers and facilitating factors brought out by the Population Council study ${ }^{8}$ to adopt practices which have direct bearing on maternal and child health in the State. On the invitation of GoB, BBC-WST developed a mass media campaign on birth spacing which consisted of a TV commercial, a radio spot, hoarding sign, newspaper advertisement and IPC toolkit for community health workers. The TVC called Ek Teen Do was launched in October 2011. The IPC toolkit is named Fayde ka Mantar was also unveiled in October 2011. Mobile Kunji is an innovative intervention which BCC-WST has developed in collaboration with Airtel. It is a set of cards in a ring which functions both for strengthening capacity of community health workers and as a counseling tool. Each card addresses a specific family health behavior and mentions a toll free phone number on it which the workers could dial to learn or refresh their knowledge about the messages that they need to give to clients. It could also be used as a counseling tool by the community health workers. They could play selected messages in front of clients to reinforce information provided by them about family health behaviors such as PNC, contraceptive methods etc. In a similar experiment in UP by the Manthan project shows that playing of voice message from mobile phones to clients increases credibility of community health workers as well as information provided by them.

\section{Micronutrient Initiative}

Micronutrient Initiative (MI) works exclusively to eliminate vitamin and mineral deficiencies among the most vulnerable populations. In June 2011, it started a program funded by the Children's Investment Fund Foundation (CIFF) in all blocks of 15 districts of Bihar to increase the use of zinc and ORS for efficient diarrhea management. MI has trained all cadre of the health system from civil surgeons to ASHAs and ICDS officials (CDPO to AWW) to diagnose, refer and distribute ORS and zinc to mothers whose child has got diarrhea. MI has also trained 69 Block Community Mobilizers (BCMs) to monitor ASHA's work. The project gives them an incentive of Rs. 500 per day to make field visits and monitor ASHA's work using checklist, with an upper limit of four visits per month. ASHAs have also been provided counseling aids in the form of flash cards. During discussions, senior managers of the program expressed their concern that CHWs do not use the counseling tools as often as they should when counseling mothers. Another major concern with the project is whether it is sustainable in the long term. Paying Rs. 500 per day as an incentive to BCMs for field visits to monitor ASHAs' work may be programmatically unsustainable.

\footnotetext{
${ }^{8}$ Shaping Demand and Practices to Improve Family Health Outcomes in India: A Framework for Behaviour Change Communication.
} 


\section{Discussion}

Key behaviors related to maternal, child and reproductive health and water and sanitation are being addressed by many development partners in the State. However, only a few organizations such as CARE, UNICEF, and B-TAST are addressing the wide range of themes. Often development partners are focusing on some specific themes of health, such as family planning, use of zinc and ORS or women empowerment. The number of districts being covered by different development partners varies considerably, generally between eight to 15 districts. Geographically, districts around Patna (e.g. Nalanda, Samastipur), northwest Bihar (e.g. Purba Champaran, Gopalganj), southeast part of the State (e.g. Bhagalpur, Banka) have had intense development activity, while the districts farthest from Patna such as Kishanganj, Kaimur, and Araria have attracted less development partners. Most of these neglected districts have been most backward, flood affected and have poor health and development indicators.

Organizations which are working in all districts of Bihar focus on system strengthening and provision of TA to the Government or promotion of family planning. Unless BCC is not fully integrated with the main focus of the program such as the way organizations like UNICEF, Janani, BBC-WST or Pathfinder International have been doing, BCC strategies will not be very effective in promoting actual behavior change in family health behaviors.

For many organizations, the communication budget is mostly spent on development of leaflets, and posters and publication of IEC material rather than developing, testing and scaling up innovative strategies to reach out a wider, non-literate audience and the disadvantaged segment of the population. BCC campaigns are mostly of short duration and hence do not succeed in making significant impact on actually changing behavior or changing social norms for continued adoption of healthy practices. In many cases, it is not clear to what extent the campaign or messages are evidence based. Moreover, very few evaluation studies with scientific rigor have been conducted to assess the impact of the BCC campaigns and the impact measured in terms of behavior changes only in negligible cases.

Organizations like Janani, PSI and UNICEF have carried out various types of mid media activities and collaborated with government departments. UNICEF has incorporated health into SHGs curricula in their integrated district and advocated social mobilization for immunization which has been very successful in increasing immunization of children. Janani is perhaps the only organization, which has sponsored and participated extensively in many local events across the state to promote contraception use. Unlike other development partners, Janani has used many forums and innovative platforms to reach various segments of the population, though its reach to the rural areas has been comparatively less compared to its reach in towns and cities.

All organizations taken together are carrying out a wide range of communication activities using mass media, mid media and IPC. However, some organizations tend to depends more on audio visual communication materials like TVCs which have been aired across the State. Such efforts raise two questions; first, the extent to which these BCC messages reach women, particularly the large segment of rural population that has no access to any mass media, and second, some of these campaigns have not been aired for a long time to reinforce messages repeatedly to the target audiences and help create a social environment that is conductive for bringing about change in knowledge, attitude and practices. For instance, PSI's TVCs on birth spacing have been aired for a few weeks to a few months.

While planning to use mass media, available data such as the Indian Readership Survey (IRS)/Television Audience Measurement (TAM) should be used to plan the timing(s) for airing the message, frequency, interval and duration of airing to ensure that the target audiences are exposed to the message several times over an extended period. Such messaging must be reinforced simultaneously by IPC. Unfortunately, we did not find any serious effort on the part of development partners in synchronizing and aligning messages. 
The review of activities of development partners' with respect to BCC shows some programmatic limitations which the SHSB needs to consider and discuss with partners from the view of implementing the BCC strategy in the State. Most development partners focus on their main project themes and BCC is generally planned, developed and implemented accordingly. While they are justified in their approach considering their commitments with donors, there are still opportunities where they could collaborate with other partners and SHSB to get longer mileage of their efforts. This is particularly true if they are working in the same geographical areas and on themes like family planning or other similar health behaviors. Often development partners work in isolation. SHSB could take lead in bringing them together and help guide them to plan and implement their BCC activities which could contribute in the overall BCC strategy of the State. Similarly, messages about specific family planning methods and other family health behaviors could be made uniform across all partners, irrespective of which organization or partner is implementing them. Unless such vision and broader coordination across development partners is developed, the missed opportunity to plan and implement a comprehensive BCC will continue. 


\section{References}

Aruldas, K. and S. Goel. 2012. "Development partners and international NGO assistance in strengthening the health sector in Bihar:" An overview in Khan M. E., F. Donnay, U. K. Tarigopula and D. Ganju (eds), Shaping Demand and Practices to Improve Family Health Outcomes Designing a Behavior Change Communication Strategy in India, Volume 2: Bihar. New Delhi: SAGE Publications.

BBC Media Action. n.d. Projects in India. www.bbc.co.uk/mediaaction/where_we_work/asia/india (accessed on 23 April 2012).

Care, IPE Global and Options Ltd. 2012. Support To Social Welfare Department (SWD), Govt. Of Bihar For Hiring A Technical Support Agency/Ies To Scale-Up Community Mobilization For Health, Nutrition, And Water And Sanitation. Patna: Care, IPE Global and Options Ltd.

India Social. 2010. Case Study: Jagran Pehel- Sapno Ko Chali Chooney Programme for Women. www.indiasocial.in/jagran-pehel-sapno-ko-chali-chooney-programme-for-women/ (accessed on 20 April 2012).

Janani. 2012. Communication Activities January to December 2011. Patna: Janani

Janani.n.d. Resources Available. www.janani.org/resources_11.htm. (accessed on 20 April 2012)

Norway-India Partnership Initiative (NIPI). Information Sheet.2008. New Delhi: NIPI.

Pathfinder International. 2011. Pathfinder International's PRACHAR Project Promoting Change in Reproductive Behavior in Bihar, India: Summary Report of Phase II Evaluation Findings. New Delhi: Pathfinder International.

Population Services International. 27 April 2012. Dissemination Event: Birth Spacing Program in Bihar. Patna. UNICEF. 2009. India Communication Update. Volume XXI. New Delhi: UNICEF.

UNICEF. 2012. UNICEF in Vaishali 2011-2012. Patna: UNICEF 


\section{EXPLORING PARTNERSHIP WITH OTHER GOVERNMENT DEPARTMENTS IN IMPLEMENTING A BCC STRATEGY}

\section{Introduction}

The previous chapters described the current status and limitations of the State Health Society Bihar (SHSB) in implementing a BCC strategy and urgent need of revamping it. Besides revamping the SHSB needs to identify potential partners who have overlapping health interests and could complement the efforts of SHSB in implementing a comprehensive BCC strategy on health.

The SHSB could partner with international development organizations and other department of the Government which have a common interest in health and a mandate to carry out BCC activities in the State. However, they have their own mandate where BCC efforts are geared towards their project goals and they work in limited geographical areas with limited resources. It is only the different government departments which have presence in the whole state, at the district, block and community levels. Some of these departments carry out activities which have a direct bearing on the health of the population and hence share some common ground with the broader objectives of the SHSB. This Chapter identifies and reviews various government departments and agencies with respect to their interest in health behavior and their potential and

Box 5.1: Selected Government departments which never shared responsibilities in health sector

- Directorate of Integrated Child Development Services

- Public Health Engineering Department (PHED)

- Bihar Mahadalit Vikas Mission

- Bihar Rural Livelihoods Promotion Society- JEEViKA

- Women Development Corporation

- Mahila Samakhya strength to partner with SHSB in implementing communication strategy. These departments (Box 5.1) were selected after consultation and discussion with UNICEF and their programmatic objectives.

\section{Methodology}

The departments which have direct or indirect interest in health sector were selected for this study. For the analysis, three key approaches were used to collect the required data including:

- Analysis of policy and program documents: An analysis of the program objectives, organizational structure, coverage and performance of each department was carried out by looking into policy papers, program documents and information on websites of these departments.

- Informal interviews with top program managers: This included meeting the Principal Secretaries of the departments and other selected Senior Program Officers to understand their perspective of the program and opportunities and interest in partnering with SHSB and UNICEF in implementing a BCC strategy for the health sector. UNICEF office played a major role in setting up these appointments. Senior officials met were: 
Executive Director (ED) of SHSB and Secretary, Health

$\checkmark$ Principal Secretary, Social Welfare Department

$\checkmark$ Principal Secretary, Public Health Engineering Department

$\checkmark$ Principal Secretary, Panchayati Raj Department

$\checkmark$ Project Director, Mahadalit Vikas Mission

$\checkmark$ Chief Executive Officer, JEEViKA - Project Bihar Rural Livelihoods Promotion Society

$\checkmark$ District Program Manager, JEEViKA - Project Bihar Rural Livelihoods Promotion Society

- Besides these departmental heads, in each department the research team met with several other senior officials such as State Program Officer for FP of the SHSB, Director (Project Management Unit) of the PHED Project, Director of the Women Department Corporation (WDC) and Project Manager of JEEViKA (Microfinance).

- Field visit and informal interviews at district, block and community level: In consultation with the State Program Officer (FP), four districts were selected for field visits, which included Vaishali, Muzaffarpur, Bhagalpur, and Gopalganj. The Population Council research team visited each of these districts and met several officials of the concerned departments at district and block levels. The team also observed functioning of these programs by attending meetings of the community members with the office bearers of civil society institution such as PRI members, SHGs and Vikas Mitras. The list of the key informants at district and block level who were interviewed is given in Appendix A.

The strengths and weaknesses of each department from the perspective of partnering with SHSB in implementing the proposed BCC strategy for health sector were assessed using a criteria of six indicators. These indicators were developed from discussions with representatives of these departments and field visits, which helped to understand why some organizations were functioning better than others and why some organizations felt more confident and expressed interest in exploring the possibility of partnering in the implementation of a comprehensive communication strategy.

The selected indicators and their operational definitions are given in Table 5.1.

Table 5.1: Operational definition of indicators for determining strength of department

\begin{tabular}{|l|l|}
\hline Indicators & Operational definition \\
\hline $\begin{array}{l}\text { Interest in influencing community } \\
\text { health sector }\end{array}$ & $\begin{array}{l}\text { Health behaviors* which are being promoted by the department and } \\
\text { overlap with the interest of SHSB. It also include health behaviors } \\
\text { which may not be the focus of SHSB but have bearing on the disease } \\
\text { burden managed by SHSB (such as water, sanitation and hygiene } \\
\text { related practices) }\end{array}$ \\
\hline Coverage & $\begin{array}{l}\text { Coverage of the program measured in terms of its implementation in } \\
\text { number of districts, blocks, families and population at large }\end{array}$ \\
\hline Key target audience & $\begin{array}{l}\text { Key audiences of the program and to what extent they overlap with } \\
\text { the key audiences of SHSB }\end{array}$ \\
\hline Organizational structure & $\begin{array}{l}\text { Organizational strength of the department is measured in terms of } \\
\text { availability of staff at district, block and community levels. Presence of }\end{array}$ \\
\hline
\end{tabular}




\begin{tabular}{|l|l|}
\hline & $\begin{array}{l}\text { regular program staff / as compared to volunteer at grassroots level } \\
\text { who can function as change agents (e.g. AWW) is considered a } \\
\text { special strength }\end{array}$ \\
\hline Profile of grassroots level workers & $\begin{array}{l}\text { Age, sex, level of education, training and opportunities of contact with } \\
\text { community }\end{array}$ \\
\hline $\begin{array}{l}\text { Availability of platforms for BCC } \\
\text { activities }\end{array}$ & $\begin{array}{l}\text { Availability of specific platform which the program has created to } \\
\text { provide opportunities to inform and educate the community about } \\
\text { their program and mobilize the community to demand and avail } \\
\text { related services. }\end{array}$ \\
\hline $\begin{array}{l}\text { * } \begin{array}{l}\text { Extent to which their platforms could be used to carry out BCC and } \\
\text { messaging activities and messages for health sector? }\end{array} \\
\text { behaviors discussed in Chapter 2. }\end{array}$ & Availability of a separate budget line in the program for BCC/IEC \\
\hline
\end{tabular}

Detailed write ups were prepared on each department to understand its mission, its functioning at the state, district, block and grassroots level and how program activities are carried out. Functioning of these program(s) was analyzed on the basis of overlapping role in promoting family heath behaviors under the focus of enquiry which have been discussed in Chapter 2 or have a potential platform to carry out BCC/IEC activities. A brief overview of the program activities of each department are discussed in this chapter.

\section{Key findings}

Based on the framework and methodology described above, each of the selected department or program was reviewed and the key observations are presented below.

\section{Directorate of Integrated Child Development Services}

Under the Department of Social Welfare, the Directorate of Integrated Child Development Services was set up for developing policies, legislations, budget, training requirements, monitoring, evaluation and supervision of programs concerning early childhood care including immunization, nutrition and management of diarrhea. The Directorate is responsible to implement three flagship programs which have direct linkages with family health, which include: the Integrated Child Development Scheme (ICDS), the Rajiv Gandhi Scheme for Empowerment of Adolescent Girls - Sabla, and the Indira Gandhi Matritva Sahyog Yojana (IGMSY).

ICDS offers a package of services for children under six years, pregnant women,

Box 5.2: Services offered by ICDS

- Supplementary nutrition for children below 6 years, pregnant women and lactating women

- Immunization of children against polio, diphtheria, pertussis, tetanus, tuberculosis and measles

- Health check-ups of children below 6 years, ANC of pregnant women and PNC of postpartum women

- Management of malnutrition, diarrhea and deworming

- Pre-school and non-formal education for children (3-6 years)

- Counseling on registration of pregnancy, TT injections, IFA supplementation, institutional delivery, full immunization and infant and young child feeding (IYCF) practices

Source: Directorate of ICDS n.d. 
and lactating women in the reproductive age group, as listed in Box 5.2.

Sabla is a centrally sponsored scheme with the objective to improve the status of adolescent girls in the age group of 11 to 18 and empower them by providing education in life-skills, health and nutrition. The program has a nutrition and non nutrition component. Out of school girls aged 11 to 18 and in-school girls aged 14 to 18 are entitled to Take Home Ration (THR) or hot cooked meals. The non-nutritional component includes disbursement of IFA supplementation, health checkups and referral services, Nutrition and Health Education (NHE), counseling on FP, Adolescent Reproductive and Sexual Health (ARSH) and child care. All these services have to be offered in coordination with the MoHFW. Life skill education and vocational training are other important components of the Sabla program.

At the village level the program envisions to have groups of 15 to 25 adolescent girls, each called Kishori Samoobs which are led by peer educators-a Sakhi and two Sahelis nominated by each group. These peer educators are expected to facilitate discussions on topics such as health, hygiene, nutrition, ARSH and life skills, motivate adolescent girls to form more Kishori Samoobs and encourage to take "take home ration," IFA, participate in the Kishori Diwas held once in three months. Another key responsibility of the Sakbi and a Saheli is to motivate and assist all adolescent girls to fill up and maintain their Kishori cards. These cards contain information such as weight, height, body mass index, IFA supplementation, deworming, referrals and services taken under Sabla for each girl. By policy, Sabla requires good interdepartmental coordination between ICDS and SHSB for its successful implementation and effective functioning.

The IGMSY is a Conditional Cash Transfer (CCT) scheme offered as maternal benefits to women for their first two live births. Under the scheme, women directly receive a total cash payment of Rs. 4,000 during childbirth and childcare provided she is above 19 years and registered at an AWC. The cash incentive is offered in three installments, first during the third trimester, second, three months after delivery and the third at six months after delivery. Each payment is contingent to satisfying certain conditions of availing services as given in Box 5.3. However, no cash incentive is provided at the time of delivery since it is already being provided under JSY. The AWW receives a cash incentive of Rs. 200 once the beneficiary receives the complete incentive.

Box 5.3: Payment of installments of IGMSY

\section{First: During third trimester for:}

- Registration of pregnancy,

- Receiving at least 1 ANC and 1 TT, IFA tables and

- At least one IYCF counseling session

\section{Second: 3 months after delivery for:}

- For birth registration,

- Receiving specified immunization: Polio-0 and BCG vaccinations, Polio- 1 and DPT- 1 vaccinations, Polio-2 and DPT- 2 vaccinations,

- Weight measurement of child done at least two times and receipts of two IYCF counseling sessions

\section{Third: 6 months after delivery for:}

- If child exclusively breastfed for 6 months,

- Complementary food introduced at 6 months,

- Child vaccinated with Polio-3 and DPT-3 vaccinations,

- Weighed twice between 3 to 6 months and

- If mother has attended two IYCF counseling sessions Source: Ministry of Women and Child Development 2011

Interest in community and family health behaviors: ICDS and SHSB have high overlapping interest in the health of mothers, children and adolescent girls (Table 5.2 at end of chapter). This makes ICDS a natural partner for SHSB in implementing its BCC strategy. The ICDS focuses on most of the behaviors that the SHSB promotes and policy guidelines underline the need and importance of close collaboration among the functionaries of the two programs. The Anganwadi Center (AWC) is a focal point of the Village Health Sanitation and Nutrition Day (VHSND) which provides an opportunity for ASHA and Anganwadi Workers (AWW) to share and integrate their efforts in identifying pregnant women, promoting four ANC checkups and integrating efforts for community mobilization for seeking the required services. Wherever 
these two functionaries have collaborated, performance of both programs has been much higher and more effective (Ahmad and Khan 2012, Sebastian et al. 2011).

Similarly, the Sabla program which addresses adolescent girls are a key audience for SHSB also. Early marriage, adolescent pregnancy, repeat pregnancies, and severe anemic condition of mothers contribute significantly to the continued high maternal mortality, high neonatal morality and high total fertility. Women aged 15 to 24 contribute 56 percent of the total fertility in India (Parasuraman et al. 2009) and still higher in Bihar. Hence, the two programs share major health sector responsibilities.

Coverage of program: ICDS is present in all districts and all blocks. Since the program has 77,994 AWWs in position and if each is reaching to a population of 1,000 , then it covers approximately 78 million individuals. Of these, 13.6 million women aged 15 to 34 and about 14 million children aged to six months could be reached and their families would benefit indirectly.

Sabla is being implemented in 12 districts (Appendix C). While in 2011 the nutritional component of the scheme is currently operating at 30,858 AWCs, the non-nutritional component is in the initial stage of implementation. If the program covers all adolescent girls in the 30,858 AWCs then it has the potential to reach 2.87 million adolescent girls.

IGMSY is presently being piloted in all blocks of two districts of the State (Appendix C). Analysis shows that IGMSY can reach to 0.93 million women aged 15 to 34 in these two districts. Details of the coverage of ICDS and all other programs are given in Table 5.3 at the end of this Chapter.

Key target audience of program: ICDS addresses issues of children aged 0-6 years, newly married couples, pregnant women and lactating women through two of its traditional ICDS platforms and through the IGMSY scheme and also addresses health and nutrition issues of adolescent girls under the Sabla program (Table 5.4). AWCs are also built in tolas where poor and socially deprived families are concentrated. These audiences are also the key for SHSB. However key audience that is not actively touched by any of the above three programs is men.

Strength of organizational structure: ICDS has a well-developed organizational structure (Table 5.4) consisting of 38 District Project Officers (DPOs) at the districts, 443 Child Development Project Officers (CDPOs) at the project blocks, 400 Lady Supervisors at the sub block level and 77,994 functional AWCs at the community level.

Roles and profile of grassroots level workers: All AWWs are female, usually young or of middle age. They are paid staff of the program and receive a monthly honorarium of Rs. 3,000 (Table 5.6). The peer educators Sakhi and Sabeli of Kishori Samoohs under the Sabla program are also being identified at the grassroots level, though they are volunteers and not paid staff. AWWs receive 21 days of training on health and nutrition and three days training on adolescent health and nutrition under Sabla. The AWW meets eligible women during home visits and play an important role in organizing VHSND and mobilizing the community to make use of the services at VHSND. She is also supposed to meet out of school adolescent girls everyday at AWC and in-school girls once a week.

Change agents and specific platforms available for carrying out BCC: For implementing the BCC strategy, AWWs can work along with the ASHAs as change agents in the community. AWCs are important platforms where every month the VHSND is organized and provides opportunities for disseminating messages and counseling women and their families (Table 5.8). Kishori Samooh meetings and Kishori Diwas are other potential platforms to interact with the community for BCC messaging and counseling.

Budget for BCC/IEC: All three programs of ICDS have separate line items which can be used for BCC activities (Table 5.8). A total of Rs. 14.6 million $(\$ 292,000)$ for supplies and IEC material has been provided for each project (which is almost equivalent to a block and includes around 150- 200 AWCs) 
under ICDS. Under Sabla, around Rs. 30,000 (\$600) per project is allocated for IEC and another 50,000 $(\$ 1,000)$ for life skills education (which includes communication) and IEC. Three percent of total State Government expenditure is mandated for IEC under the IGMSY, and in Bihar the State expenditure for 2011-12 for IGMSY program is Rs. 229.14 million ( $\$ 5$ million), hence Rs. 6.87 million ( $\$ 0.15$ million) has been estimated as allocation for IEC.

\section{Observations from field: Potential and challenges}

Strengths and potential: The biggest strength of the program is the extensive overlapping health interest of ICDS and SHS Band presence of AWW in every village. Both ICDS and Sabla programs have a Nutrition, Health and Education (NHE) component which involves counseling of women and adolescent girls. Also, the AWW is supposed to play an active role in the monthly VHSND which could be a good platform for BCC. Once Sabla begins to operate fully, Kishori Diwas which is to be held once in 3 months could also function as a good platform for BCC for adolescent girls.

AWWs and ASHAs are both from the same community and understand the dynamics of the community and health beliefs and practices of community members and thus could work as good change agents, provided they are properly trained and their skills are regularly updated. At few places, some international agencies have been instrumental in bringing about better coordination among the staff / workers at village level but strong departmental collaboration and its institutionalization is generally missing. An understanding among top program managers of ICDS and SHSB to implement communication strategy jointly could certainly achieve a lot more by complementing their motivational efforts and community mobilization.

Challenges: Field observations show that monitoring and supportive supervision at the grassroots level is not strong and community related barriers hinder them to work effectively. Discussions with the Principal Secretary of the Department and other senior officials revealed that because of financial constraints, a number of supervisors (CDPOs and DPOs) are much less required. For instance, instead of 3,000 Lady Supervisors only 400 have been appointed. The job responsibilities of supervisors are so demanding that they do not get time for field monitoring.

ICDS does not have a separate budget for IEC at the district level, neither do AWWs have any counseling aids except a few which have been provided by non-governmental organizations (NGOs) and UNICEF for projects like Dular and Muskaan Ek Abhiyaan. As a DPO said,

"During training, $A W W$ s received counseling material, but at present no such counseling aids bave been provided to $A W W$ s. There is not district level budget for IEC."

AWWs do not have the required technical as well as counseling skills. Where Sakbis and Sabelis have been selected, they are yet to be trained. The Sabla training manual has been developed by UNICEF and submitted to the state, but it is yet to be printed.

\section{Bihar rural livelihoods promotion society- JEEViKA}

Under the aegis of the Ministry of Rural Development, the Swarnjayanti Gram Swarojgar Yojana (SGSY) has been re-designed and re-structured into the AAJEEVIKA-National Rural Livelihoods Mission (NRLM) in June 2011. AAJEEVIKA NRLM has an agenda to cover 70 million below poverty line (BPL) households, across 600 districts, 6,000 blocks and six lakh villages in the country through self-managed Self Help Groups (SHGs) and federated institutions in a period of 10 years (AaJEEViKA n.d.). GoI will invest $\$ 5.1$ billion and the World Bank has committed $\$ 1$ billion for the program (World Bank n.d.). 
The Bihar Rural Livelihoods Promotion Society was set up in 2006 as an independent society by the Government of Bihar and supported by the World Bank with the objective of increasing the social and economic empowerment of the rural poor, particularly women, as one of the ways to achieve the goal of the NRLM. One of the key strategies of the program is institution and capacity building of resource persons and SHGs of women from the poorest section of society. The main activity of JEEViKA is to educate and train microfinancing and generate funds from where members of the SHGs could take a loan to start a small bussiness or stregthen/expand a family business. SHGs generally consist of 10 to 12 BPL families. JEEV $i K A$ has a provision of a Health Risk Fund (HRF) which is an amount that can be taken as a loan by an SHG member for health-related emergencies.

Interest in community and family health behaviors: Awareness generation and BCC on health is a relatively new activity for JEEViKA. Primary health issues are discussed in SHG meetings if the need is raised but there is no set agenda for discussing health in SHG meetings. Health is increasingly being recognized as an area of interest at top bureaucratic level of JEEV $i K A$. The CEO of JEEV iKA strongly feels that educating SHGs on family health behaviors is a part of women's empowerment and SHGs could contribute a lot in improving family health by encouraging their family members to adopt simple healthy behaviors well within the control of family. He also expressed interest and commitment to partner for a BCC strategy on health with SHSB. This eagerness to work on health is reflected in the recent decision of the CEO to expand a piloted project in which women outreach workers or JEEViKA sahelis promote certain health behaviors which are of interest to the SHSB such as immunization and ANC (pregnancy test, measurement of BP, weight; Table 5.2).

Coverage of program: Currently, the project is spread out in 55 blocks of nine districts (Appendix C). The program has approximately 47,602 SHGs covering 2,745 villages (February 2012). It has been estimated that the program reaches to half a million families and 3.3 million individuals (Table 5.3) among whom 1.22 million women are aged 15 to 34 . JEEV $i K A$ has plans to expand in 245 additional blocks in 2012 and to all districts of the State and will become the nodal agency for constituting and supporting SHGs in the whole State. When it expands to all blocks it would have the potential to reach 5.5 million families which is nearly 31 percent of the total population of Bihar (Table 5.3). A large proportion of this population includes SCs, STs and minority groups which are not being covered by ASHAs because of various reasons including social distance due to caste and class differences as discussed in Chapter 3. Thus SHGs platform provides a huge opportunity to reach a largely unreached population with messages and information.

Key target audience of the program: JEEViKA uses a saturation approach by forming SHGs consisting of least 80 percent of poor women of a village, hence depending on the class structure of the village, as many possible SHGs can be formed. The direct audience of the program is poor and disadvantaged families constituting 30 to 40 percent of the village population (Table 5.4). The families are generally represented in the SHGs by middle aged or elderly women who often have significant influence and control in shaping health practices of adolescents, newly married women and deciding place of deliveries. Thus, their empowerment with appropriate messages regarding health could shape both demand for services and adoption of family health behaviors in their families.

Strength of organizational structure: The structure of the program is well organized at the district, block and community levels, with a large and specialized manpower and resource persons available at the grassroots level (Table 5.5; JEEViKA 2010) which makes it a strong organization for partnering in implementation of BCC strategy. For instance, the Block Project Manager (BPM) is supported by Area Coordinators (ACs) which are responsible to manage a cluster of 30 to 35 villages and a Community Coordinators (CCs) who manage a cluster of five to eight villages. All staff up to the CC are the paid staff of JEEViKA. The representative of the program at the community level is the Community Mobilizer who belongs to the same community and directly interacts with village organization members (referred to 
as VOs) and different SHGs. The program also has a well-functioning and strong MIS which is well connected with the internet and modern technology at every block where it is working.

Roles and profile of grassroots workers: The key grassroots worker is the Community Mobilizer (CM). Though Community Mobilizers are not regular staff of JEEViKA, they are paid a monthly honorarium of Rs. 1,200-1,750, which varies with the number of linkages established and economic activities carried out by her (Table 5.6). Most CMs (90 percent) are female and have at least 10 years of schooling. Male CMs are selected only when an educated female member from the community is not available. CMs are given 30 days of training at the block level on book keeping, group dynamics and developing Micro Credit Plans (MCP) (Table 5.7). There are approx 5,500 CMs (February 2012). Their main tasks are to motivate SHGs and VOs to have regular monthly meetings, attend these meetings and help members maintain books of records and ledgers. Apart from CMs other agents at the community level are Community Resource Persons (CRP) and Village Resource Persons (VRP). Approximately 2,500 experienced women CRPs from SHGs function as community leaders to guide SHGs, while VRPs are active farmers who give guidance on agricultural methodologies (February 2012).

Change agents and specific platforms available for carrying out BCC: Community Mobilizers, SHG members, JEEViKA sahelis and VOs and wherever available, community resource persons can function as change agents for BCC; while SHGs and VOs are available platforms for BCC (Table 5.8). SHGs meet four times a month and VOs meet once a month. JEEViKA emphasizes that SHGs follow five principles or panchsutras, which include weekly meetings, weekly savings, regular lending and borrowing, timely repayment of loan and regular and accurate maintenance of books of records (JEEViKA 2007). Members are also encouraged to follow aniwarya niyam or non-negotiable norms for social advancement which are decided by the group. Some of the health-related norms that have been agreed by many SHGs include: sending children to the anganwadi and school, keeping surroundings clean, washing hands before and after meals, and immunizing children and pregnant women per schedule.

The members VO can be used for planning and monitoring BCC activities in their respective SHGs. VO is formed by taking three representatives from each of the eight to 15 SHGs from the same village and is headed by a President, a Secretary and a Treasurer who meets every month. The VO is supposed to audit and approve loans such as the Health Risk Fund (HRF) and address problems of SHGs.

Budget for BCC/IEC: The program has a communication budget of Rs. 93.7 million (\$1.8 million), most of which has not been spent (Table 5.8).

\section{Observations from field: Potential and challenges}

Strengths and potential: JEEViKA is the only department providing a special fund (i.e. HRF) that can be loaned for health purposes. Rs. 1.5 lakhs $(\$ 3,000)$ per VO is contributed by JEEViKA, and the rest by specific monthly savings of SHG members (generally Rs. 10 per month per woman of SHG). HRF is provided to the VO once the VO approves its constituent SHG requiring the loan. Members of a SHG do not need approval from the VO if they want a loan at or below Rs. 5,000 (\$100) from HRF for health emergencies, at a one percent interest rate. The study shows HRF is mostly taken for surgical operations. SGH members have not thought of taking the HRF for institutional delivery or PNC care of mother and child. Use of HRF should be extended to a broader range of health services as studies show that availability of cash at the time of need (e.g. delivery) is a barrier to access family health services (Hazra et al. 2012, Wagstaff 2002). 
The concept of Women Outreach Workers (WOW) or JEEViKA Sabelis has been piloted in three districts with 40 VOs. JEEViKA Sahelis are selected by VOs. WOW are SHG members, must have at least eight years of schooling and some experience and interest in working on health issues. The program had tied up with Janani for training in which JEEVIKA Sabelis had received six days of training on reproductive and child health, community based health initiatives and nutrition. Their roles are given in Box 5.4. JEEViKA Sahelis are paid a monthly honorarium of Rs. 500 and their performance is assessed annually by VOs. The program is now expanding to all its project villages and one JEEViKA Sabelis will be selected per two VOs (JEEViKA 2012). JEEViKA Sahelis can be oriented and trained on a wider range of issues such as promoting use of ORS, iodized salt, hand washing, menstrual hygiene, FP and so on to disseminate messages. They can even offer services such as ORS, kits to test iodine levels in salt, soaps, sanitary napkins and contraceptive methods using the concept of social marketing. JEEViKA can be a promising partner for the BCC strategy and SHGs could be taken as captive audience.

\section{Women Development Corporation}

The Women Development Corporation (WDC) was set up in 1991 under the Department of Social Welfare with a vision to ensure survival, development, protection and participation of women and adolescent girls in Bihar. It has programs in all districts of the state. Among its many programs, Mukbyamantri Nari Shakti Yojana (MNSY) was started in 2007-08 with the aim to organize, nurture and build capacity of SHGs for women's empowerment.

Interest in community and family health behaviors: UNICEF has trained 120 SHG members on healthy behaviors including ANC, institutional delivery, malnutrition, hand washing, menstrual hygiene, and delaying age of marriage (Table 5.2). These members of SHGs were used as resource persons to facilitate discussion on these health behaviors with members of all SHGs nurtured by MNSY.

Coverage of program: By the end of 2010-11, the MNSY has formed 33,246 SHGs from 5,811 villages of 1,464 Panchayats in 165 Blocks of 27 districts (WDC 2011, Appendix C). Ten to 12 families constitute a SHG, hence, it reaches to 0.39 million women who belong to these SHGs and 2.31 million individuals in their families including 0.85 million women aged 15 to 34 (Table 5.3). WDC continues its plans to expand the coverage of SHGs. According to a State level official in March 2012, the number of SHGs has increased to 42,133 SHGs with nearly 502,247 members.

Key target audience of program: The program has a direct focus on poor and socially deprived families which complements work of ASHAs who are unable to reach this segment of the population (Table 5.4). Around a fifth of villages $(1,292$ out of 5,811$)$ have been saturated, i.e. more than 75 percent of identified poor households have been brought under the umbrellas of SHGs. Moreover, around eight percent of SHGs are exclusively Mahadalit SHGs.

Strength of organizational structure: The department has a well developed organizational structure at the district and block levels, but works largely with NGOs to reach at the grassroots level (Table 5.5). NGOs are responsible to form SHGs, train them, assist women in selecting appropriate income generation activities, provide training in skill development, initiate the process of bank linkages of SHGs, 
identify Community Resource Persons (CRPs) and book keepers and monitor the functioning of SHGs. Hence a lot depends on the efficiency and performance of NGOs selected for this purpose.

Roles and profile of grassroots workers: Cluster Coordinators and CRPs function at the village level. Cluster coordinators are responsible to look after 25 to 30 SHGs constituting a cluster and are paid a monthly honorarium of Rs. 1,000 (Table 5.6). They are responsible to conduct regular SHG meetings, facilitate maintenance of book keeping, support the process of loan payment and monitor that SHGs are carrying out their activities. Cluster Coordinators belong to one of the SHGs which they are supposed to look after and are supposed to visit the community four times a month. CRPs are also erstwhile members of SHGs who have more experience in working in the community. They look after SHGs of three clusters (approx 75 to 90 SHGs) and mobilize defunct SHGs for which they are paid a monthly honorarium of Rs. 2,500 (Table 5.6).

Change agents and specific platforms available for carrying out BCC: In case of MNSY Cluster Coordinators and CRPs can be change agents for BCC; while SHG meetings and Block Federation Meetings are platforms available to be explore for BCC activities (Table 5.8). SHGs are supposed to meet four times a month though they mostly meet two or three times a month. At the block level, an SHG Federation is formed from three clusters. CRPs and federation meetings can be used for carrying out M\&E of BCC activities.

Budget for BCC/IEC: The program has proposed a budget of Rs. $200-250$ million ( $\$ 4$ to $\$ 5$ million) for 2012-13; however, there are no separate line items for IEC/BCC (Table 5.8).

\section{Observations from field: Potential and challenges}

Strengths and potential: The MNSY program aims to achieve community mobilization through its 42,133 SHGs. These SHGs can play a significant role in reaching out to the most deprived and marginalized communities where ASHAs do not make home visits.

Field observations revealed that the members of SHGs who were trained on health by UNICEF certainly discussed these issues with their group. Discussions with SHG members show that they are interested in knowing more about family health issues and sharing this information with their families. The program also plans to roll out a health risk fund similar to JEEViKA which could be used by SHG members for meeting urgent cash flow needs to avail institutional delivery and PNC services.

Challenges: Field visits revealed that the organizational structure of WDC at the grassroots is not as strong as its counterpart organizations such as JEEViKA. For instance, though SHGs are supposed to meet four times a month, they generally meet twice a month. Similarly, Cluster Coordinators are supposed to visit the community four times a month but mostly meet SHGs twice in a month. Monitoring is weak and needs to be strengthened. A formative study is needed to see whether health issues discussed in SHGs are communicated to other family members and the intervention helps in adopting healthy family behaviors and that they continue practicing it. The program relies on NGOs to nurture and facilitate SHGs; hence the effectiveness at the grassroots level depends on how effective the NGO is. There is a lack of clarity on how WDC is monitoring it or how SHGs will function when JEEViKA expands to all districts.

\section{Mahila Samakhya}

The Bihar Mabila Samakhya Society was established with the philosophy of 'education for women's equality'. The principal strategy of the program is to educate women about their rights and need to strive for empowerment and mobilize women to work collectively by forming and participating in women's groups called Mabila Samoobs. Women of the Mabila Samoobs themselves identify their main problems and 
how they could solve these problems. Mabila Samoobs promote activities related to six themes: (a) education, (b) health, (c) government schemes, (d) fight against violence, (e) economic development, and (f) constituting more federations at the district level. This year the program has started transforming Mahila Samoobs into SHGs (called Bachat Samoobs) for carrying out microfinance activities for their economic upliftment.

Interest in community and family health behaviors: The program has great interest in health behaviors including increasing uptake of ANC, institutional delivery, breastfeeding, PNC, and immunization (Table 5.2). It also addresses other health behaviors such as diarrhea management, cholera, deworming, introduction of complementary food at six months and sanitation which directly affects maternal and neonatal health, hence complements the effort of SHSB to achieve these objectives.

Coverage of program: The Mabila Samakbya program has created 8,308 Mabila Samoobs across 17 districts (Appendix C) in 77 blocks covering 6,974 villages. It reaches to approximately 99,696 families and 0.58 million individuals, including 0.21 million women who are 15-35 years old (Table 5.3). Of the 8,308 Mabila Samoobs formed, only 240 are Bachat Samoobs or savings groups, i.e. they carry out microfinance activities. According to district officials, Mabila Samkbya is in the process of expanding and forming more SHGs in villages.

Key target audience: The key target audience of the SHG program of Mabila Samakhya is poor and socially deprived families, pregnant and lactating women and adolescent girls (Table 5.4). The program was established with the objective to uplift women. The program reaches to the poor and socially deprived families many of which are not reached by ASHAs.

Strength of organizational structure: Mabila Samakbya (MS) has a well-developed organizational structure at the district and block levels (Table 5.5). The district office functions with a District Program Coordinator (DPC), two District Resource Persons (DRP) and six support staff. However, worker population ratio to work at grassroots level is much thinner than we observed in JEEViKA and WDC. For example in this case, for every 50 villages ( 5 clusters) there is a unit office, comprising three Cluster Resource Persons (CRPs), one Block Resource Person (BRP) and three trainers. The CRP is responsible to look after various programs of Mahila Samakhya such as the National Program for Education of Girls at Elementary Level and build capacity of Sabyoginis on book keeping, Microfinance and prevention of disease such as diarrhea, cholera, deworming and so on. There are 172 CRPs. Mabila Samakbya does not work with NGOs.

Roles and profile of grassroots workers: Like WDC, Mabila Samakbya works on the basis of cluster formations. A cluster is formed from every 10 villages and its activities are monitored by a Sabyogini. There are total of 177 all female Sabyoginis who are paid staff of Mabila Samakbya (they receive Rs. 3,000 per month) and they belong to one of the 10 villages that they supervise (Table 5.6). Their key roles are to monitor the Nari Adalat, train SHGs on book keeping, microfinance and prevention of diseases such as diarrhea, cholera and worms; and also actively participate in the monthly meeting of SHGs, form new SHGs and disseminate information about new government schemes. Sabyoginis receive 25 days of training at the district level in three phases ( 5 days in the first phase and 10 days each in the second and third phase) by the District Program Coordinator and resource persons on issues such as role of Nari Adalat, formation of SHGs and microfinancing.

Change agents and specific platforms available for carrying out BCC: Sabyoginis can function as change agents while SHG meetings and block federation meetings are the platforms available for BCC (Table 5.8). The members of SHGs are the captive audience. On an average, two to three SHGs are formed at every village and each Mabila Samoob/SHG has 10 to 15 members. In each Mabila Samooh/SHG, two women who are most active, known as a Sakbi, work as the mediators/communicators 
between SHG members and Sabyoginis. Sakhis motivate the group members to carry out their activities and are supposed to arrange meetings every 15 days. Hence, SHGs are scheduled to meet twice a month.

Budget for IEC/BCC: The program has a large budget of more than 50 million rupees ( $\$ 1$ million). However it does not have a separate budget for IEC and educational campaigning (Table 5.8).

\section{Observations from field: Potential and challenges}

Strengths and potential: The main argument for partnering with Mabila Samakbya is its focus on several health issues which are equally important for SHSB. Mabila Samoobs/SHGs of Mabila Samakhya have been involved in health, education and social issues since their inception and have demonstrated interest and potential to bring about changes at the community level without having a microfinance initiative Mabila Samakhya is implementing a hygiene and sanitation promotion (HSP) program involving 3,523 SHGs in 40 blocks of 10 districts. Using different forums like discussions, meetings and workshops the program promotes hygiene sanitation, prevention of diarrhea, cholera, worms, need for using toilets and importance of keeping surroundings clean. In addition to that, with financial support from PHED the program has constructed 196 toilets as well (Mabila Samakbya 2012).

Challenges: Mabila Samoobs of the program have recently begun microfinance activities by forming SHGs. However, it is unclear if the program will merge or carry out its activities independently when JEEViKA expands to the whole state.

\section{Public Health Engineering Department}

The goals of the Public Health Engineering Department (PHED) are to ensure supply and access to safe drinking water and sanitation facilitates in rural areas, monitor quality of drinking water supply, ensure participation of communities in these processes and reform the water supply and sanitation sector. The Total Sanitation Campaign (TSC), a program of PHED shares some behaviors which are critical aspects of health sector's BCC strategy. The objective of the TSC program is to eradicate the practice of open defecation by ensuring sanitation facilities in rural areas through constructing individual household toilets, community sanitary complexes, Anganwadi toilets and promoting use of toilets through BCC campaign. In order to encourage households below poverty line to construct toilets in their home the program provides a subsidy of Rs 3, 200 and expects a contribution of Rs. 300 from the beneficiary (family) to meet the total cost of toilet construction. If the family is unable to pay this amount in cash, they can contribute by providing labor or the materials. All sanitary facilities are constructed by NGOs under a tender system of the PHED. The PHED has also developed an annual IEC Action Plan which is yet to be approved.

Interest in community and family health behaviors: TSC program of PHED is expected to do promotional work related to hygiene and sanitation including hand washing and using toilets at the family and community levels (Table 5.2). BCC work related to hand washing and sanitation work is also done by other departments like ICDS, WDC, and Mabila Samakhya and VHSNC under NRHM program. Sanitation, hygiene and safe drinking water play crucial role in reducing disease burden of the family. A combined effort by TSC, VHSNC and other departments could make big difference in reducing disease burden of the family and save lives of children who die from cholera, dysentery and from other waterborne diseases.

Coverage of program: The TSC is present in all blocks and districts of the State (Table 5.3). It covers only the rural population. Hence, the program has a potential to reach 72 million people and 12.4 families. Among the 3.8 million beneficiaries of the TSC program in 2011, 2.9 million were BPL families and 0.9 million Above Poverty Line (APL) families. Among the 2.9 million BPL beneficiaries, 563,000 were SC/ST families. 
Key target audience of program: The key audiences of the program are rural families, particularly those below poverty line. It also focuses on schoolchildren, women and children using services of the AWC, and the community at large, particularly the poor (Table 5.4). Unlike many other programs reviewed in this chapter, TSC generally works with men and or heads of families who decide on toilet construction in their household. NGOs who carry out TSC interact with schoolboys to promote hand washing and school toilet construction. No other department can directly reach schoolboys.

Strength of organizational structure: At the State level is the CCDU, which is responsible for carrying out communication activities and building capacity of the functionaries of PHED. It is supposed to support district in developing and implementing their communication plans and is headed by the Director. The Unit also has State Communication Coordinator (Graphics) and a State Coordinator BCC \& Capacity Development who took positions recently, in April 2012 and are supported by UNICEF. At each district, the PHED has a District Water and Sanitation Committee (DWSC) which looks after the functioning of the overall program in accordance to the District Water and Sanitation Mission (Table 5.5). Under the DWSC is the executive engineer guides the district coordinator of the TSC program. The district coordinator supervises the block coordinator. It is the block coordinator who works with NGOs which are responsible to implement the program at the community level. Currently, 28 district coordinators are in position while 10 positions are vacant. Similarly, 450 block coordinators are in place and 94 positions are vacant. At the grassroots level the program has no organizational presence and the TSC is implemented by NGOs at community level.

Roles and profile of grassroots level workers: The Block Coordinator is the only outreach worker for the department with no paid workers at the community level. Moreover, Block Coordinators have been recently hired and the process of hiring is still going on. Block Coordinators receive 3 days of training at the State level after joining the position (Table 5.6). The role of Block Coordinator is to facilitate NGOs in construction of toilets and promote IEC on water and sanitation behaviors Block Coordinators have little opportunities to contact the community. Though he/she is expected to be present at VHSND, generally he/she does not attend these meetings. Community contact is largely made by the motivators of NGOs and their interaction is largely confined to toilet construction and distribution of IEC materials. Thus the organizational structure at the community level is almost non-existent.

Change agents and specific platform available for carrying out BCC: IEC, including mid-media and IPC to promote sanitation, build toilet and educate people about hygiene and sanitation is a wellrecognized by the department. However, BCC activity at community level carried out by NGOs are confined to motivate households to build toilets in their home and construct it if they agree. Very limited IPC on water sanitation and other hygiene related behavior is carried out. From the department, it is only block coordinators and concerned NGOs can be involved as change agents.

Other available platforms for BCC promoting healthy behaviors include the annual Swachchta Mahotsav (Table 5.8), a door-to-door educational campaign on sanitation, hygiene, and safe drinking water, which is organized at the district level from 2 October to 14 November. Another platform is observance of the sanitation fortnight and special days such as 'World Toilet Day' and 'Global Handwashing Day'. All these activities are organized by the department but need better planning and orientation. Another platform for implementing TSC is VHSND, whereby Block Coordinators are supposed to participate and promote messages on safe water and sanitation and offer toilet construction in households and Anganwadi centers.

Budget for IEC/BCC: Since its inception (1999), so far the approved budget of the TSC has been Rs. 29,338 million ( $\$ 5.9$ billion) for 15 years, through 2015, of which 15 percent has been allocated for IEC activities (Table 5.8). Hence, an estimated cost of Rs. 4,400 million ( $\$ 88$ million) is available for IEC/BCC. An analysis shows that till 2012 only 23.6 percent IEC budget has been spent mainly in printing materials with little or no impact. This to an extent shows the inability of the district offices to 
use available funds for developing and implementing innovative IEC approaches to change the desired behavior of community members.

The street plays, demonstration units, give incentives to motivators who get toilets installed and showcase the TSC program in various forums such as melas, mahotsavas, etc.

\section{Observations from field: Potential and challenges}

Strengths and potential: The program functions across the State and has a large audience. Further, changing hygiene and sanitation behaviors of community members is a key program objective and there is a designated IEC/BCC budget. The budget has potential to be channelized for greater IPC and motivational activities during the VHSND. PHED could also collaborate with institutions like Mabila Samakhya to promote behavior change communication. Strength of PHED is the autonomy which they have provided to district officials to plan their IEC activities depending on the need and context. For instance, in Muzaffarpur, it was found that at the block level, Rs. 17 are given for every toilet constructed by the NGOs for IEC activities, especially for motivating the family to keep the toilet clean; while Gopalganj has introduced Swachchta Doots. The TSC Coordinator has appointed 'Swachchta Doots' who are village based volunteers which are responsible for identifying households for constructing toilets, guiding people on the TSC schemes and how to avail the schemes, map the village and identify polluted areas of the village (due to open defecation and stagnated water), visit AWCs for educational work and creating awareness by mobilizing school children for rallies.

During our discussion, the Principal Secretary of PHED expressed interest in receiving technical assistance in developing IEC messages and playing an active role in implementing the BCC strategy.

Challenges: One of the biggest challenges in working with the department is reaching to the grassroots level and their lack of expertise on alternative forms of BCC such as IPC and community mobilization which needs to be strengthened. State officials from the department expressed that the department has little BCC expertise but is open to collaborate and work with UNICEF, Population Council and SHSB to implement BCC strategy for health sector.

Field visits show that block coordinators have been recently hired and are not clearly aware of how to carry out IEC activities and most activities are done intermittently in a camp mode, depending on the leadership of the DWSC. For instance, the Sanitation Week / Sanitation Fortnights are to be conducted once in a month at the Panchayat level. However District Coordinators themselves do not know how to carry out these activities as one of the district coordinators said,

"I have not been given any guidelines on what the Sanitation Week Fortnight is about and how to organize this."

Similarly, Block Coordinators in Muzaffarpur reported that no IEC activity had been done in the preceding six months including a 'Sanitation Week/Sanitation Fortnight'.

\section{Bihar Mahadalit Vikas Mission}

In 2007, the State Government constituted the Bihar Mahadalit Vikas Mission with a vision to fulfill the basic needs of all Mahadalit communities, the most socially and economically disadvantaged group of population in Bihar. The Mission has identified 21 out of the 22 Scheduled Castes of Bihar as Mabadalits. Many of these communities live in separate distant hamlets/tolas from the main village; a reason attributed to their backwardness.

The Mission envisages their social and economic empowerment by ensuring their full participation in the process of development. The Mission strives to ensure their access to housing, drinking water, toilets, link roads, Anganwadis, schools for developing vocational skills, mobile PDS and related services to Mahadalit 
families through 19 schemes. The Mission has appointed one Vikas Mitras (VM) for every Gram Panchayat. Vikas Mitras are grassroots level workers which facilitate and motivate Mabadalit families to avail that the benefits of 19 schemes promoted for the Mahadalits.

Interest in community and family health behaviors: Currently, the Mission is not carrying out any health related activities in the State. The main area of interest for the program is social and economic empowerment and participation of the Mahadalits in the 19 schemes focused on their social and economic development. However, the Mission Director fully appreciates the importance of healthy family in achieving the Mission's goals and expressed interest in implementing the proposed BCC strategy for the health sector.

Coverage of program: The mission is working in all 38 districts and 544 blocks. There are around 22 lakh (2.2 million) Mahadalit families in the State (Times of India 2012), therefore it is estimated that the Mission could reach to 12.76 million individuals (Table 5.3).

Key target audience of program: The key target audiences of the program are Mahadalit families which are generally not reached by ASHAs. Men are an important target audience of the Mahadalit Vikas Mission as they are the key decision makers at the household level regarding availing facilities offered under the 19 schemes.

Strength of organizational structure: At the State level, the Mission has a team of eight specialized Program Managers including a Communication Officer. However, there is no separate unit of the Mahadalit Vikas Mission at the district and block levels and the Mission is in the process of appointing District Project Officers (DPO) and Block Project Officers (BPO). The selection procedure will be finished in July 2012. Currently, District Welfare Officers (DWOs) and Block Welfare Officers (BWOs) are responsible for implementing the program at the district and block levels respectively. All DWOs for 38 districts are in place; while only 202 BWOs have been appointed (of 517 sanctioned posts). Vikas Mitra is the link between the Mahadalit community, Panchayat/Sarpanch and Block Development Office where he reports about his activities to the BWO.

Roles and profile of grassroots level workers: Vikas Mitras ('friends of development') are grassroots workers of whom one is appointed for each Gram Panchayat (four to five villages). They are selected from the community (on the basis of which Mabadalit caste is in majority at that Gram Panchayat) and are required to be educated at least up to grade five. Vikas Mitras receive an honorarium of Rs. 4,000 and report to the BWO. Of the 9,875 sanctioned Vikas Mitras posts, 9,530 have been appointed and the rest are in the process of being appointed. All Vikas Mitras have been trained for three days on their role and responsibilities and the thrust of the 19 schemes which they need to promote among Mahadalit families. All Vikas Mitras have been provided bicycles to facilitate their community visit. They are supposed to meet the community every week.

Change agents and specific platforms available for carrying out BCC: Vikas Mitras could be used as the change agents available at the community level for carrying out BCC activities. The Mission aims to set up Mahadalit anganwadis where they are concentrated in number.

Budget for BCC/IEC: The total budget for the Vikas Mitra scheme is Rs. 117.5 million (\$2.4 million) for 2012-13. There is no separate budget for BCC activities. If districts feel the need to carry out specific BCC activities such as Mahotsavs and 'Republic Day Jhankis', they request the State for funding.

\section{Observations from field: Potential and challenges}

Strengths and potential: The strength of the program lies in the fact that it could provide access to Mabadalit families through Vikas Mitras. They reach families and particularly men who are not easily reached by health workers or ASHA. Moreover, Vikas Mitras being part of the same community, enjoy 
confidence of the Mabadalits and hence could be used as effective change agents. Unlike other programs where the major thrust is on women, in this case Vikas Mitras often work with men and hence have the opportunity to sensitize men of the community about key health issues such as the need of contraceptive use. From the field visits it was observed that in case of a female Vikas Mitra, her husband would take her to the village/community on bicycle and when the female Vikas Mitra talks with women, her husband discusses the program with men.

Challenges: The program is in process of evolution. District and block offices are being fixed. Vikas Mitras have just been hired and trained, and they have no orientation on promoting healthy behaviors and BCC in health sector. They are supposed to participate and promote TSC among Mabadalit families and motivate them to build toilets in their home as well as practice other hygienic practices. This is one of the 19 schemes they need to promote and provide information to community members. However, during the field visits we found that many Vikas Mitras were not aware of the need to construct toilets nor were promoting this activity. Most of them are involved in making lists of individuals/families eligible for key schemes of the Mission such as those for housing, old age pension, sending children to school and special entitlements to the handicapped and so on. Wide variation was observed in their knowledge about the programs suggesting a need for further orientation and proper guidance from the BWO to make them efficient. As many of the BWO positions are vacant, they do not get proper guidance nor is their work supervised. We also observed some tension between Sarpanch and Vikas Mitras. At least two Sarpanchs complained to us that Vikas Mitras do not keep them informed about their work or community needs. As this is the initial phase of the program, such teething problems are expected but if they are not attentively resolved, and then we may miss out on this opportunity.

\section{Panchayati Raj Department}

The Panchayati Raj Department coordinates the functioning of the Panchayati Raj Institutions (PRIs) which were formed for decentralized governance in rural areas by elected members of the village. These elected members constitute a Gram Panchayat (village Panchayat) which is responsible for preparing plans for economic and social development and administering social justice in villages which come under its jurisdiction. A Gram Panchayat is formed for every 7,000 population. For every 500 population of the village a ward member is elected who constitutes the Panchayat members. The Panchayat members in turn elect the head of the Panchayat that is, the Mukbiya and the Dy. Mukbiya. Depending on the population of revenue villages, a Gram Panchayat may be constituted by a single revenue village but on an average, a Gram Panchayat consists of four to five revenue villages.

The Gram Panchayat being an elected body for self-governance is responsible to collaborate with the Zila Parishad and District Chief Development Officer and/or District Magistrate for carrying out development activities of their Gram Panchayat. As an elected body, constitutionally Gram Panchayats as institutions are quite autonomous and administratively Mukhiyas do not have to report to any district or state authorities but they are accountable to district officials for proper utilization and provision of expense reports of the fund the Panchayat receives for social and economic development.

The 8,463 Gram Panchayats in Bihar consist of about 118,500 Panchayat members. Under the Panchayati Raj Act of 2006, 50 percent of Mukhiyas as well as 50 percent of Panchayat members should be women. Furthermore, according to the Act, to assist local self-governance, each Gram Panchayat must establish six standing committees with specialized functions ${ }^{9}$. The committee on health and sanitation is called the

\footnotetext{
9 These include: (a) committee for planning, (b) implementing and monitoring development activities related livelihood, (c) infrastructure, (d) education, (e) social justice and (f) health and sanitation. The members of the standing committees are Panchayat members plus two or three representatives of civil society. They are included in the committee depending on the function of the committee and expertise required.
} 
Village Health Sanitation and Nutrition Committee (VHSNC). Constituting VHSNC is mandated by the NRHM particularly to have access to the unrestricted fund (of Rs. 10,000) provided for each revenue village of the Gram Panchayat for supporting health activities which have not been budgeted in any other program. Often the Mukbiya himself is the chairperson of the VHSNC and the ANM is always the member Secretary of the committee.

\section{Role of Panchayat in the health sector}

As PRI and responsible for local self-governance, the Panchayat could play a significant role in the health sector, particularly women Panchayat members who could be more sensitive to women's maternal health care needs; and could advocate adoption of healthy family behaviors in the community and ensure availability of services by monitoring and strengthening health care service delivery at the heath facility and during the VHSND.

By policy, the Gram Panchayat is supposed to participate and monitor the Village Health Sanitation and Nutrition Day (VHSND) which is held at the village level. The VHSND provides a forum for convergence of four different departments-SHSB, ICDS, PHED, and PRD; each mandated to organize and promote activities related to one or the other component of the health sector imported for community. The VHSND is supposed to be organized twice every month; once at the Anganwadi center and the second at the health sub-center. On that day all grassroots workers of the four departments are expected to work together and provide services and carry out BCC at the village level.

The strength of the Panchayati Raj system is that it covers the entire rural area and at least one Panchayat member is present in most of the villages and hence can play an active role at the grassroots level. A Panchayat member can play a role in monitoring IEC/BCC activities particularly during the VHSND through its standing committee on health and sanitation/VHSNC. Ward members can play an active role in educational campaigns and the BCC strategy if they are motivated and trained. Discussions with experts reveal that ward members have special interest in community issues to maintain political popularity since they are elected by the community. So ward members can mobilize the community to participate in the VHSND. If the ward member is present at the VHSND, then it not only makes the event credible but also will ensure that health workers of SHSB, ICDS, and PHED carry out their tasks effectively.

The Mukbiya and Panchayat members thus taken together constitute a powerful group at community level who are expected to play a critical role in the development of their Gram Panchayat work as opinion leaders and act as role models for the social and economic development of their villages/Gram Panchayat. However, our visit to the field and meetings with selected Mukhiyas indicate that their interest in the health sector is very limited and in most of the places the VHSNC is defunct. It is estimated that presently at best 10-15 percent of the VHSNC are functional. Even where the VHSNC has been formed, neither is it carrying out its roles and monitoring the VHSND, nor are the Mukbiya/members of the VHSNC trained/oriented on their roles and responsibilities as members of the committee. This can be illustrated through the words of a Mukhiya who reported,

"The standing committee on bealth has been constituted in our Gram Panchayat. The last meeting was held in March 2012 and I participated in the meeting. However, I do not know my exact role as a committee member. Construction of toilets and garbage disposal was discussed."

Further probing during the field visits show that generally formation of six standing committees itself is on paper. As mentioned by a Zila Parishad district member,

"The six standing committees are on paper, but not on the ground level. We have informed the Chairman of the Zila Parishad and discussed during the meetings, but no action bas been taken on this." 
Similarly a BDO of the Panchayat Samiti from one of the study districts said,

"We do not know about the formation of six standing committees, if I get an instruction from the district [office] then I will give instructions to PRIs immediately to form these committees."

In the same district, a Mukhiya reported,

"No order has come for constituting such standing committees".

A discussion on this issue at State level shows an apathetic situation. As it appears, the PRI department does not have the will or power to ensure if the standing committees have been constituted and properly functioning. After sending a letter to constitute the standing committee generally it is left to the Mukhiya, as a senior official commented,

"We have issued letters to the Gram Panchayat to form committees, now what else can we do?"

The analysis thus shows that while PRIs have great potential to accelerate social economic and health development in the rural areas through decentralized planning and local self-Governance, very little has been actually implemented in reality. Similarly, the VHSNC and its chairperson could help guide and monitor heath sector activities of VHSND and could be instrumental in bringing convergence of the efforts in the health sector, promoted by SHSB, ICDS, and PHED and aligning their efforts to increase adoption of healthy family behaviors and solve community health problems. However, in reality at most of the districts we visited, very little effort is being made by the Mukhiya or the VHSNC. In such a situation, special effort is required to identify some Mukhiyas and Panchayat members who could be projected 'Champions' for social development and seek their help and guidance in promoting family health behaviors. The 'Champions' as well as other PRI member need an orientation and check list tool. Which they could use for organize their work better way. On experimental basis an effort on the part of SHSB and PRI department in some district will be useful to see how best the Gram Panchayat could be involved in this effort.

\section{Conclusion}

In this chapter, six possible partners for complementing SHSB's initiative for developing and implementing a BCC strategy for the Bihar's health sector were reviewed. Besides these six programs, Panchayati Raj was reviewed as a catalyst for accelerating the process with village health planning, monitoring, implementation, and convering of the inputs of different programs at the grassroots level, particularly during VHSND. Six indicators were considered for assessing their strengths, expected roles in the health sector, and feasibility of partnering for implementing a comprehensive BCC strategy for the sector.

Measured against each of the six indicators, each organization has its own strengths and challenges as a collaborator for implementing the proposed BCC strategy. With respect to their departmental role in the health sector and overlapping interest in bringing about behavior change in the community with the SHSB, ICDS has a stronger role in improving adolescent, maternal and child health through its activities compared to all other departments. PHED's role of increasing access to safe drinking water and improving sanitation of the village and surroundings, is a critically important role in the health sector and has significant bearing on disease burden of the community. Besides these, Mabila Samakhya, WDC, JEEViKA, and Mahadalit Vikas Mission, although they have only peripheral health responsibilities and interests, have started appreciating that their success is contingent upon maintaining family health. It is not easy for a family with heavy disease burden to achieve economic empowerment. Similarly without adopting certain healthy and hygienic practices social upliftment of a disadvantaged family is not possible. Furthermore, JEEViKA, WDC, Mabila Samakbya and the Mabadalit Vikas Mission complement the audience of the SHSB by reaching out to those groups which the ASHA and to an extent AWW does not 
reach-- Mahadalits, scheduled castes, below poverty line families and minorities living in clusters. The Mahadalit Vikas Mission and PHED have the potential to reach to men who are a key audience from the perspective of decision makers in the family but are generally neglected by other programs.

ICDS's coverage is vast, particularly to women in the reproductive age group and adolescent girls. Similarly the coverage of PHED is also substantial as it covers all rural areas of the State. The coverage of JEEViKA, WDC and Mabila Samakhya is rapidly expanding and all three organizations taken together have the potential to reach the most disadvantaged women and their family members of the whole State in a few years. These three organizations together have the potential to reach to each and every disadvantaged woman from all age groups including mother-inlaws who are key influencers in the family. Box 5.5

Box 5.5: Potential of all SHGs of JEEViKA, WDC and Mahila Samakhya together

- Total number of SHGs: 89,156

- Total reach of these SHGS: 1.07 million families/6.20 million population

- This accounts for 6.01 percent of the total population of Bihar

- With the pace of expansion of JEEViKA, WDC and Mahila Samakhya and if they expand to all blocks, then they will reach a total of 13.3 percent of the population shows that together JEEViKA, WDC and Mabila Samakhya in form of SHGs offer captive audiences of 1.07 million families. The Mahadalit Vikas Mission is reaching 2.2 million families which are also covered by SHGs. Thus their involvement will not only help implement the communication strategy but it will complement the audiences, enlarge the base and create opportunities to reinforce the messages. ICDS, JEEViKA and PHED have a substantial budget and separate line items on BCC/IEC activities. Analysis also shows that generally all programs considered have one or other platform available to facilitate BCC activities. Yet some of the programs like SHSB, ICDS, JEEViKA, and WDC provide comparatively better and more stable platforms for BCC activities. As change agents ASHAs, AWWs, Kishori Samooh peer educators, JEEViKA Sahelis, Sabyoginis and Vikas Mitras could be more effective in communicating key messages to community members while Community Mobilizers, Cluster Coordinators and CRPs members can facilitate community mobilization for information dissemination and for creating a conducive environment for behavior and social norm change.

Within the health system, the VHSND emerges as a strong platform available for carrying out BCC activities since it is a forum where four different programs-SHSB, ICDS, PHED, and PRI are expected to converge and hence could complement each other's efforts for information dissemination and behavior change. Kishori Samooh meetings and Kishori Diwas days once rolled across all 12 districts can be used to reach to adolescent girls.

PRI and VHSNC offer great potential of monitoring efficient implementation of a BCC strategy as well as provision of services at the community level. However, at present most of the VHSNCs are nonfunctional. The challenge will be to identify some 'Champions' from among the Panchayat and its members to demonstrate how they could help in accelerating the adoption of desired behavioral change.

When all the departments and their strengths are scored on a three points scale, out of a total score of 15 , ICDC scored 14, showing the important role it could play in implementing the BCC strategy for the health sector (Table 5.9). It was followed by PHED (12 points), then the Mahadalit Vikas Mission (11 points) and JEEViKA (10 points). 


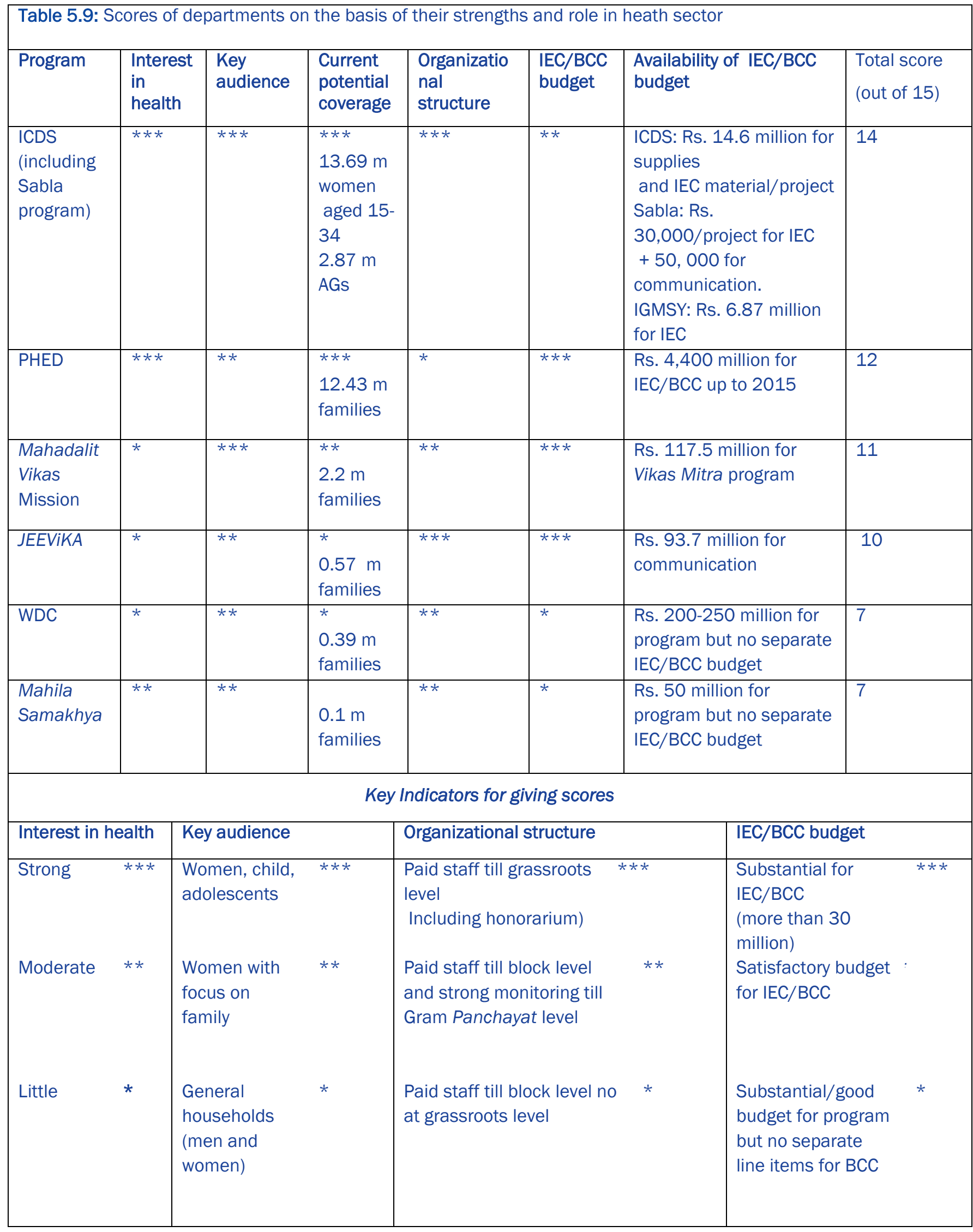


As seen in Table 5.9, the findings suggest ICDS gets the highest score, 11 out of 12 . It could be considered as the best partner for SHSB for implementing the communication strategy. ICDS has a strong interest in most of those behaviors that SHSB is promoting with particular focus on maternal and child health. AWWs share the same norms and values of the community. Hence if they understand different advantages and barriers to adoption and practice of healthy behaviors, they could effectively communicate to the community for bringing about behavior change. AWWs are not only present at the village level but have also proven successful to work along with ASHAs and jointly promote adoption of selected behaviors such as immunization and ANC. At the grassroots level, ASHAs and AWWs continue to work together and integration is required at the State, district and block level for effective functioning and achievement of their similar goals for the BCC strategy.

Social mobilization through SHGs can play a parallel role by reaching to those segments of the population which are not being reached by the ASHAs of SHSB and for reaching to families and the wider community with messages and possibly services. In terms of organizational strength and salaried staff available at the grassroots level, JEEViKA looks like another good partner for SHSB for implementing the BCC strategy on health. It scored 10, the second highest marks when all indicators are considered. The interest of JEEViKA in maternal and child health is increasing and its coverage will eventually expand to the whole State. Where JEEViKA has no presence and SHGs have been formed by WDC and Mabila Samakbya, these organizations can be roped in for the strategy. However, as JEEViKA has become the nodal department for SHG expansion, it will be a good organization for partnering, mainly because the $\mathrm{CEO}$ is willing to partner.

Analysis shows that the Mahadalit Vikas Mission is another potential partner since it has a wide reach to the most disadvantaged groups and has a potential to reach men through its grassroots workers, Vikas Mitras which reach both men and women. However, Vikas Mitras will require orientation on health. The Mission plans to develop its own organizational structure at the district and blocks levels. In terms of overall score, the Mission stands low, at seven points.

As strategy we feel at the first stage, working with ICDS and JEEViKA together will be a capable collaboration in proposed partnership to implement a BCC strategy. 


\begin{tabular}{|c|c|c|c|c|c|c|c|}
\hline & Health component promoted & ICDS & JEEVIKA & WDC & MS & PHED & MVM \\
\hline 1 & $\begin{array}{l}\text { Four antenatal checkups } \\
\text { (ANC)/complete ANC }\end{array}$ & $\checkmark$ & $\sqrt{ } *$ & $\checkmark *$ & $\checkmark$ & & \\
\hline 2 & $\begin{array}{l}\text { Safe delivery by skilled birth } \\
\text { attendant (SBA) }\end{array}$ & $\checkmark$ & & $\sqrt{ } *$ & $\checkmark$ & & \\
\hline 3 & Postnatal care & $\checkmark$ & & $\sqrt{ } *$ & $\checkmark$ & & \\
\hline 4 & $\begin{array}{l}\text { Early initiation of breastfeeding and } \\
\text { exclusive breastfeeding for six } \\
\text { months }\end{array}$ & $\checkmark$ & & $\checkmark *$ & $\checkmark$ & & \\
\hline 5 & $\begin{array}{l}\text { Newborn care practices: cord care, } \\
\text { delay in bathing and thermal care }\end{array}$ & $\checkmark$ & & $\sqrt{ } *$ & - & & \\
\hline 6 & Full immunization of children & $\checkmark$ & $\checkmark *$ & - & $\checkmark$ & & $\checkmark$ \\
\hline 7 & $\begin{array}{l}\text { Diarrhea management using ORS } \\
\text { and }\end{array}$ & $\checkmark$ & & $\sqrt{ } *$ & $\checkmark$ & & \\
\hline 8 & $\begin{array}{l}\text { Competent care during acute } \\
\text { respiratory infection (ARI) }\end{array}$ & & & & & & \\
\hline 9 & $\begin{array}{l}\text { Initiation of appropriate } \\
\text { complementary food at } 6 \text { months }\end{array}$ & $\checkmark$ & & $\sqrt{ } *$ & $\checkmark$ & & \\
\hline 10 & $\begin{array}{l}\text { Prevention and care seeking of } \\
\text { malnourished children under } 5 \text { years } \\
\text { of age }\end{array}$ & $\checkmark$ & & $\checkmark *$ & - & & $\checkmark$ \\
\hline 11 & $\begin{array}{l}\text { Consumption of sufficient amount of } \\
\text { vitamin A }\end{array}$ & $\checkmark$ & & $\checkmark *$ & - & & \\
\hline 12 & $\begin{array}{l}\text { Adoption of postpartum } \\
\text { contraception including LAM }\end{array}$ & & & - & - & & \\
\hline 13 & $\begin{array}{l}\text { Prevention of early marriages (before } \\
18 \text { years) }\end{array}$ & & & - & $\checkmark$ & & \\
\hline 14 & Birth registration within 28 days & $\checkmark$ & & - & - & & $\checkmark$ \\
\hline 15 & Use of iodized salt at household level & $\checkmark$ & & - & - & & \\
\hline 16 & $\begin{array}{l}\text { Hand washing with soap before } \\
\text { eating and after defecation }\end{array}$ & $\checkmark$ & & $\checkmark$ & $\checkmark$ & $\checkmark$ & \\
\hline 17 & $\begin{array}{l}\text { Improved access to safe water } \\
\text { sources }\end{array}$ & & & - & $\checkmark$ & $\checkmark$ & \\
\hline 18 & $\begin{array}{l}\text { Improved access to adequate } \\
\text { sanitation facilities }\end{array}$ & & & $\checkmark$ & $\checkmark$ & $\checkmark$ & \\
\hline 19 & Other health behaviors** & & $\checkmark *$ & $\checkmark$ & $\checkmark$ & & \\
\hline & \multicolumn{7}{|c|}{$\begin{array}{l}\text { Key: ICDS is Integrated Child Development Services, JEEViKA is JEEViKA Bihar Rural Livelihoods Project, } \\
\text { WDC is Women Development Cooperation, MS is Mahila Samakhya and PHED is Public Health } \\
\text { Engineering Department } \\
\text { *Either as pilot project in the case of JEEViKA and for WDC, MS- it is not a focused area but have worked } \\
\text { with UNICEF, PHED for promoting such behaviors } \\
\text { ** Includes blood pressure measurement, making sanitary napkins, health risk fund } \\
\text { Note: ICDS includes the Sabla and IGMSY programs also. Only the SHG component of JEEViKA, WDC and } \\
\text { MS has been considered when carrying out analysis of all tables. }\end{array}$} \\
\hline
\end{tabular}




\begin{tabular}{|c|c|c|c|c|c|}
\hline Program & District & Block & $\begin{array}{l}\text { Community } \\
\text { level }\end{array}$ & $\begin{array}{l}\text { Potential population/families } \\
\text { that can be reached by the } \\
\text { program }\end{array}$ & Potential target audience \\
\hline ICDS & 38 & 534 & 77,994 AWW & $\begin{array}{l}13.4 \text { million families } \\
78 \text { million population }\end{array}$ & $\begin{array}{l}\text { 13.6 million women aged } \\
15-34 \\
6.98 \text { million children aged } \\
0-3 \text { years }\end{array}$ \\
\hline $\begin{array}{l}\text { Sabla } \\
\text { program }\end{array}$ & 12 & 172 & 30,858 AWC & 30.8 million population & $\begin{array}{l}2.87 \text { million of adolescent } \\
\text { girls aged } 10-19 \text { years } \\
\text { could be reached } \\
\text { If Sabla is scaled up to all } \\
\text { districts, then it will reach } \\
7.03 \text { million AGs }\end{array}$ \\
\hline $\begin{array}{l}\text { IGMSY } \\
\text { program }\end{array}$ & 2 & 26 & -- & 5.39 million population & $\begin{array}{l}0.93 \text { million women aged } \\
15-34 \text { years in these } 2 \\
\text { districts }\end{array}$ \\
\hline $\begin{array}{l}\text { SHG formation } \\
\text { JEEViKA }\end{array}$ & 9 & 55 & 47,602 SHGs & $\begin{array}{l}0.57 \text { million families } \\
3.31 \text { million population }\end{array}$ & $\begin{array}{l}1.22 \text { million women aged } \\
15-34 \text { years }\end{array}$ \\
\hline MNSY of WDC & 27 & 165 & 33,246 SHGs & $\begin{array}{l}0.39 \text { million families } \\
2.31 \text { million population }\end{array}$ & $\begin{array}{l}0.85 \text { million women aged } \\
15-34 \text { years }\end{array}$ \\
\hline $\begin{array}{l}\text { SHG formation } \\
\text { of Mahila } \\
\text { Samakhya }\end{array}$ & 17 & 77 & 8,308 SHGs & $\begin{array}{l}99,696 \text { families } \\
0.58 \text { million population }\end{array}$ & $\begin{array}{l}0.21 \text { million women aged } \\
15-34 \text { years }\end{array}$ \\
\hline All SHGs & All SHG & 89,156 & together reach & 07 million families & \\
\hline TSC of PHED & 38 & 534 & -- & 72 million population & 12.43 million families \\
\hline $\begin{array}{l}\text { Mahadalit } \\
\text { Vikas Mission }\end{array}$ & 38 & 534 & $\begin{array}{l}9,530 \text { Vikas } \\
\text { Mitras }\end{array}$ & 12.76 million population & 2.2 million families* \\
\hline \multicolumn{6}{|c|}{ Note: To realize this potentiality it is critical that required positions and resources are in place. } \\
\hline
\end{tabular}


Table 5.4: Key target audience of the program

\begin{tabular}{|l|l|l|l|l|l|l|}
\hline Target audience & ICDS & JEEVIKA & WDC & MS & PHED & MVM \\
\hline Newly married couples & $\checkmark$ & - & $\checkmark$ & - & - & - \\
\hline Pregnant women & $\checkmark$ & - & $\checkmark$ & $\checkmark$ & - & - \\
\hline Postpartum women & $\checkmark$ & - & $\checkmark$ & $\checkmark$ & - & - \\
\hline Lactating women & $\checkmark$ & - & $\checkmark$ & $\checkmark$ & - & - \\
\hline Children under 5 & $\checkmark$ & - & - & - & - & - \\
\hline Adolescent girls & $\checkmark$ & - & $\checkmark$ & $\checkmark$ & - & - \\
\hline School children/teachers & - & - & $\checkmark$ & - & - & - \\
\hline $\begin{array}{l}\text { Poor and socially deprived } \\
\text { families }\end{array}$ & $\checkmark$ & $\checkmark$ & $\checkmark$ & $\checkmark$ & $\checkmark$ & $\checkmark$ \\
\hline Men & & & & & & \\
\hline
\end{tabular}

The focus of the Panchayati Raj Department is on all development activities including education, health, and construction and so on through six standing committees. However, in reality every few actually work. The focus is community governance. 


\begin{tabular}{|c|c|c|c|c|c|}
\hline Department & State & District & Block & $\begin{array}{l}\text { Gram } \\
\text { Panchayat/Sub } \\
\text { block }\end{array}$ & Village* \\
\hline ICDS & Director & $\begin{array}{l}\text { District } \\
\text { Program } \\
\text { Officer (38) }\end{array}$ & $\begin{array}{l}\text { Child Development } \\
\text { Project Officer (443) }\end{array}$ & $\begin{array}{l}\text { Lady Supervisor } \\
\text { at Cluster level } \\
(400)\end{array}$ & $\begin{array}{l}\text { AWW* }(77,994) \\
\text { Peer educators of } \\
\text { Kishori Samoohs }\end{array}$ \\
\hline JEEViKA & CEO & $\begin{array}{l}\text { District } \\
\text { Project } \\
\text { Manager (9) }\end{array}$ & $\begin{array}{l}\text { Block Project } \\
\text { Manager Block Level } \\
\text { Federation } \\
\text { Area Coordinator } \\
\text { Cluster Coordinator }\end{array}$ & -- & $\begin{array}{l}\text { Village Organization } \\
\text { Community } \\
\text { Mobilizer* }(5,500) \\
\text { Community } \\
\text { Resource Person } \\
(2,500) \\
\text { JEEViKA Sahelis } \\
(36) \\
\text { SHG }(47,602)\end{array}$ \\
\hline WDC & $\begin{array}{l}\text { Managing } \\
\text { Director }\end{array}$ & $\begin{array}{l}\text { District } \\
\text { Project } \\
\text { Managers } \\
(27)\end{array}$ & $\begin{array}{l}\text { Block Level } \\
\text { Federation (165) }\end{array}$ & -- & $\begin{array}{l}\text { Community } \\
\text { Resource Person* } \\
\text { Cluster } \\
\text { Coordinator* } \\
(1,558) \\
\text { SHG }(33,246) \\
\text { NGOs }\end{array}$ \\
\hline MS & $\begin{array}{l}\text { State } \\
\text { Program } \\
\text { Coordinat } \\
\text { or }\end{array}$ & $\begin{array}{l}\text { District } \\
\text { Program } \\
\text { Coordinator } \\
(17)\end{array}$ & $\begin{array}{l}\text { Cluster Resource } \\
\text { Person (172) }\end{array}$ & Sahyogini (177) & SHG $(8,308)$ \\
\hline PHED & Secretary & $\begin{array}{l}\text { Total } \\
\text { Sanitation } \\
\text { Campaign } \\
\text { Coordinator } \\
(28)\end{array}$ & $\begin{array}{l}\text { Total Sanitation } \\
\text { Campaign Block } \\
\text { Coordinator (450) }\end{array}$ & -- & -- \\
\hline MVM & Director & $\begin{array}{l}\text { District } \\
\text { Welfare } \\
\text { Officer (38) }\end{array}$ & $\begin{array}{l}\text { Block development } \\
\text { Officer/Block Welfare } \\
\text { Officer (202) }\end{array}$ & $\begin{array}{l}\text { Vikas Mitra } \\
(9,530)\end{array}$ & - \\
\hline
\end{tabular}


Table 5.6: Roles, opportunity of contact with community and profile of grassroots workers by program

\begin{tabular}{|c|c|c|c|c|}
\hline $\begin{array}{l}\text { Grassroots } \\
\text { worker }\end{array}$ & Sex & Payment & Key roles & $\begin{array}{l}\text { Opportunities of contact } \\
\text { with community }\end{array}$ \\
\hline ICDS: AWW & Female & $\begin{array}{l}\text { Monthly } \\
\text { honorarium } \\
\text { (Rs. 3,000) }\end{array}$ & $\begin{array}{l}\text { AWWs provide the following as per } \\
\text { ICDS program: } \\
\text { - } \quad \text { Supplementary nutrition/THR } \\
\text { - } \quad \text { Health check-ups } \\
\text { - } \quad \text { Referral services } \\
\text { - } \quad \text { Pre-school non-formal education } \\
\text { immunization } \\
\text { - Nutrition health education } \\
\text { counseling } \\
\text { As per Sabla, AWWs: } \\
\text { - Survey and register all adolescent } \\
\text { girls } \\
\text { Oversee the activities of Kishori } \\
\text { Diwas } \\
\text { Maintain health cards of } \\
\text { adolescent girls } \\
\text { Distribute THR and IFA to } \\
\text { adolescent girls }\end{array}$ & $\begin{array}{ll}\text { O } & \text { Present per 1,000 } \\
\text { population } \\
\text { Meets community } \\
\text { during home visits } \\
\text { Present at VHSND at } \\
\text { AWC and health } \\
\text { sub-center twice a } \\
\text { month } \\
\text { Supposed to meet } \\
\text { out of school } \\
\text { adolescent girls } \\
\text { everyday at AWC } \\
\text { and in-school girls } \\
\text { once a week }\end{array}$ \\
\hline $\begin{array}{l}\text { ICDS: Sakhi } \\
\text { and Saheli } \\
\text { (of Kishori } \\
\text { Samoohs) }\end{array}$ & Female & Volunteers & $\begin{array}{l}\text { Work as peer educators for the } \\
\text { Kishori Samooh on topics such as } \\
\text { health, hygiene, nutrition, sexual } \\
\text { and reproductive health and life } \\
\text { skills } \\
\text { Facilitate activities for AWW and } \\
\text { uptake of nutritional component } \\
\text { (THR, IFA) }\end{array}$ & $\begin{array}{l}\text { Kishori Samooh are } \\
\text { supposed to meet } \\
\text { weekly }\end{array}$ \\
\hline $\begin{array}{l}\text { JEEViKA: } \\
\text { Community } \\
\text { Mobilizer }\end{array}$ & Female & $\begin{array}{l}\text { Monthly } \\
\text { honorarium } \\
\text { (Rs. } 1,200- \\
1,750 \text { ) }\end{array}$ & $\begin{array}{l}\text { Motivate SHGs and VOs to have } \\
\text { regular monthly meetings } \\
\text { Help members maintain books of } \\
\text { records and ledgers }\end{array}$ & $\begin{array}{ll} & \text { Present in village } \\
\circ & \text { Present at SHG } \\
& \text { meetings } \\
\circ & \text { Present at VO } \\
\text { meeting }\end{array}$ \\
\hline $\begin{array}{l}\text { JEEViKA: } \\
\text { Village } \\
\text { Organization } \\
\text { (VO) }\end{array}$ & Female & Volunteers & $\begin{array}{ll}\text { - } & \text { Oversee work of SHGs } \\
\text { - } & \text { Audit and approve loans } \\
\text { - } & \text { Address any problems of SHGs } \\
\text { - } & \text { Voice SHG problems at block } \\
& \text { federation meeting if required }\end{array}$ & $\begin{array}{l}\text { VO meets once a } \\
\text { month. It consists of } \\
\text { three } \\
\text { representatives of } \\
\text { each SHGs }\end{array}$ \\
\hline $\begin{array}{l}\text { JEEViKA: } \\
\text { SHG }\end{array}$ & Female & Volunteers & $\begin{array}{l}\text { All economic activities :Weekly } \\
\text { meetings, weekly savings, regular } \\
\text { lending and borrowing, timely } \\
\text { repayment of loan and regular and } \\
\text { accurate maintenance of books of } \\
\text { records }\end{array}$ & $\begin{array}{ll} & \text { Supposed to meet } 4 \\
\text { times a month }\end{array}$ \\
\hline $\begin{array}{l}\text { JEEViKA: } \\
\text { JEEViKA } \\
\text { Saheli }\end{array}$ & Female & $\begin{array}{l}\text { Monthly } \\
\text { honorarium } \\
\text { (Rs. 600) }\end{array}$ & $\begin{array}{ll}\text { - Introducing health as an agenda } \\
\text { among SHGs } \\
\text { Delivering basic health services } \\
\text { such as checking for pregnancy, } \\
\text { checking blood pressure, weight } \\
\text { - Motivating for immunization } \\
\text { - } \quad \text { Ensuring utilization of the HRF }\end{array}$ & $\begin{array}{l}\text { Has to be member } \\
\text { of SHG hence meets } \\
\text { as frequently as } \\
\text { SHGs do (at least } 4 \\
\text { times a month) }\end{array}$ \\
\hline
\end{tabular}




\begin{tabular}{|c|c|c|c|c|c|}
\hline $\begin{array}{l}\text { WDC: Cluster } \\
\text { Resource } \\
\text { Person }\end{array}$ & Female & $\begin{array}{l}\text { Monthly } \\
\text { honorarium } \\
\text { (Rs. 2,500) }\end{array}$ & $\begin{array}{l}\text { Is responsible to cover } 3 \text { Cluster } \\
\text { Coordinator areas and mobilize the } \\
\text { defunct SHGs for making functional } \\
\text { groups. } \\
\text { Roles: } \\
\text { - To disseminate the Concept of } \\
\text { SHGs at the communities } \\
\text { - To facilitate the formation of SHGs } \\
\text { Participates once in a month at } \\
\text { the federation monthly meeting }\end{array}$ & 0 & $\begin{array}{l}\text { Present in the } \\
\text { community }\end{array}$ \\
\hline $\begin{array}{l}\text { WDC: Cluster } \\
\text { coordinator }\end{array}$ & Female & $\begin{array}{l}\text { Monthly } \\
\text { honorarium } \\
\text { (Rs. 1,000) }\end{array}$ & $\begin{array}{ll}\text { - } & \text { Facilitating regular meetings } \\
\text { - } & \text { Provide handholding support to } \\
\text { SHGs in record keeping }\end{array}$ & 0 & $\begin{array}{l}\text { Cluster Coordinator } \\
\text { expected to meet } \\
\text { SHGs } 4 \text { times a } \\
\text { month but presently, } \\
\text { it is } 2 \text { times in a } \\
\text { month }\end{array}$ \\
\hline WDC: SHG & Female & Volunteers & $\begin{array}{ll}- & \text { Economic activity } \\
\text { - } & \text { Take up health issues under } \\
\text { certain programs }\end{array}$ & 0 & $\begin{array}{l}\text { Are supposed to } \\
\text { meet } 2-4 \text { times a } \\
\text { month }\end{array}$ \\
\hline $\begin{array}{l}\text { Mahila } \\
\text { Samakhya: } \\
\text { Sahyogini }\end{array}$ & Female & $\begin{array}{l}\text { Monthly } \\
\text { honorarium } \\
\text { (Rs. 3,000- } \\
\text { 5,000) }\end{array}$ & $\begin{array}{l}\text { Monitor Mahila Sanchalan Samiti, } \\
\text { Nari Adalat } \\
\text { Train SHGs on book keeping, } \\
\text { microfinance and prevention of } \\
\text { diseases such as diarrhea, cholera } \\
\text { and worms } \\
\text { Actively participate in the monthly } \\
\text { meeting of SHGs }\end{array}$ & 0 & $\begin{array}{l}\text { Supposed to meet } \\
\text { SHGs four times in a } \\
\text { month }\end{array}$ \\
\hline $\begin{array}{l}\text { Mahila } \\
\text { Samakhya } \\
\text { SHGs }\end{array}$ & Female & Volunteers & $\begin{array}{l}\text { Economic activities } \\
\text { Development activities for } \\
\text { financial gain and women } \\
\text { empowerment such (a) } \\
\text { construction of toilets; (b) making } \\
\text { sanitary napkins, (c) horticulture, } \\
\text { (d) bee keeping (apiculture), (e) } \\
\text { making laakh ki chudiya } \\
\end{array}$ & & $\begin{array}{l}\text { SHGs meet twice a } \\
\text { month }\end{array}$ \\
\hline $\begin{array}{l}\text { PHED: Block } \\
\text { Coordinator }\end{array}$ & $\begin{array}{l}\text { Male or } \\
\text { female }\end{array}$ & $\begin{array}{l}\text { Monthly } \\
\text { salary }\end{array}$ & $\begin{array}{ll}\text { - } & \text { Facilitate NGOs to construct toilets } \\
\text { - } & \text { Facilitate IEC on health (important } \\
\text { of toilets, hand washing, school } \\
\text { sanitation and hygiene) }\end{array}$ & 0 & $\begin{array}{l}\text { Expected to meet } \\
\text { NGOs at the } \\
\text { community level }\end{array}$ \\
\hline $\begin{array}{l}\text { MVM: Vikas } \\
\text { Mitra }\end{array}$ & $\begin{array}{l}50 \\
\text { percent } \\
\text { female }\end{array}$ & $\begin{array}{l}\text { Monthly } \\
\text { salary } \\
\text { (Rs. 4,000) }\end{array}$ & $\begin{array}{l}\text { Ensure } 19 \text { schemes of MVM to } \\
\text { Mahadalit families } \\
\text { Hence, prepare lists of BPL and so } \\
\text { on }\end{array}$ & & $\begin{array}{l}\text { Visiting community } \\
\text { depends on micro } \\
\text { plan prepared by } \\
\text { Vikas Mitra } \\
\text { Supposed to meet } \\
\text { community every } \\
\text { week }\end{array}$ \\
\hline
\end{tabular}


Table 5.7: Training related information by grassroots worker of each program.

\begin{tabular}{|c|c|c|c|c|}
\hline $\begin{array}{l}\text { Grassroots } \\
\text { worker }\end{array}$ & $\begin{array}{l}\text { Place } \\
\text { where } \\
\text { training is } \\
\text { given }\end{array}$ & $\begin{array}{l}\text { Duration } \\
\text { of training }\end{array}$ & Trainer & Issues covered in training \\
\hline ICDS: AWW & $\begin{array}{l}\text { District } \\
\text { level }\end{array}$ & 21 days & $\begin{array}{l}\text { NGOs hired by } \\
\text { Directorate of } \\
\text { ICDS }\end{array}$ & $\begin{array}{ll}\text { - } & \text { Immunization } \\
\text { - } & \text { Supplementary nutrition for pregnant } \\
\text { - } & \text { Health checkup and services } \\
\text { - } & \text { Referral services } \\
\text { - } & \text { Pre-school non-formal education } \\
\text { - } & \text { Nutrition health and education } \\
\text { - } & \text { Infant and young child feeding (IYCF) } \\
& \text { practices }\end{array}$ \\
\hline $\begin{array}{l}\text { ICDS: AWW } \\
\text { (For Sabla) }\end{array}$ & $\begin{array}{l}\text { CDPO Office } \\
\text { at Block } \\
\text { level }\end{array}$ & 3 days & $\begin{array}{l}\text { NGOs hired by } \\
\text { Directorate of } \\
\text { ICDS }\end{array}$ & $\begin{array}{ll} & \text { Anemia prevention } \\
\text { - } & \text { Adolescent reproductive and sexual } \\
& \text { health } \\
\text { - } & \text { Family planning } \\
\text { - } & \text { Health and hygiene } \\
\text { - Immunization }\end{array}$ \\
\hline $\begin{array}{l}\text { ICDS: AWW } \\
\text { (For IGMSY) }\end{array}$ & $\begin{array}{l}\text { CDPO Office } \\
\text { at Block } \\
\text { level }\end{array}$ & 1 day & Lady Supervisor & $\begin{array}{ll}\text { - } & \text { Selection criteria of beneficiaries } \\
\text { - } & \text { Registration of pregnant women } \\
\text { - } & \text { IYCF practices }\end{array}$ \\
\hline $\begin{array}{l}\text { ICDS: } \\
\text { Kishori } \\
\text { Samooh }\end{array}$ & Block level & 3 days & $\begin{array}{l}\text { NGOs hired by } \\
\text { Directorate of } \\
\text { ICDS }\end{array}$ & $\begin{array}{ll}\text { - } & \text { Life skills } \\
\text { - } & \text { Adolescent reproductive and sexual } \\
& \text { health } \\
\text { - } & \text { Nutrition } \\
\text { - } & \text { Hygiene }\end{array}$ \\
\hline $\begin{array}{l}\text { JEEViKA: } \\
\text { Community } \\
\text { Mobilizer }\end{array}$ & Block level & 30 days & $\begin{array}{l}\text { Block Trainer of } \\
\text { JEEViKA }\end{array}$ & $\begin{array}{ll} & \text { Bookkeeping } \\
\text { - } & \text { Microfinance } \\
\text { - } & \text { Thrift \& credit } \\
\text { - } & \text { Social empowerment of women } \\
\end{array}$ \\
\hline $\begin{array}{l}\text { JEEViKA: VO } \\
\text { members }\end{array}$ & Village & 6 days & $\begin{array}{l}\text { Block Trainer of } \\
\text { JEEViKA }\end{array}$ & $\begin{array}{ll} & \text { Need for VO } \\
\text { - } & \text { Role \& responsibilities } \\
\text { - } & \text { Management norms } \\
\text { - } & \text { Record keeping }\end{array}$ \\
\hline $\begin{array}{l}\text { JEEViKA: } \\
\text { JEEViKA } \\
\text { saheli }\end{array}$ & State level & 8 days & $\begin{array}{l}\text { Surya Clinics by } \\
\text { Janani }\end{array}$ & $\begin{array}{ll}\text { - } & \text { Pregnancy check-up } \\
\text { - } & \text { Blood pressure check } \\
\text { - } & \text { Reproductive and child health } \\
\text { - } & \text { Community based health initiatives } \\
\text { - } & \text { Nutrition }\end{array}$ \\
\hline $\begin{array}{l}\text { WDC: } \\
\text { Cluster } \\
\text { coordinator }\end{array}$ & Block level & $\begin{array}{l}4 \text { days }(2 \\
\text { days in- } \\
\text { house and } \\
2 \text { days } \\
\text { field) }\end{array}$ & $\begin{array}{l}\text { Training } \\
\text { Coordinator of } \\
\text { WDC }\end{array}$ & $\begin{array}{ll}\text { - } & \text { Microfinance } \\
\text { - } & \text { Thrift \& credit } \\
\text { - } & \text { Health and hygiene } \\
\text { - } & \text { Legal rights } \\
\text { - } & \text { Social empowerment women } \\
\text { - } & \text { Mahila Helpline }\end{array}$ \\
\hline $\begin{array}{l}\text { WDC: } \\
\text { SHGS }\end{array}$ & $\begin{array}{l}\text { Block level/ } \\
\text { Community }\end{array}$ & 5 days & $\begin{array}{l}\text { Training } \\
\text { Coordinator }\end{array}$ & $\begin{array}{ll} & \text { Objectives } \\
\text { - } & \text { Rules of SHGs } \\
\text { - } & \text { Bank linkage } \\
\text { - } & \text { Record keeping }\end{array}$ \\
\hline $\begin{array}{l}\text { Mahila } \\
\text { Samakhya: }\end{array}$ & Block level/ & 5 days & $\begin{array}{l}\text { District Program } \\
\text { Coordinator and }\end{array}$ & $\begin{array}{ll}\text { - } & \text { Formation of SHGs } \\
\text { - } & \text { Bank linkage }\end{array}$ \\
\hline
\end{tabular}




\begin{tabular}{|c|c|c|c|c|}
\hline Sahyogini & State level & & Resource Persons & $\begin{array}{ll}\text { - } & \text { Microfinance } \\
\text { - } & \text { Thrift \& credit } \\
\text { - } & \text { Social empowerment women }\end{array}$ \\
\hline $\begin{array}{l}\text { Mahila } \\
\text { Samakhya: } \\
\text { Sakhi }\end{array}$ & $\begin{array}{l}\text { District } \\
\text { level }\end{array}$ & 5 days & Resource groups & $\begin{array}{ll}\text { - } & \text { Education } \\
\text { - } & \text { Health } \\
\text { - } & \text { Economic development } \\
\text { - } & \text { Leadership development }\end{array}$ \\
\hline $\begin{array}{l}\text { PHED: Block } \\
\text { Coordinator }\end{array}$ & State level & 3 days & $\begin{array}{l}\text { Master Trainer of } \\
\text { State TSC }\end{array}$ & $\begin{array}{ll}\text { - } & \text { Sanitation and Hygiene } \\
\text { - } & \text { Safe drinking water } \\
\text { - } & \text { Module of toilet }\end{array}$ \\
\hline $\begin{array}{l}\text { MVM: Vikas } \\
\text { Mitra }\end{array}$ & $\begin{array}{l}\text { State and } \\
\text { district } \\
\text { levels }\end{array}$ & $\begin{array}{l}\text { days } \\
\text { residential }\end{array}$ & $\begin{array}{l}\text { Master Trainer of } \\
\text { Mahadalit Vikas } \\
\text { Mission (Hired by } \\
\text { the Department) }\end{array}$ & - $\quad$ All 19 schemes of MVM \\
\hline
\end{tabular}


Table 5.8: Possible platforms/change agents for BCC and available BCC budget under the program/ scheme

\begin{tabular}{|c|c|c|c|}
\hline Program & Platforms for BCC & Change agents & BCC/IEC budget \\
\hline ICDS & $\begin{array}{ll} & \text { VHSND } \\
\circ & \text { Kishori } \\
& \text { Samooh } \\
& \text { meetings } \\
& \text { Kishori Diwas }\end{array}$ & $\begin{array}{ll} & \text { AWW } \\
\circ & \text { Kishori } \\
& \text { Samoohs }\end{array}$ & $\begin{array}{l}\text { ICDS: Rs. } 14.6 \text { million }(\$ 292,000) \text { for supplies } \\
\text { and IEC material for each project } \# \\
\text { Sabla: Rs. } 30,000(\$ 600) \text { per project for IEC and } \\
\text { Rs. } 50,000(\$ 1,000) \text { for communication and IEC } \\
\text { per project. } \\
\text { IGMSY: Rs. } 6.87 \text { million }(\$ 0.15 \text { million) for IEC for } \\
\text { whole program. }\end{array}$ \\
\hline JEEViKA & $\begin{array}{ll} & \text { SHG meeting } \\
\circ & \text { VO meetings* }\end{array}$ & $\begin{array}{ll}\circ & \text { Community } \\
& \text { Mobilizers } \\
\circ & \text { SHG members } \\
\circ & \text { JEEViKA } \\
& \text { Sahelis } \\
& \text { VOs* }\end{array}$ & Rs. 93.7 million for communication (\$1.8 million) \\
\hline $\begin{array}{l}\text { WDC } \\
\text { (MNSY } \\
\text { program) }\end{array}$ & $\begin{array}{ll} & \text { SHG meeting } \\
\circ & \text { Federation } \\
\text { meetings* }\end{array}$ & $\begin{array}{ll}\circ & \text { SHG members } \\
\circ & \text { Cluster } \\
& \text { Coordinators } \\
& \text { CRPs }\end{array}$ & $\begin{array}{l}\text { Proposed Rs. 200-250 million for 2012-13 (\$4- } 5 \\
\text { million) } \\
\text { No separate line items for IEC/BCC in budget }\end{array}$ \\
\hline $\begin{array}{l}\text { Mahila } \\
\text { Samakhya }\end{array}$ & $\begin{array}{ll} & \text { SHG meetings } \\
\circ & \text { Federation } \\
\text { meetings* }\end{array}$ & $\begin{array}{ll}\circ & \text { Sahyogini } \\
\circ & \text { SHG members }\end{array}$ & $\begin{array}{l}\text { Rs. } 50 \text { million rupees (\$1 million) for 2010-11 } \\
\text { No separate line items for IEC/BCC in budget }\end{array}$ \\
\hline PHED & $\begin{array}{ll} & \text { VHSND } \\
& \text { Swachchta } \\
& \text { Mahotsav } \\
& \text { Sanitation } \\
& \text { fortnight } \\
& \text { Special days } \\
& \text { like World } \\
& \text { Toilet Day, } \\
& \text { World Hand } \\
& \text { washing Day }\end{array}$ & $\begin{array}{ll}\text { Block } \\
& \text { Coordinators* } \\
& \text { Mobilizers } \\
& \text { from NGOs }\end{array}$ & $\begin{array}{l}15 \text { percent of Rs. } 29,338 \text { million ( } \$ 5.9 \text { billion) for } \\
\text { IEC up to } 2015 \text { i.e. approx Rs. } 4,400 \text { million ( } \$ 88 \\
\text { million) for communication }\end{array}$ \\
\hline MVM & $\begin{array}{l}\text { Mahadalit } \\
\text { Anganwadi } \\
\text { (schools could } \\
\text { be a possibility) }\end{array}$ & o Vikas Mitras & $\begin{array}{l}\text { Rs. } 117.5 \text { million ( } \$ 2.4 \text { million) for Vikas Mitra } \\
\text { program for } 2012-13\end{array}$ \\
\hline \multicolumn{4}{|c|}{$\begin{array}{l}\text { *This platform can be used for planning and monitoring, not fc } \\
\text { \# Almost equivalent to a block and includes } 150 \text { to } 200 \text { AWCs }\end{array}$} \\
\hline
\end{tabular}




\section{References}

AaJEEViKA.n.d. AaJEEViKA-National Rural Livelihoods Mission. aaJEEViKA.in/. (accessed on 23 May 2012).

Ahmad, J. and M. E. Khan. 2012. "Increasing compliance to complete immunization of children in rural Bihar," in Khan M. E., F. Donnay, U. K. Tarigopula and K. Aruldas (eds), Shaping Demand and Practices to Improve Family Health Outcomes in Bihar, Final Survey Report. New Delhi: Population Council (forthcoming).

Directorate of ICDS. n.d. About ICDS in Bihar. www.newconceptinfosys.com/dsw_demo/Schemes_Programmes/Schemes_Programmes.php?gr $\mathrm{pID}=4 \&$ SubGroupID $=1$ (accessed on 27 March 2012).

Hazra, A., M. E. Khan and D. S. Varma. 2012. "Increasing institutional deliveries and access to emergency obstetric care services in rural Bihar," in Khan M. E., F. Donnay, U. K. Tarigopula and K. Aruldas (eds), Shaping Demand and Practices to Improve Family Health Outcomes in Bihar, Final Survey Report. New Delhi: Population Council (forthcoming).

JEEViKA. 2007. Community Operation Manual. Patna: JEEViKA.

JEEViKA. 2010. Empowerment on Wings. Patna: JEEViKA and Government of Bihar.

JEEViKA. 2012. Policy Note of JEEViKA Sabeli. Patna: JEEViKA.

Mabila Samakbya. 2012. Annual Report 2010-11. Patna: Mabila Samakbya.

Ministry of Women and Child Development. 2011. Indira Gandbi Matritva Sahyog Yojana: A Conditional Maternity Benefit Scheme Implementation Guidelines for State Governments and UTs. New Delhi: Ministry of Women and Child Development.

Parasuraman, S., S. Kishor, S.K. Singh and Y. Vaidehi. 2009. A Profile of Youth in India. National Family Health Survey (NFHS-3), India, 2005-06. Mumbai: International Institute for Population Sciences; Calverton, Maryland, USA: ICF Macro.

Sebastain, M. P., M. E. Khan and K. Kumari. 2011. "Increasing postpartum checkups and contraceptive use to reduce maternal and child mortality." Research Update No. 1. New Delhi: Population Council.

Times of India. 23 March 2012. "CM launches radio scheme for Mahadalits."

Wagstaff, A. 2002. Poverty and Health Sector Inequalities. Bulletin of World Health Organization, 80(2). Geneva: WHO.

Women Development Corporation (WDC). 2011. Annual Progress Report 2010-11. Patna: WDC.

World Bank. n.d. India's National Rural Livelihoods Mission: An Overview. 


\section{CONCEPTUALIZING A BEHAVIOR CHANGE COMMUNICATION STRATEGY IN HEALTH SECTOR: NEED OF A PARADIGM SHIFT}

\section{Introduction}

The study reveals three important aspects which need to be taken into account when conceptualizing the framework for developing a behavior change communication (BCC) strategy for the health sector.

First, the State Health Society of Bihar (SHSB) does not have any effective BCC infrastructure which could plan and implement BCC activities in a comprehensive and sustained manner without revamping its human resources responsible for implementing BCC at the State, district and block levels. Presently the State Program Officer (SPO, FP) is coordinating SHSB's IEC activities with support from two specialists: a Graphic Designer and Social and Behavior Change Communication (SBCC) Coordinator. Two other posts conceptualized for the BCC cell, an M\&E Officer and a Training Officer, are vacant. At the district level, the Mass Media Unit in all districts are defunct, as all professional and technical staff of the Units have retired or been transferred. In several districts, posts of District Community Mobilizer (DCM) and Block Community Mobilizer (BCM) are vacant and where they are posted, they are working below their capacity. At the community level, ASHAs and ASHA facilitators lack interpersonal communication (IPC) skills and skill to mobilize the community to adopt healthy behaviors having direct bearing on maternal and child mortality and morbidity. Studies show that reach of ASHA is limited to about 50 percent of the families.

Second, SHSB is not the only department responsible for BCC activities related to health. Other departments such as the ICDS program of Social Welfare Department and PHED also have their program objectives of promoting behavior change. While ICDS promotes behavior change related to $\mathrm{MCH}$ and nutrition, PHED has responsibility of hygiene and sanitation and managing safe drinking water at home and in the community.

Third, there are several other departments and programs which may not have a health component in their departmental goals directly but their success is dependent on improving and maintaining family health. Furthermore, their activities have an embedded BCC component that could be effectively used for promoting healthy behaviors and keeping members free from diseases. For example, SHGs nurtured by various programs of departments such as JEEViKA, WDC, and Mabila Samakhya are all working towards women's empowerment by promoting microfinance and strengthening the social and economic base of these families, which is directly related to the health of these families. Expenditure on treatment and wage loss is the major cause of family indebtedness. Often loans are taken at a monthly interest rate of 20 percent or more. Similarly, the Mahadalit Vikas Mission envisages social and economic empowerment of Mahadalit, the most backward community in Bihar. The Mahadalit Community cannot develop without improvement in their family health. All statistics on disease burden shows that they are the worst sufferers. Hence, adoption of healthy behavior is strongly associated with the objectives and goals of all these departments.

BCC in the health sector is thus a broader concept and implementation of the BCC strategy should be a collective responsibility of all departments who directly or indirectly influence health behaviors and/or 
strive for adoption of healthy practices in the community to achieve their departmental goals. Indeed, SHSB has to take the lead role in implementing the BCC strategy and their change agents-ASHAs and ANMs together with ICDS staff such as AWWs will have the key roles at the community level. But the change agents of other departments also have their own share of responsibilities either as change agents or in reinforcing messages or as facilitators by providing supportive supervision. Unless all departments play their roles in implementing the BCC strategy, their departmental achievements will be much less than what they could achieve collectively by promoting healthy practices in the community.

For SHSB this joint approach for promoting BCC in the health sector is important because of yet another reason. As discussed in Chapter 3, the reach of mass media to rural poor is very limited, and ASHAs do not reach to more than 50 percent of the families. Most of these 50 percent of families belong to relatively better educated higher or middle standard of living and/or higher castes/other backward caste families while scheduled castes, Mabadalit and minority communities living in clusters remain neglected. These 40 to 45 percent of the "leftover" families could be reached through SHGs, using its change agents like Community Mobilizers (CM) and members of Village Organization (VO) and Vikas Mitras (VM), the change agents of the Mahadalit Vikas Mission.

Considering these constraints and visualizing broader aspects of the BCC strategy, the present chapter is divided into two parts. The first part presents a framework for implementing the BCC strategy for the health sector. The second part concentrates on the SHSB, which will be the key stakeholder in this effort and thus suggests steps to revamp their media unit at different levels—state, district, block, community.

\section{Framework for implementing BCC strategy for health sector}

Figure 6.1 presents the conceptual frame work for implementing the BCC strategy in the health sector. As the Figure shows the change agents and different forums provided by different departments could play critical roles either as prime change agents or for reinforcing the messages through IPC and community mobilization.

The frame work visualizes frontline workers like ASHAs, ASHA facilitators and ANMs from the SHSB, AWWs from ICDS and VMs from the Mabadalit Vikas Mission and VO members from SHGs formed by different departments (such as JEEViKA, WDC and Mabila Samakbya) as prime change agents. Block Resource Coordinators (BRC) from PHED, Community Mobilizers for SHGs and peer leaders of Kishori Samoohs from ICDS are identified sources for reinforcing messages. PRI has a critical role in water and sanitation and health planning of villages and have been visualized to supervise and monitor community level BCC activities including effective functioning of VHSND. For instance, ANMs and ASHAs will continue to deliver messages on ANC, PNC and routine immunization; while AWWs will promote behaviors related to Infant and Young Child Feeding (IYCF), nutrition, diarrhea management, IFA, iodized salt, adolescent health and VMs and VO members can promote the concept of health and how it is linked to the economic empowerment of their community. Presence of ward members of the Panchayat to observe presence of different stakeholders in the VHSND and their functioning and reporting these observations to the VHSNC could be a good way to establish community monitoring the program. 
Figure 6.1: Framework for implementing BCC strategy in health

\section{Planning, implementation and monitoring of BCC strategy (SHSB BCC Cell, CCDU of PHED, VHSNC of PRI)}
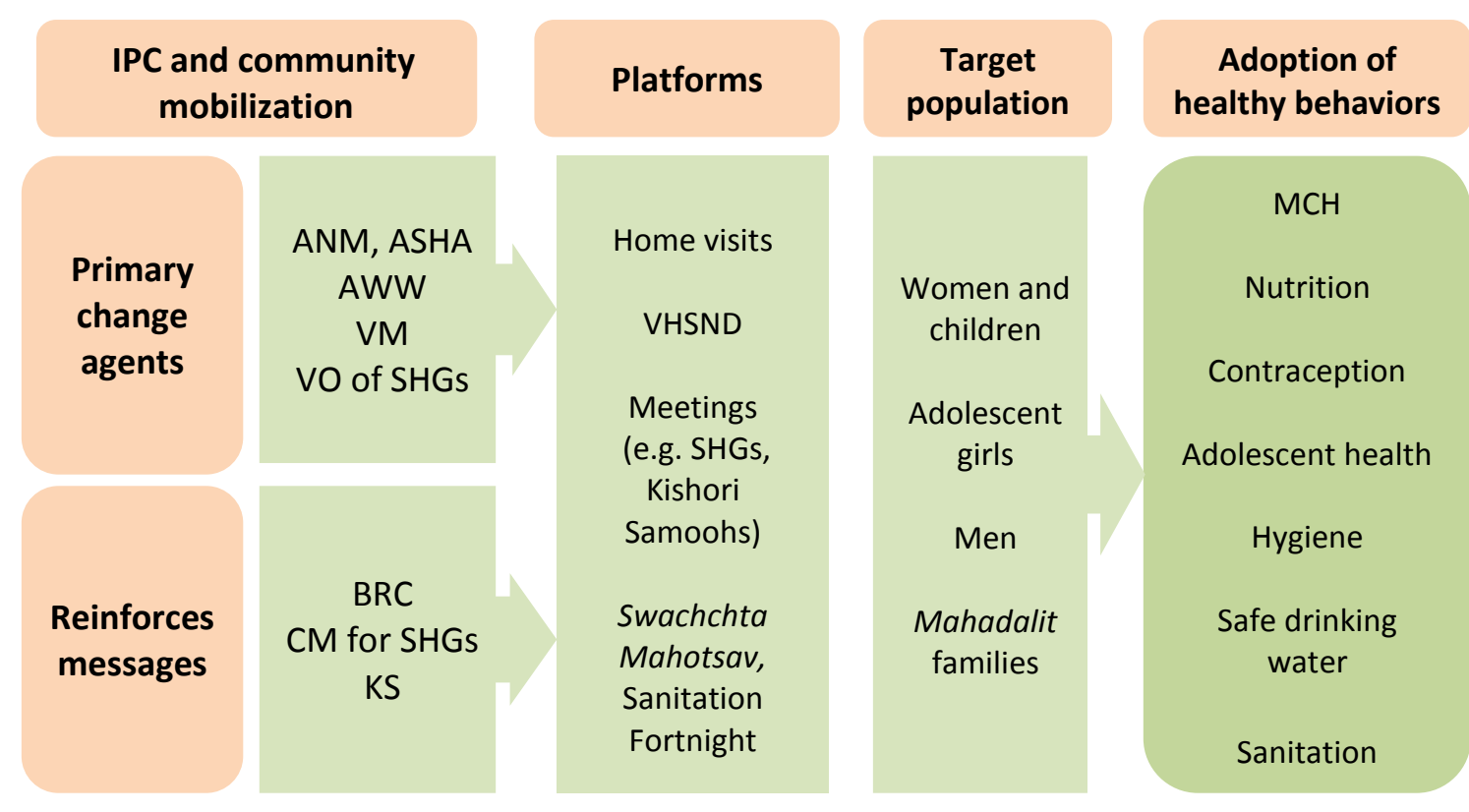

The BCC matrix given in Table 6.1 provides an idea about the activities that will be followed by different change agents. The suggestion to develop a simple checklist is important both to ensure that change agents give all messages which they are supposed to give to the community and also to monitor the work by their immediate supervisors. Availability of such lists is critical and it has been observed that such simple tools help make counseling easier and uniform.

At the State level and their respective units at the district and block levels, the BCC package could be planned, implemented, coordinated and monitored together by the BCC Cell of the SHSB and the Communication and Capacity Development Unit (CCDU) of the PHED i.e. the Mass Media Unit of the SHSB and a proposed District Media Planning and Implementation Committee for SHSB and the District Water and Sanitation Committee (DWSC) and Village Water and Sanitation Committee (VWSC) of PHED. At the village level, the VHSNC of the Gram Panchayat could play an active role in monitoring BCC activities, particularly VHSND.

\begin{tabular}{|c|c|c|c|}
\hline Department & Change Agent & Proposed activities & Input required \\
\hline SHSB & $\begin{array}{l}\text { ASHA/ASHA } \\
\text { Facilitator } \\
\text { ANM } \\
\text { (Primary } \\
\text { change } \\
\text { agents) }\end{array}$ & $\begin{array}{l}\text { - ASHA counsel women during home } \\
\text { visits/VHSND } \\
\text { - Use checklist to ensure all relevant } \\
\text { topics have been covered } \\
\text { - Follow up: all newly married } \\
\text { couples for delaying first } \\
\text { pregnancy, pregnant women for } \\
\text { registering for ANC, institutional } \\
\text { delivery, mothers of newborns on } \\
\text { thermal care, women with unmet } \\
\text { need } \\
\text { Provide number of pregnant } \\
\text { women identified, women receiving } \\
\text { ANC, PNC etc. from Mahadalit } \\
\text { families to ANM/BCM }\end{array}$ & $\begin{array}{l}\text { Develop counseling checklist } \\
\text { for ASHA to ensure she } \\
\text { covers all topics. Orient } \\
\text { ASHAs on how to use it } \\
\text { Develop checklists to follow } \\
\text { up: newly married couples, } \\
\text { pregnant women, newborns, } \\
\text { women with unmet need } \\
\text { Develop M\&E checklist for } \\
\text { ANM/BCM to supervise } \\
\text { counseling activities of ASHA } \\
\text { and coverage of } \\
\text { Mahadalit/minority } \\
\text { communities }\end{array}$ \\
\hline
\end{tabular}




\begin{tabular}{|c|c|c|c|}
\hline ICDS & $\begin{array}{l}\text { AWW } \\
\text { (Primary } \\
\text { change agent) } \\
\text { Kishori } \\
\text { Samoohs peer } \\
\text { leaders } \\
\text { (Reinforces) }\end{array}$ & $\begin{array}{l}\text { AWWs counsel women at AWC and } \\
\text { during home visits/ } \\
\text { VHSND/Bachpan Diwas } \\
\text { Use checklist to ensure all relevant } \\
\text { topics such as IYCF, immunization } \\
\text { etc. have been covered } \\
\text { - Follow up all malnourished } \\
\text { children, drop outs of immunization } \\
\text { Provide list of Mahadalit families } \\
\text { with malnourished children and } \\
\text { drop outs of immunization to VMs } \\
\text { for counseling and action } \\
\text { Form Kishori Samoohs (KS) and } \\
\text { train them } \\
\text { AWWs to provide information to } \\
\text { AWW Supervisor on number of KS } \\
\text { organized and number belonging to } \\
\text { Mahadalit families } \\
\text { KS peer leaders use checklists to } \\
\text { ensure that they have covered all } \\
\text { health topics that need to be } \\
\text { discussed during KS meetings }\end{array}$ & $\begin{array}{l}\text { Develop counseling checklist } \\
\text { for AWW to ensure she } \\
\text { covers all topics. Orient } \\
\text { AWWs on how to use it } \\
\text { Develop checklists to follow } \\
\text { up malnourished children } \\
\text { and drop outs immunization } \\
\text { Develop M\&E checklist for } \\
\text { AW Supervisor to supervise } \\
\text { counseling activities of AWW } \\
\text { Could introduce a 'Swasthya } \\
\text { Parivaar Puruskar' for those } \\
\text { AWCs where at least } 70 \\
\text { percent of families have } \\
\text { accepted healthy behaviors } \\
\text { (this needs to be developed } \\
\text { further) }\end{array}$ \\
\hline PHED & $\begin{array}{l}\text { Block } \\
\text { Resource } \\
\text { Coordinator } \\
\text { (BRC) } \\
\text { (Reinforces) }\end{array}$ & $\begin{array}{l}\text { Besides VHSND, BRCs should } \\
\text { reinforce messages on importance } \\
\text { of using toilets, safe drinking water, } \\
\text { hand washing, and services offered } \\
\text { by TSC once a month in other } \\
\text { forums such as SHG meetings, } \\
\text { meetings organized by VMs, } \\
\text { Bachpan Diwas, Kishori Diwas, at } \\
\text { schools etc. } \\
\text { BRC should use checklist to } \\
\text { monitor BCC activities of NGO } \\
\text { mobilizers }\end{array}$ & $\begin{array}{l}\text { Develop checklist for BRCs } \\
\text { on topics to reinforce } \\
\text { messages on health } \\
\text { Develop M\&E checklist for } \\
\text { BRCs to monitor NGOs' BCC } \\
\text { activities }\end{array}$ \\
\hline $\begin{array}{l}\text { Mahadalit } \\
\text { Vikas } \\
\text { Mission }\end{array}$ & $\begin{array}{l}\text { Vikas Mitra } \\
\text { (VM) (Primary } \\
\text { change } \\
\text { agents) }\end{array}$ & $\begin{array}{l}\text { - VMs promote that family health is } \\
\text { critical for economic wellbeing and } \\
\text { inform about Govt. schemes like } \\
\text { JSY, VHSND, untied fund of VHSNC } \\
\text { VMs facilitate counseling sessions } \\
\text { with ASHA /ANM/AWW and } \\
\text { Mahadalit community } \\
\text { On information provided by } \\
\text { AWW/ASHA, follow up families with } \\
\text { pregnant women, malnourished } \\
\text { children, drop outs of } \\
\text { immunization, etc., to ensure } \\
\text { advice given is followed } \\
\text { Reinforce/provide messages to } \\
\text { men on healthy behaviors } \\
\text { Mobilize Mahadalit community to } \\
\text { participate in VHSND } \\
\text { Encourage parents of children } \\
\text { below } 6 \text { years/pregnant/lactating } \\
\text { women to avail services at } \\
\text { AWC/VHSND } \\
\text { Use checklists to ensure toilet } \\
\text { construction in Mahadalit families } \\
\text { and support TSC }\end{array}$ & 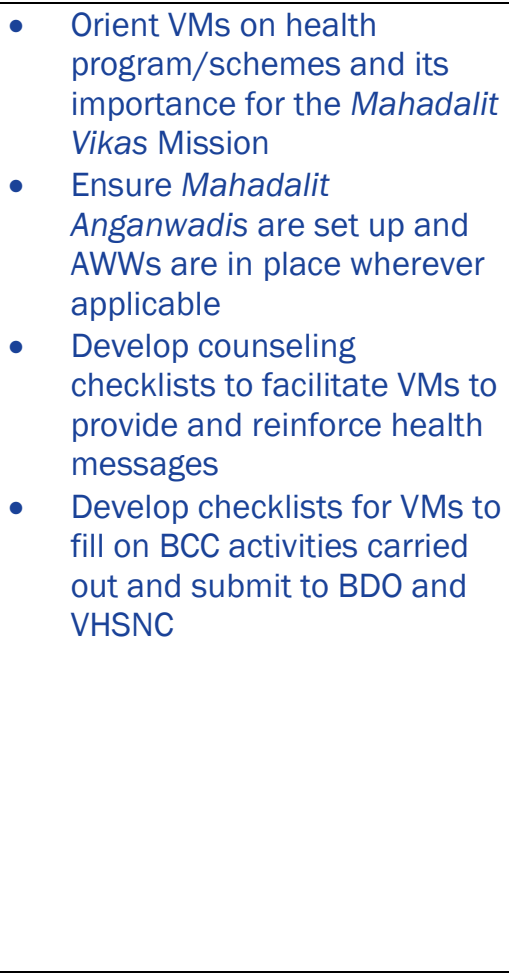 \\
\hline $\begin{array}{l}\text { JEEViKA, } \\
\text { WDC, MS }\end{array}$ & $\begin{array}{l}\text { VO members } \\
\text { (Primary }\end{array}$ & $\begin{array}{l}\text { VO members should discuss health } \\
\text { messages with SHGs once a month }\end{array}$ & $\begin{array}{l}\text { Integrate concept of health } \\
\text { with microfinance training of }\end{array}$ \\
\hline
\end{tabular}




\begin{tabular}{|c|c|c|c|}
\hline & $\begin{array}{l}\text { change } \\
\text { agents) } \\
\text { Community } \\
\text { Mobilizer (CM) } \\
\text { (Reinforces) }\end{array}$ & $\begin{array}{l}\text { Invite ASHA/AWW to talk with SHG } \\
\text { members on health behaviors } \\
\text { VO members to identify pregnant } \\
\text { women, women with unmet need, } \\
\text { drop outs of immunization and } \\
\text { provide this list to ASHAs/AWW } \\
\text { every two months } \\
\text { VOs members can function as } \\
\text { depot holders of contraceptive } \\
\text { methods, sanitary napkins, ORS } \\
\text { Roll out health risk fund (HRF), } \\
\text { which could be also used for } \\
\text { institutional delivery and } \\
\text { pregnancy/delivery complications }\end{array}$ & $\begin{array}{l}\text { CMs \& NGOs and in the } \\
\text { orientation of SHGs } \\
\text { Provide checklist to VO } \\
\text { members to fill on (a) new } \\
\text { pregnancy identified, ANC, } \\
\text { (b) births and status of PNC, } \\
\text { (c) drop outs of } \\
\text { immunization, (d) } \\
\text { contraceptive use every two } \\
\text { months } \\
\text { Develop and provide } \\
\text { checklist on health topics to } \\
\text { be discussed by } \\
\text { CM/VO/ASHA/AWW at SHG } \\
\text { forum }\end{array}$ \\
\hline PRI & $\begin{array}{l}\text { VHSNC } \\
\text { (Facilitator } \\
\text { and Motivator) } \\
\text { Ward } \\
\text { members } \\
\text { (Facilitators } \\
\text { and } \\
\text { Motivators) }\end{array}$ & $\begin{array}{l}\text { VHSNC to ensure VHSND is } \\
\text { regularly held } \\
\text { Make health, drinking water and } \\
\text { sanitation plans for village } \\
\text { Invite VM in the planning meetings } \\
\text { of VHSNC } \\
\text { VHSNC to identify ward members } \\
\text { who can participate in VHSND; } \\
\text { membership to rotate every 3-4 } \\
\text { months } \\
\text { Ward members could fill checklists } \\
\text { on who (among stakeholders) } \\
\text { attended VHSND and what BCC } \\
\text { activities were carried out } \\
\text { VHSNC can facilitate smooth } \\
\text { transportation in case of } \\
\text { emergency when no other transport } \\
\text { is available, eg. institutional } \\
\text { delivery }\end{array}$ & $\begin{array}{l}\text { Orient VHSNC on health } \\
\text { planning and importance of } \\
\text { health and its roles } \\
\text { Propagate incentive of } \\
\text { Nirmal Gram Puruskar (NGP) } \\
\text { for rewarding PRIs of model } \\
\text { villages free from open } \\
\text { defecation } \\
\text { Develop checklists for ward } \\
\text { members to report } \\
\text { functioning of VHSND } \\
\text { attended by them and } \\
\text { provide it to VHSNC }\end{array}$ \\
\hline
\end{tabular}

\section{Strengthen existing IEC/mass media units at state, district, and block levels}

As discussed, while different departments will play a collective role to implement BCC strategy for the health sector, the key stakeholder will be SHSB. The following section discuss steps SHSB could take to strengthen the existing IEC/Mass Media Unit at state, district and block levels:

- Building human resources for BCC by filling vacant positions and hiring experts

- Capacity building of IEC/Mass Media Unit for effective performance.

\section{Building human resources for BCC by filling vacant positions and hiring experts}

State level: A BCC unit exists on paper, with two staff seconded from UNICEF, but with little visible activity. Presently, BCC/IEC activities are coordinated by the State Program Officer (SPO, FP). Hence, the first action should be strengthening SHSB's BCC/Media Unit to coordinate and implement all BCCrelated work. The proposed BCC Unit should comprise four key positions-a State Program Officer (SPO, BCC), a Mass Media and BCC Materials Development Officer, a BCC Coordinator for Development Partners, and a BCC M\&E Officer (Figure 6.2). As sanctioning new posts and hiring officials may take time, as an interim measure, these three positions could be filled by specialist 
consultants. Figure 6.2 also clearly defines the roles and responsibilities of each of these experts and has been expanded in Note 6.1 at the end of the Chapter.

Figure 6.2: Human resource requirement at state BCC unit and key responsibilities

\begin{tabular}{|c|c|c|c|}
\hline & & Executive Director (SHSB) & \\
\hline & $\begin{array}{l}\text { State Program Officer } \\
\qquad \text { (SPO-BCC) }\end{array}$ & & $\begin{array}{c}\text { ASHA Resource Center } \\
\text { (ARC) }\end{array}$ \\
\hline & & & $\begin{array}{r}1 \\
1 \\
1 \\
1 \\
1 \\
1\end{array}$ \\
\hline $\begin{array}{l}\text { Program Officer } \\
\text { Materials Development } \\
\text { (PO- MD) (Consultant) }\end{array}$ & $\begin{array}{l}\text { Program Officer BCC } \\
\text { Coordinator (PO-C) } \\
\text { (Consultant) }\end{array}$ & $\begin{array}{l}\text { Program Officer M\&E } \\
\text { Officer (PO-M\&E/BCC) } \\
\text { (Consultant) }\end{array}$ & $\begin{array}{l}\text { competency based } \\
\text { training, Overseeing } \\
\text { ASHA Diwas is } \\
\text { optimally utilized for } \\
\text { sustained }\end{array}$ \\
\hline $\begin{array}{l}\text { - Developing } \\
\text { messages by } \\
\text { consultative } \\
\text { processes and field } \\
\text { testing } \\
\text { Designing, } \\
\text { printing/production } \\
\text { Developing } \\
\text { counseling tools } \\
\text { - Coordinating with } \\
\text { districts for material } \\
\text { development and } \\
\text { supply } \\
\text { Strategizing efficient } \\
\text { use of diverse forms } \\
\text { of media channels } \\
\text { to reach entire } \\
\text { community }\end{array}$ & $\begin{array}{l}\text { - Coordinating BCC } \\
\text { activities of } \\
\text { development } \\
\text { partners } \\
\text { - Standardizing all } \\
\text { BCC messages of } \\
\text { development } \\
\text { partners (DP) } \\
\text { (requires } \\
\text { development of } \\
\text { guideline) } \\
\text { Ensuring approval of } \\
\text { SHSB for } \\
\text { communication } \\
\text { activities of DP in a } \\
\text { time bound manner } \\
\text { Coordinating with } \\
\text { media houses } \\
\text { Coordinating with } \\
\text { other departments } \\
\text { which agree to } \\
\text { partner in } \\
\text { implementing the } \\
\text { communication } \\
\text { strategv } \\
\end{array}$ & $\begin{array}{l}\text { - M \&E of all activities } \\
\text { of the BCC program } \\
\text { Developing required } \\
\text { checklists for } \\
\text { monitoring and } \\
\text { feedback from } \\
\text { DCMs and BCMs, } \\
\text { - Analyses and } \\
\text { provide feedback to } \\
\text { districts and blocks } \\
\text { on their BCC } \\
\text { activities/ } \\
\text { performance. } \\
\text { Undertake special } \\
\text { BCC studies to } \\
\text { understand barriers } \\
\text { and evaluation of } \\
\text { the BCC program }\end{array}$ & $\begin{array}{l}\text { ASC activities of } \\
\text { ASHAs } \\
\text { positions of DCMs } \\
\text { and BCMs are filled } \\
\text { Reorientation of } \\
\text { DCMs and BCMs so } \\
\text { that they perform } \\
\text { their work and } \\
\text { strengthen } \\
\text { monitoring of } \\
\text { ASHAs' activities } \\
\text { including } \\
\text { community } \\
\text { mobilization } \\
\text { Overseeing activities } \\
\text { of DCMs and BCMs } \\
\text { Provide allowances } \\
\text { for field travel and } \\
\text { mobile phone } \\
\text { charges to BCMs so } \\
\text { they could do field } \\
\text { visits and monitor } \\
\text { ASHAs }\end{array}$ \\
\hline
\end{tabular}


District level: As discussed earlier in Chapter 3, all districts Mass Media Units are defunct. To strengthen and implement the BCC strategy, it is important that the Mass Media Unit at the district level should be revamped and a clear linkage between the DHS and Mass Media Unit can be established so they can work jointly to achieve departmental goals (Figure 6.3).

Figure 6.3: Constitution of district media planning \& implementation committee

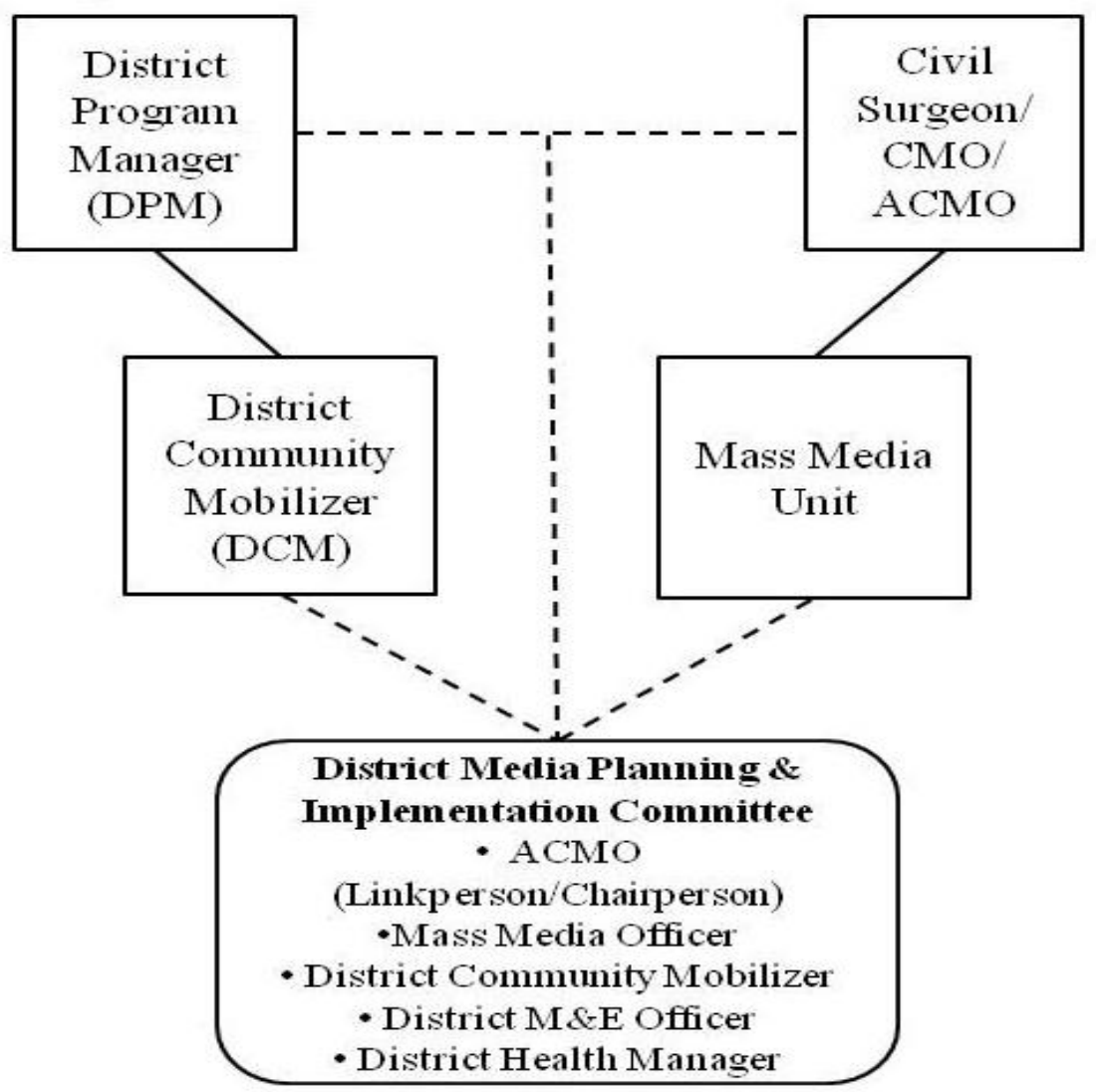

To oversee the BCC activities in the district and give guidance, we have suggested that a District Media Implementation Committee should be constituted (Figure 6.3). In the first six months it could meet every 15 days to plan activities, strategize priorities and review progress of work and what initial problems are arising in revitalizing BCC activities in the district. The observations and concerns should be reported to the SPO (BCC).

Once the system is established, frequency of this media planning and review meeting could be reduced to once a month. This monthly meeting should be organized two or three days before the monthly meeting of the MOIC at the district headquarter so that observations from the BCC meeting could be shared in this MOIC meeting and action to be taken at the block PHC and community at large could be decided. In the MOIC monthly meeting, one hour should be exclusively allocated for review of BCC activities and its performance. These reports, observations and action points should be sent as part of monthly reporting of the Media Unit to SPO (BCC). The monthly report should also report the performance statistics based on their activities and checklists that DCMs need to fill on their monitoring activities and their reports received from BCMs on their monitoring activities, visits to the field and attending ASHA facilitator meetings and topics covered during the ASHA Diwas. Considering the overlap in the activities of media unit and motivational and community mobilization effort made by ASHAs, all media reports will also be marked to the manager of the ARC and the three POs within media unit. 
Block level: All the positions of Block Extension Officer (BEO) are vacant and we do not see how these positions could be filled easily. Hence at least all vacant positions of BCMs need to be filled on priority and they should be made responsible for some of the broader BCC activities performed by BEE apart from monitoring ASHA's activities. The MOIC should ensure that the BCM and Mass Media Officer coordinate and help each other in BCC activities. We also propose that the block level BCC responsibilities be jointly shared by the BCM and $\mathrm{BHM}$, which include:

- Planning distribution and strategic position for display of BCC materials;

- Orienting ASHAs on counseling skills during ASHA Diwas and during meetings by ASHA Facilitators;

- Monitoring BCC activities of ASHAs using a standardized checklist;

- Monitoring and supporting BCC activities during VHSND and strengthening the forum for convergence of departments like ICDS, PHED and the Panchayat;

- Coordinating alignment of BCC activities undertaken by partner departments like ICDS, JEEViKA, PHED and so on;

- Full and effective use of Health Educator (HE) for BCC activities and monitoring their work using standard checklists.

Similar to the District BCC Implementation committee, a Block BCC Implementation Committee needs to be constituted consisting of BEE (if appointed), BCM, Block Health Manager (BHM) and Health Educators (HE) of all APHCs of that block. It should meet every month to plan and finalize monthly activities.

BCM and BHM should use standardized checklists to review BCC activities carried out by the HE, ASHA facilitator and ASHA. Similarly checklists developed by PO (M\&E) should be used to review and report BCC activities undertaken at VHSND.

\section{Capacity building of BCC unit for effective performance}

Training and capacity building: Once the BCC Unit is in place at state, district and block levels, all officials would need to be oriented on what BCC is, how it is different from IEC, and how BCC activities are carried out and evaluated. The details of the training would need to be decided including: (a) who will conduct the orientation, (b) where it will be done, (c) what topics will be covered, and (d) what will be the duration of such orientation.

Planning and implementation: While planning the strategy, implementation guidelines need to be developed for carrying out BCC activities to ensure that all officials are aware of what tasks are required by each of them. These guidelines will help respective POs and their colleagues to implement each activity and develop micro level work plans to meet the objectives of the strategy. Micro level work plans can be developed by respective district and block officials in coordination with the State BCC unit. Guidelines must specify the process of implementing all BCC activities including:

- Activities required by Mass Media Unit during VHSND and other special health and sanitation.

- Coordinate with ARC on how best the ASHA Diwas/ASHA facilitators meeting can be usedeither for orienting ASHAs and BCMs on BCC activities or for M\&E by BCMs of ASHA BCC.

- Detailed guideline to ensure uniformity in BCC messages and the campaigns of development partners so that messages and BCC materials such as counseling tools are not different and contradictory but are aligned with the messages promoted by SHSB. 
Monitoring and evaluation: An effective BCC strategy should be measured in terms of actual behavior change. BCC activity impact can be measured both by immediate outputs and intermediate and final outcomes depending on duration of implementation. For instance, immediate outputs of VHSND could include but are not limited to: (a) Is the VHSND regularly happening? (b) Are all BCC activities during the VHSND taking place? (c) Are ASHAs counseling clients as per guidelines? (d) Are representatives of ICDS, PHED, and PRD present?

The intermediate outcome could be: (a) How many women coming for ANC? (b) How many children are brought for immunization? (c) How many women/couples coming for contraceptive services? And the final outcomes could be: (a) How many women had complete ANC? (b) How many children were fully immunized? (c) Is the unmet need for contraception decreasing?

To help the Media Unit a simple user friendly BCC monitoring and evaluation manual is required and could be easily developed. The manual could give specific examples from different contexts, M\&E methods suitable in the given contexts and steps need to be taken to ensure scientific rigor in monitoring and evaluation of the BCC activities. Availability of such BCC M\&E manual would be useful for assessing the progress and outcomes of the program. 


\section{Note 6.1: Role and responsibilities of different State Media Unit staff}

The State Program Officer (SPO-BCC): Will head the BCC Unit at the State and is especially designated to overlook and manage all BCC activities under the overall leadership of the Executive Director (ED), SHSB. The Officer's key responsibilities include taking lead in planning and developing the BCC strategy, coordinating with other State Program Officers such as SPO (FP), Manager, ARC etc. He/she will also lead in building partnerships and integrate BCC activities as an integral part of the health and family welfare program. Besides these, he will coordinate with and help guide his/her other colleagues of the media unit to implement the BCC strategy effectively with a common vision and focus.

The Program Officer Materials Development (PO-MD): Will develop messages, strategy how messages from various media (mass media and mid media) reach community effectively, develop counseling tools (in coordination with the ARC), designing, field testing, printing and produce content for mass media (print, TV, radio) and mid media and involve local artists and district/block level staff in context specific materials development and supply. For an effective BCC strategy, it is crucial that participatory approaches are used to develop concepts, messages and materials. The PO MD needs to work in close collaboration with the Program Officer M\&E (PO M\&E) to be aware of the feedback on BCC activities and possible intervention if required by producing special needs based materials or messages.

The Program Officer BCC Coordinator (PO-C): Will be responsible to coordinate various BCC activities of development partners, standardize all BCC messages of development partners so that there is consistency and alignment in the messages given by the SHSB and development partners using different mode of communication. This would require development of a broad guideline and indicators for ensuring uniformity in messaging by all development agencies. The Program Officer Coordinator BCC (POC-BCC) also needs to ensure that communication activities and BCC materials of development partners are approved by SHSB before their implementation. However it should be done in a time bound manner. While certain coordination of the BCC activities of development partners is important, it is also critical that such coordination and approval process should not become a hindrance in the timely implementation of the activities of development partners. The POC-BCC will be also be responsible for program coordination with departments or agencies and media houses that agree to collaborate with SHSB in implementing BCC strategy. The focus of such meetings should be ensuring alignment and synchronization of their effort.

The Program Officer M\&E /BCC (PC-M\&E): Would need to monitor, evaluate and document the achievements and lessons learnt from all BCC activities of the strategy including evaluation of BCC activities of development partners. If the communication strategy has been successful then there should be actual change in adoption of behaviors. The M\&E Officer would need to ensure that impact of a BCC activity is measured by actual change in behaviors and not just increase in knowledge and change in attitudes. He/she would be required to develop a number of checklists which could be helpful in monitoring activities expected to be carried out by the DCMs and BCMs. Similarly PO M\&E/BCC needs to develop a reporting form which could be filled by each ASHA on their activities and performance and by ASHA facilitators on their activities and observation of ASHAs. He will also be responsible for analyzing monthly performance statistics which are collected by ASHA facilitators, Block Community Mobilizers and District Community Mobilizers on performance of BCC activities and provide regular feedback at all levels. 


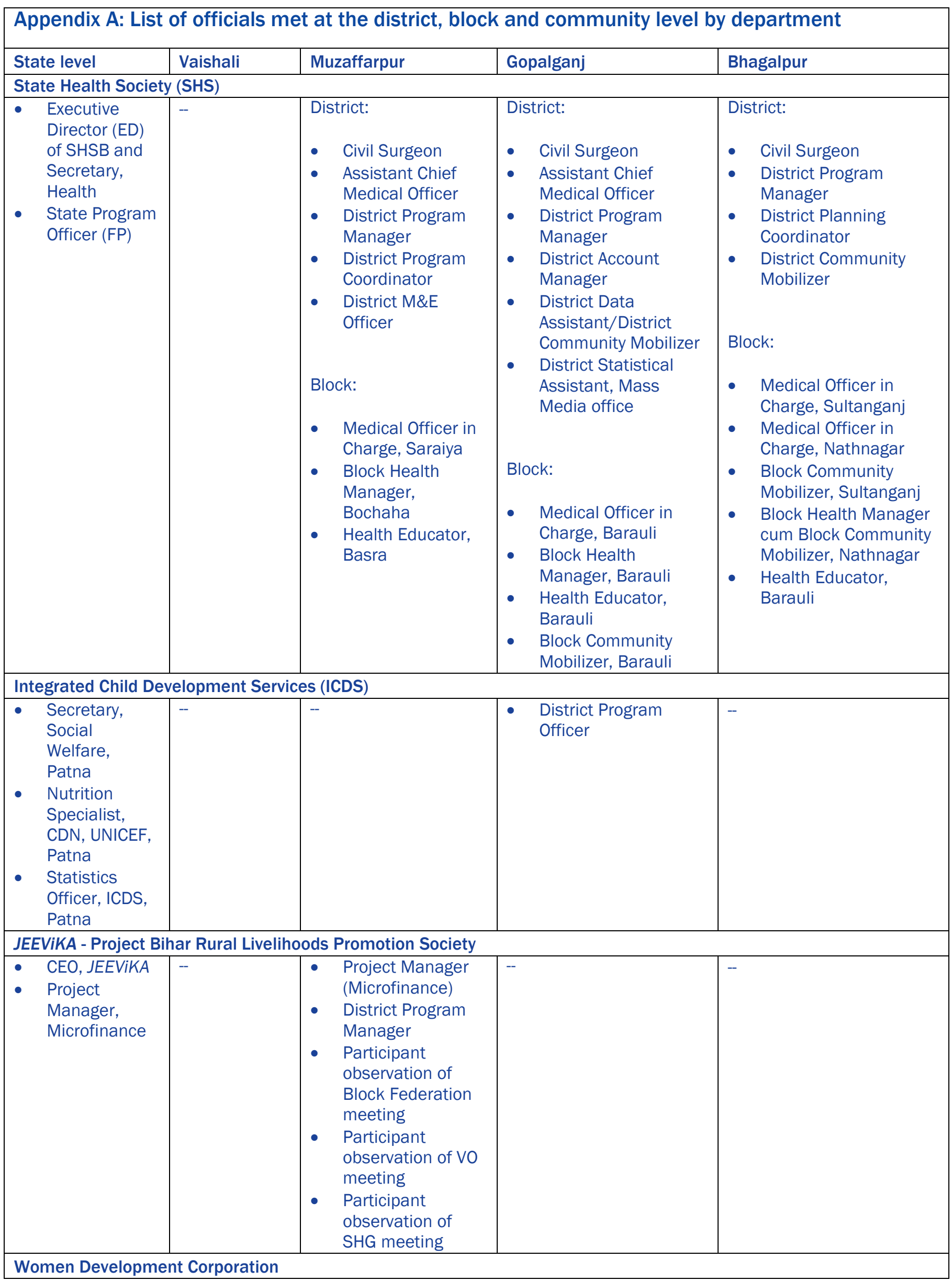




\begin{tabular}{|c|c|c|c|c|}
\hline $\begin{array}{l}\text { Project } \\
\text { Director, WDC } \\
\text { State Project } \\
\text { Manager, } \\
\text { Capacity } \\
\text { Building, }\end{array}$ & $\begin{array}{ll} & \text { FGD with } \\
\text { SHG } \\
\text { members } \\
\text { - } \\
\text { President } \\
\text { of SHG } \\
\text { Federation }\end{array}$ & & -- & -- \\
\hline \multicolumn{5}{|l|}{ Mahila Samakhya } \\
\hline $\begin{array}{ll}\text { - } & \text { State Project } \\
\text { Coordinator } \\
\text { State } \\
\text { Resource } \\
\text { Persons (2) }\end{array}$ & -- & $\begin{array}{ll}- & \text { District Program } \\
& \text { Coordinator } \\
\text { - } & \text { FGD with SHG } \\
\text { members }\end{array}$ & - & -- \\
\hline \multicolumn{5}{|c|}{ Public Health Engineering Department (PHED) } \\
\hline $\begin{array}{ll} & \text { Principal } \\
\text { Secretary } \\
\text { - } & \text { Director, PMU } \\
\text { Sanitation } \\
\text { Specialist, } \\
\text { UNICEF, Patna }\end{array}$ & -- & $\begin{array}{ll}\text { PHED-Head } \\
\text { Clerk } \\
\text { Ex-TSC } \\
\text { Coordinator } \\
\text { Block } \\
\text { Coordinators (2), } \\
\text { Saraiya, } \\
\text { Bochaha } \\
\end{array}$ & $\begin{array}{ll}- & \text { District TSC } \\
& \text { Coordinator } \\
\text { - } & \text { Block Coordinators } \\
& (2)\end{array}$ & -- \\
\hline \multicolumn{5}{|c|}{ Mahadalit Vikas Mission } \\
\hline $\begin{array}{ll}\text { - } & \text { Project } \\
\text { Director } \\
\text { Assistant } \\
\text { Director, } \\
\text { Computer, } \\
\text { Social Welfare } \\
\text { State Project } \\
\text { Officer, MVM } \\
\end{array}$ & - & $\begin{array}{ll}- & \text { District Welfare } \\
& \text { Officer } \\
\text { - } & \text { Statistical Officer } \\
\text { - } & \text { Master Trainer of } \\
& \text { Vikas Mitra } \\
\text { - } & \text { Block Welfare } \\
& \text { Officer } \\
\text { - } & \text { Vikas Mitras (7) } \\
\end{array}$ & $\begin{array}{ll} & \text { District Welfare } \\
& \text { Officer } \\
\text { - } & \text { Block Development } \\
& \text { Officer, Vijaypur } \\
\text { - Vikas Mitra, Jagritola }\end{array}$ & - \\
\hline \multicolumn{5}{|c|}{ Panchayati Raj Department } \\
\hline $\begin{array}{l}\text { Principal } \\
\text { Secretary } \\
\text { UNICEF, } \\
\text { Sectoral } \\
\text { Specialist, } \\
\text { PRD }\end{array}$ & $\begin{array}{l}\text { Mukhiya, } \\
\text { Mohamma } \\
\text { dabad } \\
\text { Panchayat }\end{array}$ & $\begin{array}{ll}- & \text { Zila Parishad - } \\
\text { Head Clerk } \\
\text { - } \quad \text { Female member } \\
\text { of Zila Parishad } \\
\text { Block } \\
\text { Development } \\
\text { Officers (2), } \\
\text { Saraiya, Bochaha } \\
\text { Mukhiya } \\
\text { Pramukh } \\
\text { Mukhiya } \\
\end{array}$ & $\begin{array}{ll}\text { - } & \text { Deputy Development } \\
\text { - } & \text { Commissioner } \\
\text { Panchayati Raj } & \text { Officer } \\
\text { - } & \text { Block Development } \\
\text { Officer, Vijaypur } \\
\text { - } \quad \text { Block Panchayati Raj } \\
\text { Officer, Hathua } \\
\text { - Mukhiya, Jagritola }\end{array}$ & -- \\
\hline 19 & 3 & 36 & 22 & 9 \\
\hline
\end{tabular}




\begin{tabular}{|l|l|}
\hline $\begin{array}{l}\text { Appendix B: Informants from development partners working in Bihar, by themes } \\
\text { addressed, coverage and BCC activity }\end{array}$ \\
\hline Organization & Informant(s) \\
\hline $\begin{array}{l}\text { United Nations Population Fund } \\
\text { (UNFPA) }\end{array}$ & State Representative \\
\hline DFID/B-TAST & $\begin{array}{l}\text { Chief of Party } \\
\text { Senior Social development Specialist, Options Consulting UK }\end{array}$ \\
\hline CARE & Deputy Chief of Party \\
\hline Population Services International & Country Representative \\
& National Manager- Research \\
& Senior Program Manager, Bihar and Jharkhand \\
\hline Janani-DKT & Deputy Director, Operations \\
& Head of Communications \\
\hline Micronutrient Initiative & State Program Manager \\
& Documentation Consultant \\
\hline
\end{tabular}




\begin{tabular}{|c|c|c|c|c|c|c|}
\hline \multicolumn{7}{|c|}{ Appendix C: Districts covered by various programs } \\
\hline S. No. & District & Sabla & IGMSY & JEEViKA & WDC & MS \\
\hline 1 & Araria & & & & & \\
\hline 2 & Arwal & & & & & \\
\hline 3 & Aurangabad & & & & & \\
\hline 4 & Banka & & & & & \\
\hline 5 & Begusarai & & & & & \\
\hline 6 & Bhagalpur & & & & & \\
\hline 7 & Bhojpur & & & & & \\
\hline 8 & Buxar & & & & & \\
\hline 9 & Darbhanga & & & & & \\
\hline 10 & East Champaran & & & & & \\
\hline 11 & Gaya & & & & & \\
\hline 12 & Gopalganj & & & & & \\
\hline 13 & Jahanabad & & & & & \\
\hline 14 & Jamui & & & & & \\
\hline 15 & Kaimur & & & & & \\
\hline 16 & Katihar & & & & & \\
\hline 17 & Khagaria & & & & & \\
\hline 18 & Kishanganj & & & & & \\
\hline 19 & Lakhisarai & & & & & \\
\hline 20 & Madhepura & & & & & \\
\hline 21 & Madhubani & & & & & \\
\hline 22 & Munger & & & & & \\
\hline 23 & Muzaffarpur & & & & & \\
\hline 24 & Nalanda & & & & & \\
\hline 25 & Nawada & & & & & \\
\hline 26 & Patna & & & & & \\
\hline 27 & Purnea & & & & & \\
\hline
\end{tabular}




\begin{tabular}{|r|l|l|l|l|l|l|}
\hline 28 & Rohtas & & & & & \\
\hline 29 & Saharsa & & & & & \\
\hline 30 & Samastipur & & & & & \\
\hline 31 & Saran & & & & & \\
\hline 32 & Seoher & & & & & \\
\hline 33 & Sheikhpura & & & & & \\
\hline 34 & Sitamarhi & & & & & \\
\hline 35 & Siwan & & & & & \\
\hline 36 & Supol & & & & & \\
\hline 37 & Vaishali & & & & & \\
\hline 38 & West Champaran & & & & \\
\hline \multicolumn{2}{|l|}{ Total } & 12 & & & \\
\hline Note: WDC, MS and JEEViKA are expanding in more districts & & & \\
\hline
\end{tabular}

